


\section{Predictores de Calidad de Vida en pacientes con Daño Cerebral Adquirido: Déficit, Actividad y Participación}

Tesis doctoral Helena Mondragón Llorca

Dirigida por: Dra. Dña. Gloria María Saavedra Muñoz y Dr. D. Igor Bombín González

Castellón, Mayo 2017 

A Quique,

Por darle razón a mi emoción

A mis padres,

Por orientarme siempre en el buen camino 



\section{AGRADECIMIENTOS}

Siempre que he tenido la oportunidad de leer una tesis me he detenido unos segundos en los agradecimientos que el autor hacía. Casi siempre se trataba de un texto más o menos corto donde había muchos sentimientos que hacían que me emocionara. Ahora, aunque pensaba que nunca iba a llegar este momento, me toca a mí escribir estas líneas.

Muchas son las personas que me han acompañado en este proceso y muchos de los que aquí hago referencia saben en qué situación me he encontrado en el último tiempo. Gracias a ellos y a mi esfuerzo y tozudez por sacar esto adelante, las frustraciones y miedos que han aparecido en estos últimos meses se han convertido en mi mayor logro conseguido. Contenta y satisfecha me dispongo, ahora sí, a agradecer a todos aquellos que me han acompañado en este proceso.

A Gloria, por abrirme la puerta de su despacho cuando buscaba llenar mi tiempo con prácticas voluntarias en lo que más me gustaba, por confiar en mí y darme la oportunidad de formar parte de su equipo de trabajo, por permitir aprender y crecer a su lado, por ofrecerme herramientas para acercarme mejor a los pacientes, tan fuertes pero a la vez tan frágiles, por ser mi mentora en este inquietante mundo de la neuropsicología clínica.

A Igor, por aceptar codirigir esta tesis desde la distancia, por tu conocimiento, tu experiencia y por guiar esta investigación. Ha sido un placer poder contar contigo en este proyecto.

A Mari Carmen, por tu ayuda altruista, tu apoyo, supervisión, tu preocupación... No tengo suficientes palabras de agradecimiento, me abriste el camino cuando más perdida estaba. Sin tu ayuda este trabajo no hubiera llegado a su fin. Mil gracias. 
A tí, amiga y compañera, sabrás por estas líneas que eres tú. Por las llamadas de tiempo infinito, con muchos kilómetros de por medio, para compartir nuestro amor por la neuropsicología, nuestra profesión, y muchas otras cosas. Gracias por confiar en mí, por tu aliento en esta recta final y por tu ayuda incondicional.

A mis padres porque gracias a vuestro esfuerzo y constancia habéis logrado sacar lo mejor de mí. Porque especialmente en éste último tiempo donde ha sido fácil tirar la toalla habéis confiado y apostado por mí y habéis conseguido que saque este proyecto adelante. Éste y otros tantos logros también son vuestros.

A Quique, por todo lo compartido en estos años. Porque sólo nosotros sabemos lo que nos ha costado llevar a cabo nuestras tesis, nacidas casi al mismo tiempo. Gracias por tu cariño, tu apoyo, tu confianza, tu paciencia, por no soltarme y por facilitarme los días, especialmente estos últimos. Gracias por tanto. Gracias por todo.

A mis compañeras y amigas del trabajo, por dejarme compartir mis agobios con vosotras y por entender mis ausencias. Os debo varias.

A mis amigas de Barcelona, por no poder haber estado ahí en ninguno de vuestros encuentros, por no preguntaros $y$, aparentemente, no preocuparme por vosotras. No obstante, siempre os he tenido presente. A vosotras, también os debo muchas.

Por último y no menos importante, no me gustaría cerrar este texto sin agradecer a todos aquellos pacientes y familiares que me brindaron la oportunidad de acercarme a ellos, aprender, crecer, ofrecerles mi ayuda lo mejor que pude y formar parte de esta investigación.

Gracias a todos. 


\section{RESUMEN}

La consecuencia fundamental del daño cerebral adquirido en la persona que lo padece es la pérdida de funciones cerebrales previamente desarrolladas o adquiridas, pudiendo afectar al rendimiento cognitivo, a la capacidad de regulación conductual y emocional, a la actividad física, al grado de independencia funcional-participación y a la percepción de satisfacción y calidad de vida.

El objetivo de esta tesis es conocer la percepción de calidad de vida de una muestra de pacientes con daño cerebral adquirido tras finalizar su proceso neuro-rehabilitador, así como averiguar los factores con los que se asocia y sus posibles variables predictoras. Para ello se recogieron, a través de un protocolo de evaluación creado para este estudio, los datos sociodemográficos, clínicos de la lesión, el perfil cognitivo y conductual, el grado de participación y la percepción de calidad de vida, de cada uno de los participantes, y se realizaron análisis correlacionales y predictivos que nos permitieron comprobar las hipótesis de estudio.

La estructura de esta tesis se basa principalmente en dos partes diferenciadas: la primera presenta la fundamentación teórica y la segunda, el trabajo empírico realizado.

El marco teórico se compone de tres capítulos. En el primero se describe la Clasificación Internacional de Funcionamiento, Discapacidad y Salud propuesto de la Organización Mundial de la Salud como sistema universal para describir la salud y los estados relacionados con ella. La CIF permite obtener un perfil de gran utilidad acerca del funcionamiento del individuo, entendiéndose como el conjunto de las funciones corporales, actividad y participación. En el segundo capítulo se describe el Daño Cerebral Adquirido, explicando su epidemiología, la etiología, las 
consecuencias que se derivan del mismo tanto a nivel cognitivo como conductual, emocional y de independencia funcional con un apartado acerca de la rehabilitación y sus medidas de resultado. El tercer capítulo del marco teórico hace referencia a la Calidad de Vida en los pacientes con Daño Cerebral Adquirido, ofreciendo una conceptualización y evaluación del constructo así como describiendo sus determinantes según la literatura existente.

La segunda parte, dedicada al trabajo empírico, se compone de varios capítulos. En el capítulo 4 se establecen los objetivos e hipótesis de estudio. En el capítulo 5 se detalla la metodología de estudio, describiendo la muestra participante, explicando las variables e instrumentos de medida empleados, el procedimiento llevado a cabo así como los análisis estadísticos. El capítulo 6 y 7 se dedican a mostrar los resultados encontrados y hacer una discusión al respecto comparando estos resultados con la literatura. Finalmente se describen brevemente las conclusiones.

Los resultados de este estudio confirman que la calidad de vida es una valoración subjetiva y personal que realiza el sujeto sin que haya variables que puedan explicarla objetivamente en su totalidad. De esta manera habrá que analizar de manera individual, para cada uno de nuestros pacientes, aquellos factores que la persona considera importantes y determinantes de su nivel de satisfacción y percepción de calidad de vida. 


\section{ABREVIATURAS}

ACV: Accidente Cerebro-Vascular

AVD: Actividades de la Vida Diaria

BADS: Behavioural Assessment of the Dysexecutive Syndrome

CHART: Craig Handicap Assessment and Reporting Technique

CIDDM: Clasificación Internacional de Deficiencias, Discapacidades y

Minusvalías

CIE-10: Clasificación Internacional de Enfermedades, 10a Revisión

CIF: Clasificación Internacional del Funcionamiento, de la Discapacidad y de la Salud

CIQ-R: Community Integration Questionnaire, Revised

CPT: Continuous Performance Test

CV: Calidad de Vida

DCA: Daño Cerebral Adquirido

DEX: Dysexecutive Questionnaire

DSM-V: Diagnostic and Statistic Manual of Mental Disorders, $5^{\text {a }}$ edición

DT: Desviación Típica

FAM: Functional Assessment Measureme

FAS: Test de Asociación controlada de palabras

FAST: Prueba breve de evaluación del funcionamiento

FIM: Functional Independence Measure

OMS: Organización Mundial de la Salud

PT: Puntuaciones Típicas

QLESQ: Cuestionario de calidad de vida Satisfacción y Placer

TAVEC: Test Auditivo Verbal España Complutense

TCE: Traumatismo Craneoencefálico

WAIS-III: Escala de inteligencia Wechsler para Adultos-III

WCST: Wisconsin Card Sorting Test

WHO-DAS: World Health Organization-Disability Assessment Schedule

WMS: Escala de memoria Wechsler para adultos 



\section{ÍNDICE}

\section{MARCO TEÓRICO}

\section{CAPÍTULO 1: CLASIFICACIÓN INTERNACIONAL DEL FUNCIONAMIENTO, DISCAPACIDAD Y SALUD}

1. ANTECEDENTES Y DESARROLLO DE LA CIF................................... 23

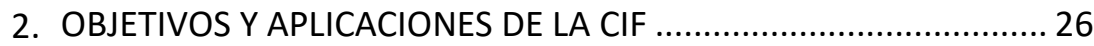

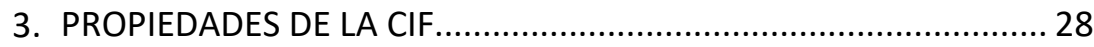

4. PERSPECTIVA DE LOS COMPONENTES DE LA CIF ......................... 30

4.1 Funciones y Estructuras Corporales ..................................... 32

4.2 Actividades y Participación .................................................... 33

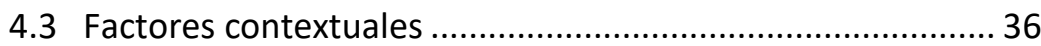

5. MODELO DE FUNCIONAMIENTO Y DE LA DISCAPACIDAD ............ 36

\section{CAPÍTULO 2: DAÑO CEREBRAL ADQUIRIDO}

1. DAÑO CEREBRAL ADQUIRIDO: DEFINICIÓN, EPIDEMIOLOGÍA Y

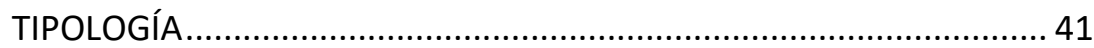

1.1 Definición y Epidemiología................................................... 41

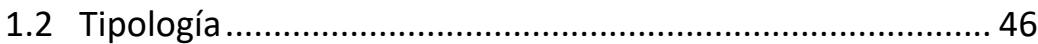

1.2.1 Accidente cerebrovascular o ictus ................................. 46

1.2.2 Traumatismo Craneoencefálico ........................................ 52

2. CONSECUENCIAS DEL DAÑO CEREBRAL ADQUIRIDO: .................... 57

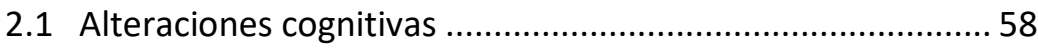

2.2 Alteraciones conductuales-emocionales .............................. 60

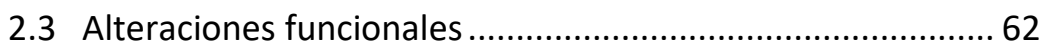


3. REHABILITACIÓN DEL DAÑO CEREBRAL ADQUIRIDO: MEDIDAS DE

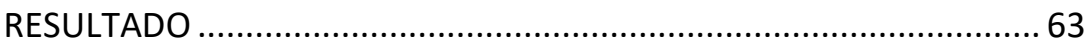

\section{CAPÍTULO 3: CALIDAD DE VIDA EN DAÑO CEREBRAL AQUIRIDO}

1. CONCEPTUALIZACIÓN Y EVALUACIÓN DE CALIDAD DE VIDA ........ 77

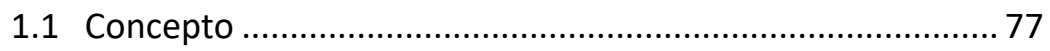

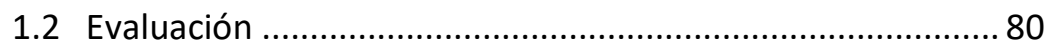

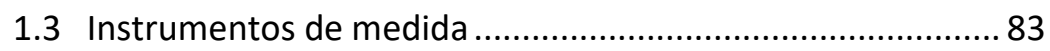

2. DETERMINANTES DE CALIDAD DE VIDA EN DCA........................... 90

\section{PARTE EMPÍRICA}

CAPÍTULO 4: OBJETIVOS E HIPÓTEIS METODOLOGÍA .......................99

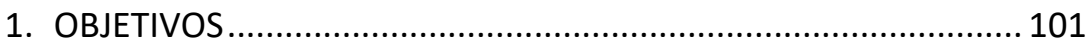

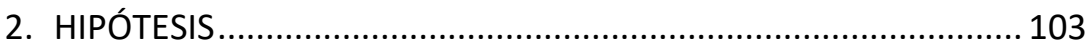

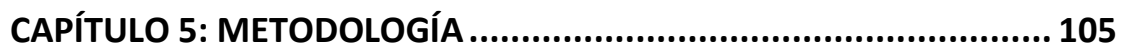

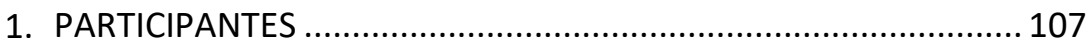

2. VARIABLES E INSTRUMENTOS DE MEDIDA ................................ 108

2.1 Variables sociodemográficas ............................................. 109

2.2 Variables de lesión Cerebral ............................................... 110

2.3 Variables cognitivas........................................................ 110

2.3.1 Atención y procesamiento de la información .................. 111

2.3.1.1 Dígitos en orden directo (WAIS) ............................. 111

2.3.1.2 Localización espacial, orden directo (WMS)........... 112

2.3.1.3 Test de cancelación de campanas ........................... 113

2.3.1.4 Test de Trazados de colores parte I........................ 113 
2.3.1.5 Continuous Performance test (CPT-II).................. 114

2.3.2 Aprendizaje y memoria ......................................... 115

2.3.2.1 Test Auditivo Verbal España Complutense (TAVEC) ..... 115

2.3.3 Memoria de trabajo ............................................ 117

2.3.3.1 Dígitos, orden inverso (WAIS) ............................ 117

2.3.3.2 Localización espacial, orden inverso (WMS) ......... 117

2.3.3.3 Color Trails Test-II........................................... 118

2.3.4 Funcionamiento ejecutivo .................................... 118

2.3.4.1 Wisconsin Card Sorting Test (WCST) .................... 118

2.3.4.2 Test de Asociación controlada de palabras (FAS) ......... 120

2.3.4.3 Test de Matrices (WAIS) .................................. 120

2.3.4.4 Test de anticipación espacial de Brixton ............... 121

2.3.4.5 Test de búsqueda de la llave (BADS) .................... 122

2.3.4.6 Continuous Performance Test (CPT-II) .................. 122

2.4 Variables conductuales y emocionales .......................... 123

2.4.1 Dysexecutive Questionnaire -DEX- (BADS)................. 123

2.5 Variables de Actividad y Participación: ........................... 125

2.5.1 Índice de Barthel ................................................. 125

2.5.2 Community Integration Questionnaire, Revised (CIQ-R)..... 126

2.5.3 Craig Handicap Assessment and Reporting Technique (CHART).128

2.5.4 Prueba breve de evaluación del funcionamiento (FAST)..... 129

2.6 Variables de calidad de vida ...................................... 130

2.6.1 Cuestionario sobre Calidad de Vida Satisfacción y Placer (Q-LES-Q) 130

2.7 Otras variables neuropsicológicas................................. 134 
2.7.1 Conciencia de déficit 134

2.7.1.1 Cuestionario de conciencia de déficit Flemming......... 134

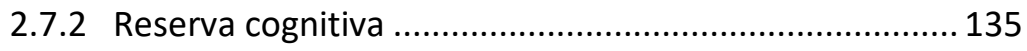

2.7.2.1 Cuestionario de reserva cognitiva .......................... 135

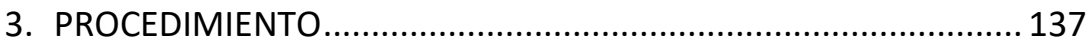

4. CÁLCULO DE PUNTUACIONES TRANSFORMADAS........................... 139

5. ANÁLISIS ESTADÍSTICOS .......................................................... 143

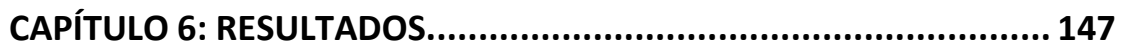

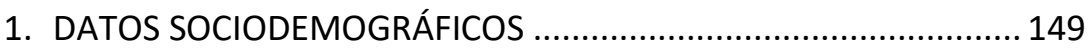

2. VARIABLES CLÍNICAS DE LA LESIÓN:.......................................... 151

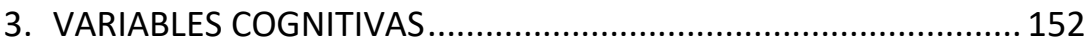

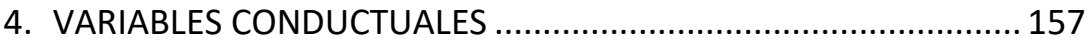

5. ACTIVIDAD E INDEPENDENCIA FUNCIONAL-PARTICIPACIÓN ...... 160

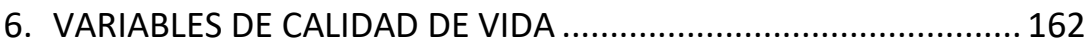

7. OTRAS VARIABLES NEUROPSICOLÓGICAS................................... 167

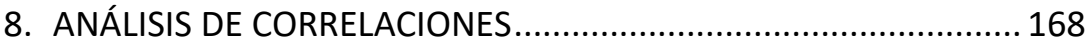

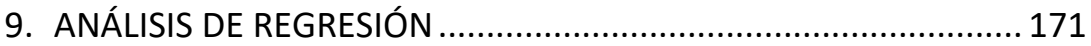

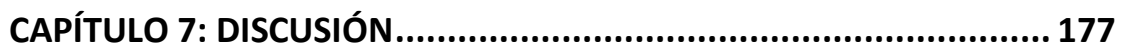

III. CONCLUSIONES …....................................................................197

IV. REFERENCIAS BIBLIOGRÁFICAS.................................................201 


\section{ÍNDICE FIGURAS}

Figura 1.1. Estructura de la CIF (Adaptado de OMS, 2001) ............................24

Figura 1.2. Interacción entre los componentes de la CIF ...............................37

Ilustración 2.1. Causas del DCA ....................................................................... 44

Ilustración 2.2. Incidencia por tipo de daño y género .......................................44

Ilustración 2.3. Incidencia por etiología.............................................................. 44

Ilustración 2.4. Prevalencia por edad .................................................................4 44

Ilustración 2.5. Discapacidad para ABVDs....................................................... 45

Ilustración 2.6. Causas de Accidente Cerebrovascular ....................................50

Ilustración 2.7. Causas externas de TCE en Europa ............................................56

Ilustración 6.1. Porcentaje de afectación en Atención...................................154

Ilustración 6.2. Porcentaje de afectación en Aprendizaje y Memoria.................. 154

llustración 6.3. Porcentaje de afectación en Memoria de Trabajo....................154

Ilustración 6.4. Porcentaje de afectación en Funciones Ejecutivas....................154 


\section{ÍNDICE TABLAS}

Tabla 1.1. Visión del conjunto de la CIF. Extraído de (OMS, 2001) ................ 31

Tabla 1.2. Actividades y Participación. Extraído de (OMS, 2001) ................... 34

Tabla 2.1. La atención al DCA en la Comunidad Valenciana ............................46

Tabla 2.2. Resultados del daño según la Clasificación CIDDM-2 .....................66

Tabla 2.3. Cuadro resumen definiciones CIF................................................... 72

Tabla 2.4. Clasificación de medidas de resultado.............................................. 73

Tabla 3.1. Características principales de medidas de CV específicas. ............ 86

Tabla 5.1. Pruebas neuropsicológicas según el dominio evaluado..............111

Tabla 5.2. Correspondencia de las puntuaciones estandarizadas ............... 141

Tabla 5.3. Pruebas neuropsicológicas según el dominio evaluado.............. 143

Tabla 6.1. Datos sociodemográficos ........................................................... 150

Tabla 6.2. Datos clínicos de la lesión............................................................. 152

Tabla 6.3. Frecuencias del grado de alteración y medias de dominios cognitivos globales..................................................................................... 153

Tabla 6.4. Medias de las Puntuaciones Típicas de las pruebas cognitivas . 156

Tabla 6.5. Porcentaje de pacientes por rango de Puntuaciones T en cada prueba cognitiva .............................................................................................. 157

Tabla 6.6. Resultados del Cuestionario Disejecutivo -DEX-.......................... 158

Tabla 6.7. Frecuencia de respuestas para cada ítem del Cuestionario Disejecutivo -DEX- ............................................................................... 159

Tabla 6.8. Resultados medida de actividad. Índice de Barthel. ..................... 160

Tabla 6.9. Resultados medidas de Independencia Funcional-Participación ... 161

Tabla 6.10. Resultados medida de Calidad de Vida...................................... 162 
Tabla 6.11. Descripción del grado de satisfacción de los ítems del QLEQ relacionados con el Estado de Salud Física.

Tabla 6.12. Descripción del grado de satisfacción de los ítems del QLEQ relacionados con el Estado de ánimo

Tabla 6.13. Descripción del grado de satisfacción de los ítems del QLEQ relacionados con las Actividades de la Casa

Tabla 6.14. Descripción del grado de satisfacción de los ítems del QLEQ relacionados con las Actividades de Ocio y Tiempo Libre 165

Tabla 6.15. Descripción del grado de satisfacción de los ítems del QLEQ relacionados con las Relaciones sociales 166

Tabla 6.16. Descripción del grado de satisfacción de los ítems del QLEQ relacionados con las Actividades Generales. 166

Tabla 6.17. Otras variables neuropsicológicas: Reserva cognitiva y Conciencia de déficit 168

Tabla 6.18. Correlaciones entre los dominios cognitivo-conductuales y la CV.. 170 Tabla 6.19. Correlaciones entre las diferentes medidas de Participación y las de Calidad de Vida 171

Tabla 6.20. Variables neuropsicológicas predictoras de CV mediante Análisis de Regresión Lineal

Tabla 6.21. CHART como predictor de CV mediante Análisis de Regresión Lineal. 173 Tabla 6.22. ClQ-R como predictor de CV mediante Análisis de Regresión Lineal ... 174 Tabla 6.23. FAST como predictor de CV mediante Análisis de Regresión Lineal ....175 Tabla 6.24. Análisis de regresión lineal introduciendo como predictores las variables neuropsicológicas, y las tres escalas de participación. 176 



\section{MARCO TEÓRICO}

Predictores de Calidad de Vida en pacientes con Daño Cerebral Adquirido:

Déficit, Actividad y Participación 



\section{Clasificación Internacional del Funcionamiento, Discapacidad y Salud}

Predictores de Calidad de Vida en pacientes con Daño Cerebral Adquirido: Déficit, Actividad y Participación 



\section{ANTECEDENTES Y DESARROLLO DE LA CIF}

El presente capítulo se trata de un resumen de la Clasificación Internacional del Funcionamiento, de la Discapacidad y de la Salud (CIF) para poder contextualizar dentro de un marco teórico esta investigación.

La Clasificación Internacional del Funcionamiento, de la Discapacidad y de la Salud (CIF), pertenece al conjunto de clasificaciones internacionales desarrolladas por la Organización Mundial de la Salud (OMS, 2001). Se trata de un sistema universal que establece un marco y un lenguaje general y consensuado para describir la salud y los estados relacionados con ella. La CIF se divide en dos partes ("Funcionamiento y Discapacidad"; "Factores contextuales") y posee cuatro dominios relacionados con el estado de salud determinado de una persona: (1) funciones y estructuras corporales, (2) actividad y participación, (3) factores ambientales y (4) factores personales. La primera parte incluye el componente de "Funciones y Estructuras corporales" que hace referencia a los cambios en los sistemas fisiológicos y en las estructuras anatómicas y el componente de "Actividad y Participación" que se relaciona con la capacidad de realización y desempeño de una tarea. La segunda parte incluye "Factores ambientales", es decir, las influencias externas a la persona y los "Factores personales", correspondiente a los atributos y variables propias de la persona (ver Figura 1.1.).

Teniendo en cuenta todos estos constructos, la ClF permite obtener un perfil de gran utilidad acerca del funcionamiento del individuo, entendiéndose como el conjunto de las funciones corporales, actividad y participación, como contrapuesto a la discapacidad entendida como las dificultades y limitaciones en la actividad o participación. Por tanto, la CIF 
ofrece una perspectiva múltiple, partiendo desde el enfoque biopsicosocial que se refleja en un modelo multidimensional.

Figura 1.1. Estructura de la CIF (Adaptado de OMS, 2001)

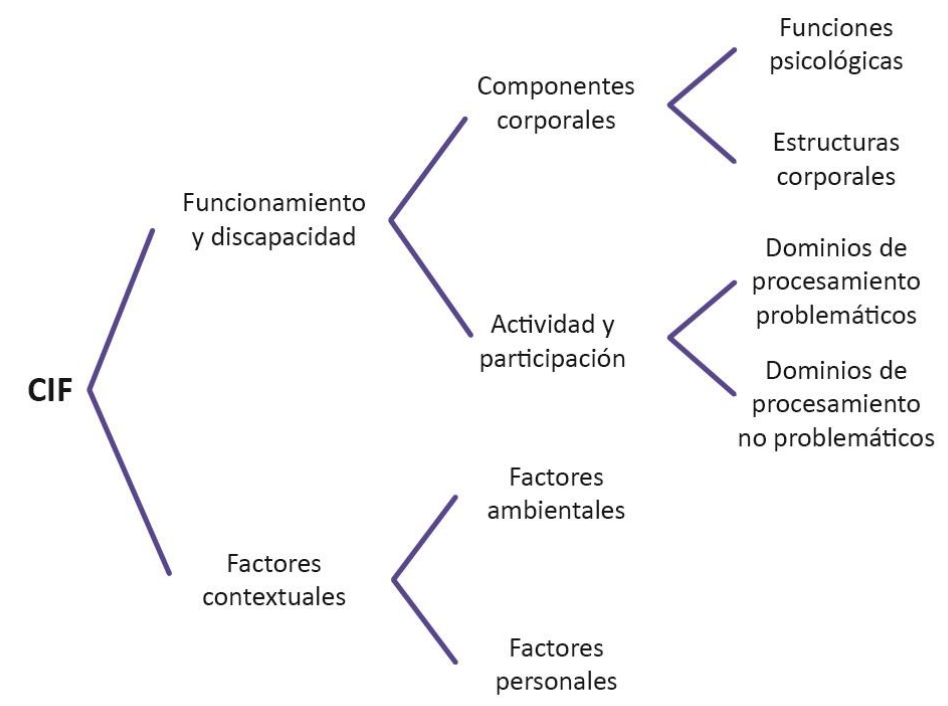

Uno de los motivos que impulsó el desarrollo de la CIF fueron las limitaciones que presentaba el modelo de discapacidad presente en la clasificación anterior, es decir, la Clasificación Internacional de Deficiencias, Discapacidades y Minusvalías -CIDDM-, creada por la OMS en 1980 para valorar el impacto y las repercusiones de las enfermedades en los individuos. Su desarrollo supuso un cambio en la conceptualización de la discapacidad y en la valoración de la influencia del entorno en el funcionamiento de los individuos. No obstante, proponía un modelo lineal de discapacidad centrado principalmente en las deficiencias y aspectos negativos de la enfermedad, donde los factores sociales y contextuales pasaban desapercibidos. En esta clasificación, el déficit refleja la disfunción orgánica o anormalidades de la estructura corporal. La discapacidad se refiere a las consecuencias de los déficits en términos del 
rendimiento funcional del paciente. La minusvalía se refiere a las desventajas sociales derivadas del déficit y discapacidad. Unos años más tarde, en 1999, se revisó la CIDDM para proporcionar medidas de resultado respecto a la salud en relación al cuerpo, la persona y la función social así como para ofrecer un marco común de cara a la investigación (World Health Organization., 1999).

En esta nueva revisión hubo ciertos cambios en la terminología; la discapacidad y minusvalía pasaron a ser limitaciones en la actividad y restricción en la participación así como incluyó nuevos factores contextuales.

Dentro de las clasificaciones internacionales de la OMS, los estados de salud (enfermedades, trastornos, lesiones, etc.) se clasifican principalmente en la CIE-10 (Clasificación Internacional de Enfermedades, 10a Revisión) o en el DSM-V (Diagnostic and Statistic Manual of Mental Disorders, 5ạ edición), y se organizan principalmente en función de la etiología sin tener en cuenta las consecuencias funcionales de la enfermedad o trastorno. Dado que, como se ha comentado anteriormente, la CIF brinda información sobre el funcionamiento y discapacidad -y la CIE-10 ofrece un diagnóstico de enfermedades, trastornos $u$ otras condiciones de salud-, ambas clasificaciones son en realidad complementarias, por lo que se recomienda el uso conjunto de las mismas. La información acerca del diagnóstico clínico junto con la del funcionamiento brinda una visión más extensa y significativa del estado de salud del individuo pudiendo ayudar, por tanto, en los procesos de toma de decisiones.

La CIF ha pasado de ser una clasificación de "consecuencias de enfermedades" (versión de 1980) a una clasificación de "componentes de salud". Las primeras hacen referencia al efecto resultante de una enfermedad u otra condición de salud, mientras que los segundos 
identifican los componentes de la salud. De manera parecida, este planteamiento es también diferente del abordaje basado en los "determinantes de salud" o en los "factores de riesgo". Para facilitar el estudio de estos aspectos, la CIF incluye una lista de factores ambientales que describen el contexto en el que vive el individuo.

\section{OBJETIVOS Y APLICACIONES DE LA CIF}

La Clasificación Internacional del Funcionamiento, de la Discapacidad y de la Salud (CIF) es una clasificación diseñada con un propósito múltiple para ser utilizada en varias disciplinas y diferentes sectores. Sus objetivos específicos pueden resumirse en:

- Proporcionar una base científica para la comprensión y el estudio de la salud, así como los estados relacionados con ella, los resultados y los determinantes.

- Establecer un lenguaje común para describir la salud y los estados relacionados con ella, para mejorar la comunicación entre distintos usuarios, tales como profesionales de la salud, investigadores, diseñadores de políticas sanitarias y la población general, incluyendo a las personas con discapacidades.

- Permitir la comparación de datos entre diferentes países, entre disciplinas sanitarias, entre varios servicios, y diferentes momentos a lo largo del tiempo.

- Proporcionar un esquema de codificación sistematizado para ser aplicado en los sistemas de información sanitaria. 
Estos objetivos están relacionados entre sí, ya que la necesidad y el uso de la CIF requiere la construcción de un sistema relevante y útil que pueda aplicarse en distintos ámbitos: en política sanitaria, en evaluación de la calidad asistencial, y para la evaluación de consecuencias en diferentes culturas (OMS, 2001).

Desde su aprobación en 1980, el modelo de la Clasificación Internacional del Funcionamiento, de la Discapacidad y de la Salud (CIF) y los instrumentos desarrollados a partir de ella han sido utilizados para diferentes fines. Entre las principales aplicaciones de la CIF podemos considerar las siguientes:

- Herramienta estadística, en la recogida y registro de datos de estudios y encuestas de salud poblacional o en sistemas de manejo de información.

- Herramienta de investigación para evaluar resultados, medidas de calidad de vida o factores ambientales.

- Herramienta clínica para valorar necesidades, estandarizar tratamientos de enfermedades, homogeneizar programas de rehabilitación y evaluar resultados.

- Herramienta de política social en la planificación de sistemas de seguridad social, sistemas de compensación y en el diseño e implementación de políticas sociales.

- Herramienta educativa para la elaboración y diseños curriculares, para la toma de conciencia de la sociedad respecto al fenómeno de la discapacidad y para poner en marcha actividades sociales.

Por la relación que la CIF tiene con todos los aspectos vinculados con la salud, en los últimos años ha sido aceptada como una de las clasificaciones sociales de las Naciones Unidas e incorpora Las Normas 
Uniformes para la Igualdad de Oportunidades para las Personas con Discapacidad. En consecuencia, la CIF se considera como un instrumento adecuado para implementar mandatos internacionales y legislaciones nacionales sobre los derechos humanos.

Dicha clasificación tiene un amplio rango de aplicaciones tanto en el ámbito nacional como en el internacional, considerándose marco de referencia en los aspectos de atención médica como la prevención, promoción de la salud y mejora de la participación. A nivel social, funciona evitando trabas sociales y promoviendo el desarrollo de soportes sociales y elementos facilitadores.

La CIF proporciona un marco idóneo para estudiar y analizar la interacción entre el estado de salud de una persona y el contexto en el que se desenvuelve en todas las áreas de la vida (Ayuso-Mateos, NietoMoreno, Sánchez-Moreno, \& Vazquez-Barquero, 2006).

\section{PROPIEDADES DE LA CIF}

La Clasificación Internacional del Funcionamiento, de la Discapacidad y de la Salud (CIF) organiza la información en dos partes diferenciadas. La primera se centra en el Funcionamiento y Discapacidad, mientras que la segunda parte se centra en los Factores Contextuales. Cada una de estas partes consta, a su vez, de dos componentes.

\section{Componentes de Funcionamiento y Discapacidad}

El componente Cuerpo clasifica, por una parte, a los Sistemas corporales y, por otra, a las Estructuras del cuerpo. El componente de 
Actividades y Participación implicaría todos los dominios relacionados con el funcionamiento, tanto desde una perspectiva individual como social. Estos componentes pueden emplearse para indicar tanto problemas (ej., dificultades, limitaciones, deficiencias o restricciones en la participación) incluidos bajo el concepto de discapacidad, o bien aspectos más neutrales, no tan problemáticos, que se incluirían en el concepto de funcionamiento.

\section{Componentes de Factores Contextuales}

El componente de los Factores Ambientales afecta a todos los componentes del funcionamiento y de la discapacidad, desde el entorno más inmediato y cercano del individuo hasta el entorno general. Los Factores Personales son un componente de los factores contextuales pero no están clasificados en la CIF debido a la gran variabilidad social y cultural asociada a los mismos.

El funcionamiento y la discapacidad de una persona se concibe como una interacción dinámica entre los estados de salud (enfermedades, lesiones, trastornos, etc.) y los factores contextuales, siendo estos últimos un componente esencial de la clasificación al actuar los factores ambientales, principalmente como elemento facilitador o de barrera de las características del mundo físico, social y actitudinal.

La CIF describe la situación de cada persona dentro de un conjunto de dominios de salud o dominios "relacionados con la salud" en el contexto de los factores ambientales o personales. 


\section{PERSPECTIVA DE LOS COMPONENTES DE LA CIF}

Antes de pasar a describir de manera exhaustiva cada uno de los componentes de la Clasificación Internacional del Funcionamiento, de la Discapacidad y de la Salud (CIF), se presenta un resumen esquemático en la Tabla 1.1. Tal y como se ha comentado en el apartado anterior, la CIF tiene dos partes y, a su vez, cada una de estas partes consta de dos componentes, pudiendo ser expresado en términos positivos y negativos:

I. Funcionamiento y Discapacidad:
a. Funciones y Estructuras Corporales
b. Actividades y Participación

II. Factores contextuales:
c. Factores Ambientales
d. Factores Personales 
Tabla 1.1. Visión del conjunto de la CIF. Extraído de (OMS, 2001)

\begin{tabular}{|c|c|c|c|c|}
\hline & \multicolumn{2}{|c|}{$\begin{array}{l}\text { Parte 1: } \\
\text { Funcionamiento y Discapacidad }\end{array}$} & \multicolumn{2}{|c|}{$\begin{array}{l}\text { Parte 2: } \\
\text { Factores contextuales }\end{array}$} \\
\hline Componentes & $\begin{array}{l}\text { Funciones y } \\
\text { Estructuras } \\
\text { corporales }\end{array}$ & $\begin{array}{l}\text { Actividades y } \\
\text { Participación }\end{array}$ & $\begin{array}{c}\text { Factores } \\
\text { Ambientales }\end{array}$ & $\begin{array}{l}\text { Factores } \\
\text { Personales }\end{array}$ \\
\hline Dominios & $\begin{array}{l}\text { Funciones } \\
\text { Corporales } \\
\text { Estructuras } \\
\text { Corporales }\end{array}$ & $\begin{array}{c}\text { Áreas vitales } \\
\text { (tareas, } \\
\text { acciones) }\end{array}$ & $\begin{array}{c}\text { Influencias } \\
\text { externas sobre el } \\
\text { funcionamiento y } \\
\text { la discapacidad }\end{array}$ & $\begin{array}{c}\text { Influencias } \\
\text { internas sobre el } \\
\text { funcionamiento y } \\
\text { la discapacidad }\end{array}$ \\
\hline Constructos & $\begin{array}{c}\text { Cambios en } \\
\text { las funciones } \\
\text { corporales } \\
\text { (fisiológicos) } \\
\text { Cambios en } \\
\text { las estructuras } \\
\text { del cuerpo } \\
\text { (anatómicos) }\end{array}$ & $\begin{array}{l}\text { Capacidad. } \\
\text { Realización de } \\
\text { tareas en un } \\
\text { entorno } \\
\text { uniforme } \\
\text { Desempeño/ } \\
\text { realización. } \\
\text { Realización de } \\
\text { tareas en el } \\
\text { entorno real }\end{array}$ & $\begin{array}{c}\text { El efecto } \\
\text { facilitador o de } \\
\text { barrera de las } \\
\text { características del } \\
\text { mundo físico, } \\
\text { social y actitudinal }\end{array}$ & $\begin{array}{l}\text { El efecto de los } \\
\text { atributos de la } \\
\text { persona }\end{array}$ \\
\hline \multirow[t]{2}{*}{$\begin{array}{l}\text { Aspectos } \\
\text { positivos }\end{array}$} & $\begin{array}{l}\text { Integridad } \\
\text { funcional y } \\
\text { estructural }\end{array}$ & $\begin{array}{l}\text { Actividades y } \\
\text { Participación }\end{array}$ & Facilitadores & No aplicable \\
\hline & \multicolumn{2}{|c|}{ Funcionamiento } & & \\
\hline $\begin{array}{l}\text { Aspectos } \\
\text { negativos }\end{array}$ & Deficiencia & $\begin{array}{l}\text { Limitación } \\
\text { en la } \\
\text { Actividad. } \\
\text { Restricción } \\
\text { en la } \\
\text { Participación }\end{array}$ & $\begin{array}{l}\text { Barreras/ } \\
\text { obstáculos }\end{array}$ & No aplicable \\
\hline
\end{tabular}

Discapacidad 


\subsection{FUNCIONES Y ESTRUCTURAS CORPORALES}

Las funciones y estructuras cerebrales se clasifican en dos secciones para poder utilizarse de manera paralela. Así, las funciones corporales se refieren a los sentidos básicos como las "funciones auditivas" y las estructuras relacionadas serían en este caso el "oído y las partes vinculadas". En el caso de las funciones cognitivas con función corporal, la estructura relacionada sería el cerebro y sus conexiones. Aunque en la versión CIDDM de 1980 se consideraba el término "órgano" la CIF lo sustituye por el de "estructura corporal" dado que es difícil identificar y definir los límites de un órgano, como por ejemplo los del ojo o el oído, que han sido tradicionalmente considerados como órganos.

Se consideran deficiencias aquellas anomalías, defectos, pérdidas o cualquier otra desviación en las estructuras corporales que sean aparentes o puedan detectarse tanto por la persona afectada como por los demás, a través de la observación directa o por la interferencia realizada a partir de esa observación. Tal y como advierte la CIF, las deficiencias no son equivalentes a la patología subyacente, sino que constituyen la forma de manifestarse esa patología. Se trata de un concepto más amplio que incluye más aspectos que el de trastorno o el de enfermedad, por ejemplo, la pérdida de una extremidad o las dificultades en la capacidad de planificación son deficiencias y no trastornos o enfermedades. De aquí que, las deficiencias son parte o una expresión de un estado de salud, pero no indican necesariamente que la enfermedad esté presente o el individuo sea considerado como un enfermo.

Las deficiencias representan una desviación de la "norma" en relación al estado biomédico del cuerpo y sus funciones, generalmente aceptada y definida por personas capacitadas para juzgar el 
funcionamiento físico y mental. La desviación de la norma puede ser leve o grave y puede fluctuar en el tiempo, de forma que las deficiencias se pueden manifestar de muchas maneras: temporales o permanentes, progresivas, regresivas o estables e intermitentes o continuas. Los criterios de clasificación de las deficiencias de funciones y estructuras corporales son: (a) pérdida o ausencia; (b) reducción; (c) aumento o exceso; y (d) desviación.

Las funciones corporales se ven afectadas por los factores ambientales, de manera que, el estado de una superficie actuará sobre el tipo de pisada y por tanto sobre el patrón de la marcha, por ejemplo, o la capacidad atencional se verá afectada por los estímulos ambientales como ruidos estridentes.

Tal y como se indica en la CIF, la clasificación de Funciones y Estructuras Corporales ha sido creada para ser utilizada junto con las categorías Actividades y Participación, que se explican en el siguiente apartado.

\subsection{ACTIVIDADES Y PARTICIPACIÓN}

El componente Actividad y Participación puede utilizarse para indicar actividades $(A)$, participación $(P) \circ$ ambos e incluyen nueve dominios, que pueden calificarse cada uno de ellos por dos calificadores: desempeño/realización y capacidad (Ver Tabla 1.2.). El calificador de desempeño/realización (Participación) indica lo que hace una persona en su contexto, incluyendo el entorno social en el que está inmerso. Sería entonces "el acto de involucrarse en una situación vital" con los factores ambientales (sociales, físicos y actitudinales) inherentes a ella, incluidos. 
Por su parte, el calificador capacidad (Actividad) describe la competencia del individuo para el desempeño de una determinada tarea o acción, en un entorno normalizado y neutral empleado normalmente para la evaluación de la capacidad objeto de estudio. Para poder establecer comparaciones individuales, este ajuste debe ser igual en todos los países y para todas las personas. La diferencia entre capacidad y desempeño/realización radica principalmente en el entorno en el que se encuentra el individuo en el momento de la ejecución de una determinada tarea o acción. Mientras la capacidad se valora en un entorno estándar, la realización o desempeño se hace en el contexto propio y habitual del individuo. La limitación o restricción mide la discordancia entre el desempeño/realización observado y el esperado según los estándares comúnmente aceptados en la población sana sin un estado de salud similar (enfermedad, trastorno, daño, etc.).

Tabla 1.2. Actividades y Participación. Extraído de (OMS, 2001)

\begin{tabular}{|l|l|l|}
\hline \multicolumn{2}{|c|}{ Dominios } & \multicolumn{2}{c|}{ Calificadores } \\
\hline Desempeño/ & Realización & Capacidad \\
\hline D1 & Aprendizaje y aplicación de conocimientos \\
\hline D2 & Tareas y demandas generales \\
\hline D3 & Comunicación \\
\hline D4 & Movilidad \\
\hline D5 & Autocuidado \\
\hline D6 & Vida doméstica \\
\hline D7 & Interacciones y relaciones interpersonales \\
\hline D8 & Áreas principales de la vida \\
\hline D9 & Vida comunitaria, cívica y social \\
\hline
\end{tabular}


Dada la dificultad para distinguir "Actividades" y "Participación" la CIF aporta una lista para diferenciarlas en función de cuatro maneras de estructurarlas:

I. Grupos diferentes de dominios de Actividad (A) y dominios de Participación (P) (sin solapamiento)

En esta clasificación, los dos grupos de categorías son mutuamente excluyentes, de manera que los dominios correspondientes a Actividad serán diferentes a los de Participación.

II. Solapamiento parcial entre los grupos de dominios Actividades y los grupos de dominios Participación.

En esta alternativa, uno o varios dominios pueden considerarse indicadores tanto de Actividad como de Participación.

III. Categorías detalladas como Actividades y categorías amplias como Participación, con o sin solapamiento.

En esta opción, las categorías generales de cada dominio corresponderían a Participación, mientras que las categorías más específicas a Actividad.

IV. Utilización de los mismos dominios tanto para Actividades como para Participación, con solapamiento total de los dominios.

En esta clasificación todos los dominios pueden considerarse tanto como Actividades o como Participación. 


\subsection{FACTORES CONTEXTUALES}

Los factores contextuales, como se ha comentado anteriormente incluyen los Factores Ambientales y los Factores Personales. Los Factores Ambientales hacen referencia a todos aquellos elementos físicos, sociales o actitudinales externos a la persona que pueden influirle tanto de manera negativa como positiva en su capacidad y realización de una tarea o en sus estructuras y funciones corporales. Estos factores pueden ser individuales cuando se sitúan en el contexto próximo del individuo (hogar, trabajo o lugares que frecuenta así como contactos con amigos, familia, compañeros...) o sociales cuando se refieren a sistemas formales o informales de la comunidad (entorno laboral, legislaciones, actividades comunitarias...).

Los Factores Personales por su parte, son todas aquellas características propias del individuo y de su estilo de vida tales como el género, raza, edad, hábitos, educación, profesión, características psicológicas... Aunque estos factores aún no están clasificados en la CIF, sí que se consideran importantes por el papel que desempeñan en la discapacidad.

\section{MODELO DE FUNCIONAMIENTO Y DE LA DISCAPACIDAD}

Como clasificación, la CIF no establece un modelo para el "proceso" del funcionamiento y discapacidad, no obstante proporciona diferentes elementos (Figura 1.2.) que forman parte de este proceso para poder 
analizarlos y crear nuestros propios modelos explicativos según el individuo que estamos valorando.

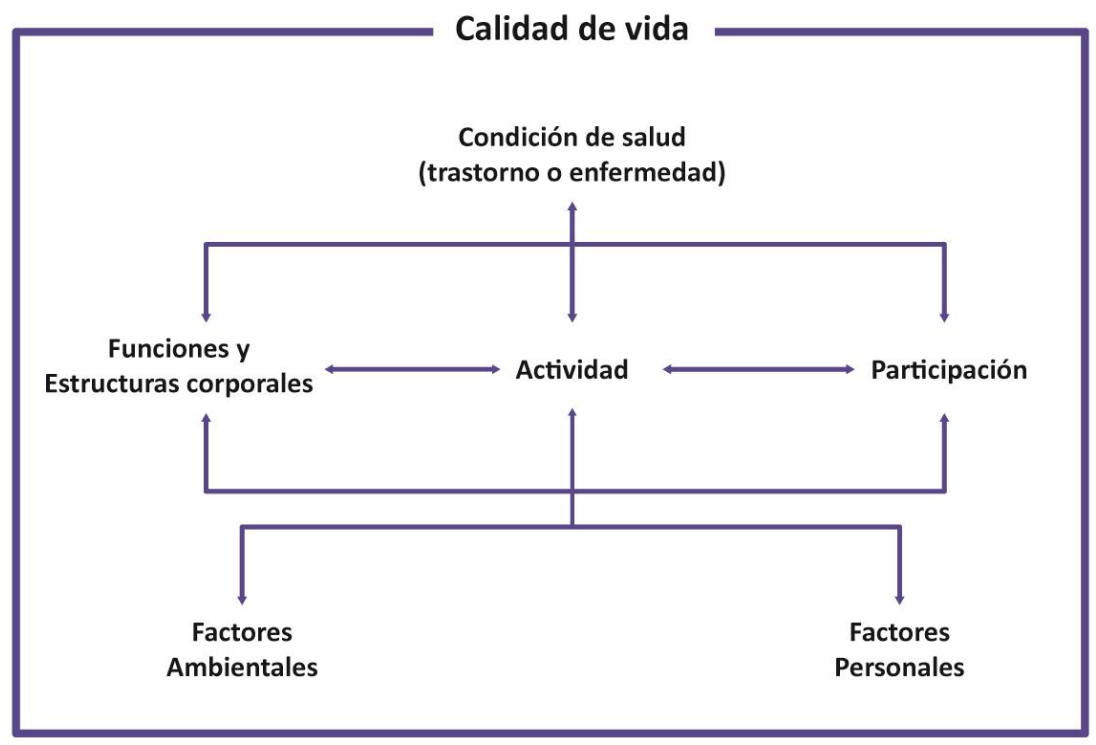

Figura 1.2. Interacción entre los componentes de la CIF

El esquema que aparece en la Figura 1.2. muestra las múltiples interacciones que existen entre los distintos elementos para explicar el proceso de funcionamiento y discapacidad. Por ejemplo, cómo los factores contextuales afectan tanto al nivel de actividad y participación como a las propias funciones y estructuras corporales, o cómo una función corporal determinada influye sobre la actividad del individuo.

Específicamente en el campo que nos ocupa de la rehabilitación, que se rige por un modelo biopsicosocial en la que la intervención clínicas pretende no sólo disminuir o eliminar una limitación, sino mejorar y potenciar el funcionamiento del paciente en distintas áreas de si vida, la CIF ha tenido una notable aceptación como tal y como muestra la 
literatura con numerosas publicaciones al respecto (Aiachini et al., 2010; Ayuso-Mateos et al., 2006; Koskinen, Hokkinen, Sarajuuri, \& Alaranta, 2007; Stucki, Ewert, \& Cieza, 2002).

En este sentido, la CIF se considera un instrumento debido a la inclusión de los calificadores "Desempeño" y "Capacidad", que permiten evaluar las distintas discrepancias existentes entre lo que un paciente realiza en su vida cotidiana y su potencial desempeño en un contexto idóneo. Además, la CIF recoge información sobre las barreras y facilitadores existentes en su ambiente que se tornan con frecuencia en objetivo de intervención. 


\section{Daño Cerebral Adquirido}

Predictores de Calidad de Vida en pacientes con Daño Cerebral Adquirido: Déficit, Actividad y Participación 



\section{DAÑO CEREBRAL ADQUIRIDO: DEFINICIÓN, EPIDEMIOLOGÍA Y TIPOLOGÍA}

\subsection{DEFINICIÓN Y EPIDEMIOLOGÍA}

La Organización Mundial de la Salud (Geneva, 1996) define el daño cerebral adquirido (DCA) como una lesión en el cerebro que ocurre después del nacimiento y no está relacionado con una enfermedad congénita o degenerativa, produciendo una serie de consecuencias que pueden ser temporales o permanentes y causar una discapacidad parcial o funcional o desajuste psicosocial.

Según la Federación Española de Daño Cerebral Adquirido (FEDACE), el DCA es una lesión repentina en el cerebro por causas externas (traumatismos craneoencefálicos -TCE-) o internas (accidentes cerebrovasculares -ACV- o ictus, tumores, anoxias, infecciones) que altera el funcionamiento normal del cerebro de una manera más o menos brusca, habiendo tenido hasta la fecha un desarrollo normal. Cuando las fuerzas son externas el cerebro se puede dañar directamente por un objeto penetrante que atraviesa el cráneo, como al recibir un disparo de bala (lesión abierta), o porque la cabeza reciba un golpe tan violento que haga que el cerebro choque con las paredes internas del cráneo (lesión cerrada). Las causas más comunes de daño cerebral de origen interno son los accidentes cerebrovasculares (hemorragia o bloqueo de una arteria cerebral), anoxias (interrupción del suministro de oxígeno al cerebro), tumores (crecimiento anormal de células cerebrales).

En cualquiera de los casos, la consecuencia fundamental es la pérdida de funciones cerebrales previamente desarrolladas o adquiridas, 
pudiendo afectar a las habilidades motoras, sensoriales, cognitivas, comunicativas, así como a la capacidad para regular la conducta y las emociones. Estas pérdidas suponen una merma de la independencia funcional en relación al estado premórbido, situación de discapacidad que condiciona el funcionamiento, no sólo de quien lo padece sino también de las personas más próximas al sujeto (National Institutes of Health (NIH), 1998)

De acuerdo con el informe realizado por FEDACE con la colaboración del Real Patronato sobre Discapacidad durante el año 2015 en España viven 420.000 personas con Daño Cerebral Adquirido. Un 78\%, se deben a accidentes cerebrovasculares y el $22 \%$ restante a otras causas como traumatismos craneoencefálicos, anoxias, infecciones cerebrales, tumores y otras patologías. En cuanto a la distribución del Daño Cerebral Adquirido por edad y sexo un $52,5 \%$ son varones y un $47,5 \%$ mujeres. A partir de las altas hospitalarias anuales producidas por las principales causas de DCA, según el Conjunto Mínimo Básicos de Datos (CMBD) de hospitalización del Ministerio de Sanidad, Servicios Sociales e Igualdad, se producen anualmente 104.701 nuevos casos de DCA, de los cuales, 99.284 son causados por un accidente cerebrovascular o ictus. A éste le sigue el traumatismo craneoencefálico con 4.937 casos anuales y la anoxia con 481 . Esto es, un 95,40\% del total de DCAs anuales son ACVs, un $4,74 \%$ TCEs y un $0,46 \%$ anoxias (FEDACE, 2015).

Las lesiones cerebrales son relativamente frecuentes. Casi 4 de cada 1.000 personas sufren algún tipo de daño cerebral adquirido, una cifra muy superior a los 4 de cada 100.000 o los 10 de cada 10.000 que sufren lesión medular y parálisis cerebral, respectivamente. Las lesiones cerebrales internas ocurren a un 2-3 por 1.000 de la población aumentando su frecuencia con la edad, teniendo como factores de resigo los niveles altos de colesterol, el consumo de alcohol y tabaco, la tensión 
arterial, etc. Una de cada 1000 personas es hospitalizada por un TCE, causado generalmente por caídas, golpes en juegos y deportes y accidentes de tráfico. Por estos motivos las lesiones abiertas aunque afecta a las personas de todas las edades es más prevalente en mayores debido a que por su debilidad y falta de agilidad y fuerza son más susceptibles a sufrir caídas y en jóvenes (de 15 a 24 años) por su participación en juegos y deportes y la conducción imprudente (Bilbao, Jiménez, \& Palomar, 2014).

Los datos que se muestran en las Ilustraciones 2.1-2.5., fueron presentados el 26 de octubre de 2015 en Madrid, y tienen su origen en el Estudio de la situación y necesidades de las personas con Daño Cerebral Adquirido elaborado por la FEDACE con el apoyo del Real Patronato de la Discapacidad durante los años 2013-2015. La causa más frecuente con un $78 \%$ del total de los casos fue el ACV, mientras que el TCE y otras causas suponían un $22 \%$ del total de los casos (Ilustración 2.1.). De todos ellos el $52 \%$ eran hombre y el $48 \%$ mujeres (Ilustración 2.2 ), concretamente tal y como se observa en la llustración 2.3., del total de ACVs un 53,4\% lo sufrían hombres y un $46,6 \%$ lo sufrían mujeres y del total de TCEs la prevalencia era mayor en hombres $(66,9 \%)$ que en mujeres $(33,1 \%)$. En cuanto a la prevalencia por edad (Ilustración 2.4.) el 65\% del total de casos con DCA eran mayores de 65 años y respecto a la discapacidad resultante (Ilustración 2.5.), el 89\% de los afectados presentaban algún tipo de dificultad para el correcto desempeño de las Actividades Básicas de la Vida Diaria. 


\section{Causas}

- Ictus TCEs y otras causas

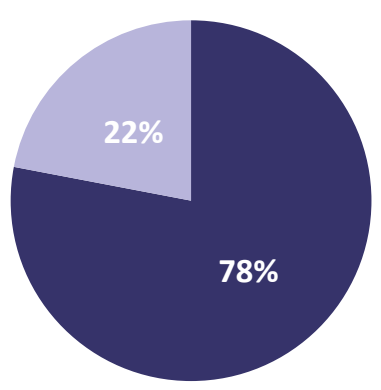

Ilustración 2.1. Causas del DCA

Incidencia

- Hombres Mujeres

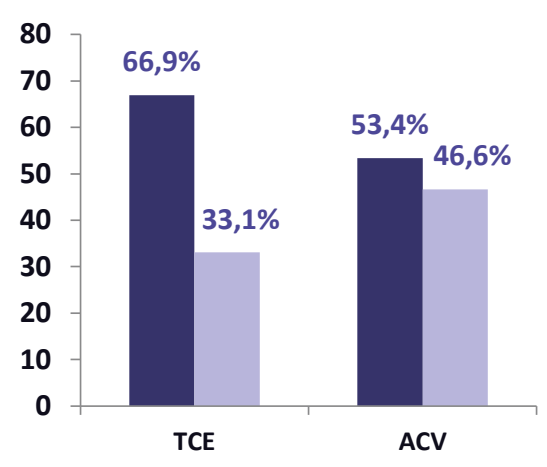

Ilustración 2.3. Incidencia por etiología

\section{Prevalencia total por género}

nujeres $\quad$ Hombres

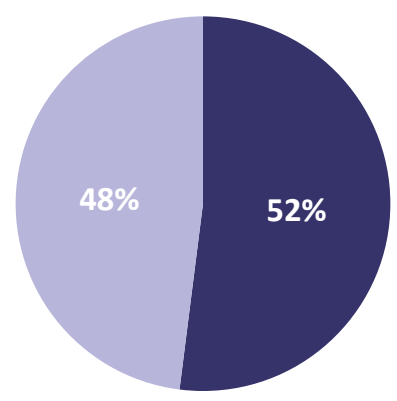

Ilustración 2.2. Incidencia por tipo de daño y género

\section{Prevalencia por edad}

- $>65$ años

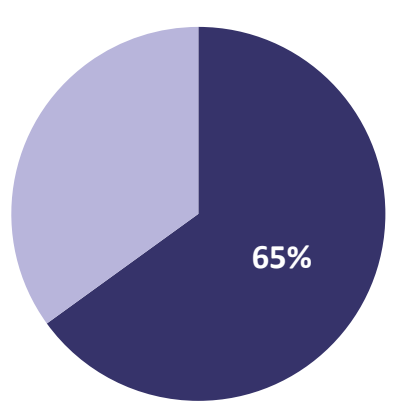

Ilustración 2.4. Prevalencia por edad 


\section{Discapacidad para ABVDs}

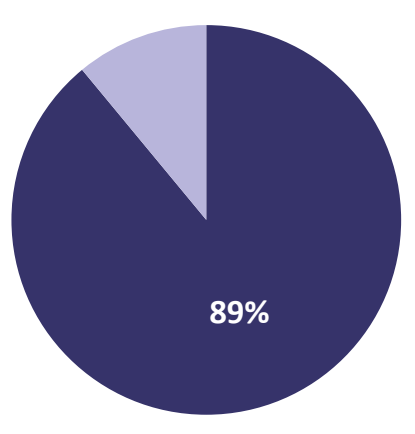

- Presentan alguna discapacidad para realizar Actividades Básicas de la Vida Diaria (ABVDs)

Ilustración 2.5. Discapacidad para ABVDs

De acuerdo con los datos proporcionados por la Consejería de Sanidad, en la Comunidad Valenciana más de 56.000 personas viven con DCA y anualmente se producen 12.500 casos nuevos, de los cuales 8.000 presentan secuelas graves y moderadas y aproximadamente 1.500 personas de ellas son menores de 65 años.

En la provincia de Castellón, de donde procede la mayor parte de los participantes en este estudio, se producen cada año casi 1.500 nuevos casos y de ellos más de 939 personas presentarán una discapacidad como consecuencia del daño. De ella, 167 son menores de 65 años. En cuanto a la prevalencia general, en la provincia de Castellón existen seis 6.500 personas con DCA y 755 de ellas son menores de 65 años y presentan dificultades importantes para la realización de las actividades básicas de la vida diaria. El $52,2 \%$ de esta población son mujeres y el $78 \%$ de estos casos se deben a ACVs y el $29 \%$ son menores de 65 años (Tabla 2.1.) 
Tabla 2.1. La atención al DCA en la Comunidad Valenciana.

\begin{tabular}{|l|c|c|c|}
\hline & \multicolumn{3}{c|}{ INCIDENCIA ANUAL } \\
POBLACIÓN & DCA & Con Secuelas & $<65$ años \\
\hline Comunidad Valenciana & 12.500 & 8.000 & 1.424 \\
Castellón & 1.467 & 939 & 167 \\
& & & \\
\hline & PREVALENCIA & \\
\hline POBLACIÓN & DCA & $<65$ años con secuelas ABVD \\
\hline Comunidad Valenciana & 56.484 & 6.433 \\
Castellón & 6.631 & 755
\end{tabular}

\subsection{TIPOLOGÍA}

Dado que el ictus y el TCE son las dos causas más frecuentes de DCA y también las más prevalentes dentro de la muestra total de sujetos de esta tesis, el presente apartado se centrará en estas dos tipologías de daño.

\subsubsection{ACCIDENTE CEREBROVASCULAR O ICTUS}

El término ictus procede del latín y significa golpe o ataque, su correspondencia anglosajona stroke tiene idéntico significado, ambos expresan lo mismo y describen el carácter brusco y súbito del proceso. Popularmente es conocido por múltiples nombres: infarto cerebral, trombosis, embolia, derrame cerebral o apoplejía (Castellví et al., 2007).

La Organización Mundial de la Salud define el accidente cerebrovascular como el síndrome clínico de inicio rápido de un daño cerebral focal (o global, como en la hemorragia subaracnoidea), que dura más de 24 horas (a menos que sea interrumpido por cirugía o muerte), sin otra causa aparente que vascular (Hatano, 1976). 
En los países desarrollados, hasta $75-80 \%$ de los accidentes cerebrovasculares se atribuyen a la isquemia cerebral, mientras que el 10$15 \%$ de los accidentes cerebrovasculares representan hemorragia intracerebral primaria (HIC) y aproximadamente $5-10 \%$ son hemorragia subaracnoidea (HSA). En términos generales, el accidente cerebrovascular es un deficiente neurológico repentino debido a la isquemia o hemorragia cerebral localizada. La mayoría de los accidentes cerebrovasculares se atribuyen a la oclusión focal del vaso sanguíneo cerebral (accidente cerebrovascular isquémico) y el resto son el resultado de la ruptura de un vaso sanguíneo (accidente cerebrovascular hemorrágico).

El accidentes cerebrovascular o ictus es una de las principales enfermedades no transmisibles de importancia para la salud pública. Después de la enfermedad coronaria y el cáncer, el accidente cerebrovascular es la causa más común de muerte en la mayoría de los países industrializados (World Health Organization, 2006).

Según la naturaleza de la lesión, los dos grandes tipos de ictus son (Castellví et al., 2007; Díez-Tejedor, Fuentes, Gil Nuñez, Gil Perlta, \& Matías Guiu, 2006)

- Ictus isquémico o infarto cerebral: Se produce cuando hay una oclusión o taponamiento de un vaso impidiendo que la sangre pueda llegar a una zona determinada del cerebro. Ésta parte queda entonces sin oxígeno ni nutrientes y se lesiona produciendo la isquemia cerebral. Si esta situación se mantiene en el tiempo el tejido se necrosa y muere dando lugar al infarto cerebral. Se considera que ha sido prolongado cuando el déficit neurológico tiene una duración superior a 24 horas. 
Esta obstrucción puede deberse a:

- Una embolia: coágulo sanguíneo que se origina en otro lugar del organismo, generalmente el corazón, y viaja por el torrente sanguíneo hasta el cerebro. Este coágulo obstruye una arteria que conduce al cerebro o que se encuentra dentro de él.

- Una Trombosis: Coágulo sanguíneo («trombo») que se produce en el propio vaso obstruyendo el flujo de sangre a ciertas partes del cerebro.

Entre los ictus isquémicos se encuentra el Accidente Isquémico Transitorio (AIT) que consiste en un episodio breve de disfunción neurológica, con síntomas clínicos que duran menos de una hora y no muestra evidencias de infarto en las técnicas de neuroimagen (Díez-Tejedor et al., 2006).

- Ictus hemorrágico: Extravasación de sangre dentro del encéfalo como consecuencia de la rotura d un vaso dentro del cerebro (hemorragia intracerebral) $o$ en sus envolturas (hemorragia subaracnoidea). Debido a que la sangre no se puede liberar al exterior que el cerebro está cubierto por el cráneo, la sangre presiona el tejido blando impidiendo que se oxigene adecuadamente, provocando así la atrofia y/o muerte de esos tejidos comprimidos.

Según la etiología, se dan diferentes tipos de ictus isquémicos (DíezTejedor et al., 2006): 
- Ictus isquémico aterotrombótico por ateroesclerosis de arteria grande: infarto generalmente de tamaño medio o grande, de topografía cortical o subcortical y localización carotídea o vertebrovasilar con presencia de ateroesclerosis.

- Ictus isquémico cardioembólico: ictus generalmente de tamaño medio o grande de topografía habitualmente cortical con presencia de alguna cardiopatía embolígena.

- Enfermedad oclusiva de pequeño vaso arterial (infarto lacunar): infarto pequeño en la zona de una arteria perforante cerebral generalmente en pacientes con antecedentes de hipertensión y otros factores de riesgo vascular, en ausencia de otra etiología que lo explique.

- Ictus isquémico de etiología inhabitual: infarto de cualquier tamaño y localización en un paciente en el que se ha descartado el origen aterotrombótico, cardioembólico o lacunar.

- Ictus isquémico de etiología indeterminada: infarto de tamaño medio o grande.

Entre todos los ACVs, el $80 \%$ son ictus isquémicos, el $15 \%$ hemorragias intracerebrales y el $5 \%$ restantes son consecuencia de hemorragias subaracnoideas. El $50 \%$ de los ictus isquémicos se consideran arterotrombóticos por ateroesclerosis de arteria grande, el $25 \%$ enfermedad intracraneal de pequeño vaso, el $20 \%$ son ictus isquémicos cardioembólicos y el $5 \%$ son debido a causas extrañas/etiología indeterminada (World Health Organization, 2006) (Ver Ilustración 2.6.). 

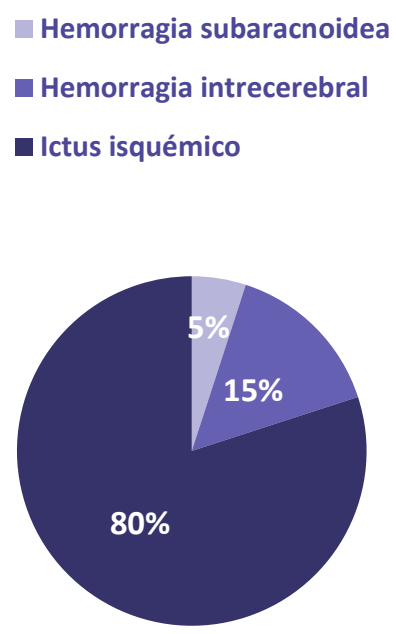

- Arterotrombótico

- De pequeño vaso

- Cardioembólico

Causas extrañas

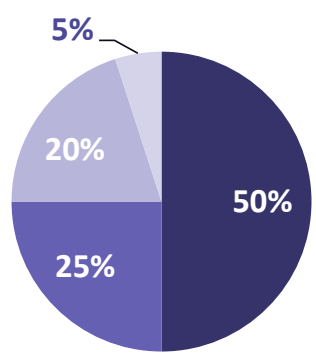

Ilustración 2.6. Causas de Accidente Cerebrovascular. Adaptado de (World Health Organization, 2006)

Alrededor del $30 \%$ de los pacientes muere dentro en el trascurso del primer año tras el ACV. El fallecimiento precoz tras un accidente cerebrovascular se debe generalmente a las complicaciones de la lesión cerebral. La recuperación después del ACV ocurre a través de varios procesos que se superponen. En las primeras horas y días, estos procedimientos pueden incluir la resolución de la isquemia, edema cerebral y comorbilidades (por ejemplo, infección) que exacerban los efectos funcionales del propio accidente cerebrovascular. Posteriormente, la plasticidad neural por la cual las neuronas asumen nuevas funciones, la adquisición de nuevas habilidades a través del entrenamiento (por ejemplo, fisioterapia y terapia ocupacional) y la modificación del entorno del paciente conducen a mayores ganancias en la función. 
No obstante, entre los supervivientes de un ACV es común encontrar a largo alteraciones cognitivas y demencia. Su desarrollo depende de varios factores tales como los propios de la lesión (volumen de tejido afectado por infarto y hemorragia, localización, proceso de isquemia) (Brott \& Bogousslavsky, 2000), el nivel de estudios o la presencia o no de tratamiento rehabilitador, entre otros. La prevalencia de demencia post-ACV en es de alrededor del 30\%, y la incidencia de inicio demencia tras un accidente cerebrovascular aumenta de un 7\% después de un año a $48 \%$ después de 25 años. Tener un accidente cerebrovascular dobla el riesgo de demencia (World Health Organization, 2006).

Un avance importante en el manejo del ictus es la aparición y el desarrollo de servicios especializados de ictus (unidades de ictus) en la mayoría de los países desarrollados. Estos servicios se organizan como unidades hospitalarias especializadas centradas exclusivamente en el tratamiento del ictus. La evidencia favorece que todos los accidentes cerebrovasculares sean tratados en unidades de ictus independientemente de la edad del paciente y la gravedad y subtipo del accidente cerebrovascular. La evidencia de ensayos aleatorios muestra que el tratamiento en unidades de accidente cerebrovascular es muy eficaz, especialmente cuando se compara con el tratamiento en salas médicas generales, salas geriátricas o cualquier otro tipo de departamento hospitalario en el que ninguna cama o personal especializado se dedica exclusivamente al cuidado del accidente cerebrovascular. La Stroke Unit Trialist's Collaboration (2002) ha demostrado que las unidades específicas de atención al ictus reducen en un $28 \%$ la mortalidad prematura (muerte dentro de las 12 semanas) y en un $17 \%$ (reducción del riesgo relativo) al final del seguimiento de un año. Estas unidades también ayudan a disminuir la discapacidad y producen más altas en el hogar, en lugar de institucionalizar a los pacientes (Brott \& Bogousslavsky, 2000) 
Los ictus son la causa más frecuente de Daño Cerebral Adquirido. Entre estos, un $80 \%$ son de tipo isquémico y un $20 \%$ de tipo hemorrágico. Los principales factores de riesgo de ictus según la OMS son la hipertensión, el tabaco, la inactividad física, la diabetes y la fibrilación auricular, sin embargo, es el ictus el que más se puede prevenir, según informa el Servicio de NeuroRehabilitación de Hospitales Nisa (Servicio NeuroRehabilitación. Hospitales Nisa, 2016). Una alimentación sana y equilibrada, con cifras de grasa (colesterol y triglicéridos) y azúcar (glucemia) en la sangre dentro de los límites de la normalidad, el abandono de los hábitos tóxicos, como el tabaquismo y el alcohol, y algo de actividad física semanal, pueden evitar esta enfermedad, que tanta morbilidad y tantas secuelas conlleva.

\subsubsection{TRAUMATISMO CRANEOENCEFÁLICO:}

El Traumatismo Craneoencefálico se define como una alteración en la función cerebral, u otra evidencia de patología cerebral, causada por una fuerza externa, que puede dar lugar a un deterioro significativo en los aspectos físicos, cognitivos y de funcionamiento psicosocial de la persona. En los Estados Unidos, se estima que entre 1,5 y 2 millones de personas sufren un TCE cada año, principalmente como resultado de accidentes de tráfico, caídas, actos de violencia y accidentes deportivos. El número de personas que sobreviven al TCE con un cierto grado de deterioro como consecuencia del mismo ha aumentado significativamente en los últimos años, por lo que resulta necesario una atención de emergencia más rápida y eficaz, un transporte más rápido y seguro y unas instalaciones de tratamiento especializado así como avances en el manejo médico agudo. EI TCE afecta a personas de todas las edades y es la principal causa de discapacidad a largo plazo entre los niños y los adultos jóvenes (National Institutes of Health (NIH), 1998). 
En España se producen todos los años del orden de 200 traumatismos craneoencefálicos (TCE) por 100.000 habitantes, de los cuales aproximadamente un $10 \%$ serán considerados graves, un $10 \%$ moderados y leves el $80 \%$ restante. EI TCE es tres veces más frecuentes en varones que en mujeres, siendo el grupo de edad de mayor incidencia el comprendido entre los 15 y 35 años de edad. En cuanto a la etiología, los accidentes de tráfico representan la causa más importante de Traumatismo Craneoencefálico, alrededor del $75 \%$, seguido por las caídas (20\%) y lesiones deportivas (5\%), existiendo diferencias según el grupo de edad y sexo. Así, los atropellos y las caídas son más frecuentes en niños y adultos mayores de 65 años, mientras que los accidentes de motocicleta se centran en el grupo de jóvenes menores de 25 años y los de automóvil en el de adultos. Aproximadamente uno de cada cinco supervivientes de un TCE presentará una discapacidad moderada o grave. La mortalidad global del Traumatismo Craneoencefálico es del $11 \%$ de los casos, con una tasa de mortalidad de 15 muertes por 100.000 habitantes y año siendo la primera causa absoluta de muerte e incapacidad en los individuos con edad inferior a los 45 años (Servicio de neurorrehabilitación. Hospitales Nisa, 2015).

Teniendo en cuenta la definición de TCE como "lesión en el cerebro causado por una fuerza externa que desencadena una serie de alteraciones en el individuo" se puede considerar relevante tres aspecto: la afectación cerebral, la existencia de una fuerza eterna y las consecuencias de la misma sobre las funciones de la persona que lo padece. Las fuerzas por contacto directo suelen provocar hematomas que son lesiones focales a nivel subdural o epidural generalmente. En función del tipo de fuerza ejercida sobre el cerebro durante el golpe puede romperse o no el cráneo y dejar visible el tejido cerebral, dando lugar a los distintos tipos de TCEs y lesiones asociadas que se relatan a continuación (TraumaticBrainlnjury.com, 2001): 
- Lesión cerrada: en este tipo de traumatismos no hay penetración en el cráneo quedando éste intacto por lo que el tejido cerebral no queda expuesto al exterior.

- Lesión abierta: traumatismo en el que un objeto rompe la capa del cráneo penetrando en él y exponiendo al exterior el tejido cerebral.

- Lesión axonal difusa: lesión difusa en el cerebro por el movimiento rotatorio rápido.

- Contusión: moretón en una parte del cerebro como consecuencia del sangrado.

- Trauma penetrante: cualquier objeto que entra en el cerebro causando un daño directo por impacto que empuja fragmentos del cráneo al cerebro.

- Lesión secundaria: como consecuencia del TCE pueden darse otras lesiones como hemorragias intracraneales, inflamación del cerebro, aumento de la presión intracraneal, falta de oxígeno en el cerebro (anoxia), infección dentro del cráneo, cambios químicos que conducen a la muerte celular o aumento del líquido cefalorraquídeo (hidrocefalia).

La clasificación inicial del TCE se basa en el nivel de gravedad a través de un examen, la Escala de Coma de Glasgow (Jones, 1979) que es llevado a cabo por el médico en el lugar del accidente y en puertas de urgencias. Esta escala clasifica el daño en tres niveles de severidad (leve, moderado y severo) según el grado de respuesta ocular, verbal y motora. Alrededor del $90 \%$ de los TCEs se clasifican como leve, lo que implica que el paciente está despierto, pero puede haber tenido una pérdida de conciencia y/o una amnesia corta. Sólo el 3-5\% de los TCEs son graves, lo que significa que el paciente está inconsciente en el momento de la exploración médica. (World Health Organization, 2006). En el TCE leve la 
tasa de mortalidad está por debajo del $1 \%$, mientras que en el TCE grave se encuentra entre el $20-50 \%$ y el TCE moderado tiene una tasa de mortalidad de 2-5\%. Es común encontrar en los pacientes con TCE un cierto grado de discapacidad tras la hospitalización (Thornhill et al., 2000), de hecho, la lesión cerebral traumática es la principal causa de discapacidad en personas menores de 40 años de edad (Berg, Tagliaferri, \& Servadei, 2005). En los TCE leves o moderados, la mitad de los pacientes presentan discapacidad, mientras que en los TCEs graves tres cuartas partes de los supervivientes presentan discapacidad, incluso entre los pacientes jóvenes con lesiones leves y un buen estado previo a la lesión, un tercio de ellos no logra una buena recuperación. La forma más rara de discapacidad después del TCE es el estado vegetativo. Puede ser transitoria, disminuyendo después de un mes o así, pero puede persistir a lo largo del tiempo en muchos casos (Thornhill et al., 2000).

Entre las causas más frecuentes del TCE se encuentran los accidentes de tráfico, las caídas y la violencia (Tagliaferri, Compagnone, Korsic, Servadei, \& Kraus, 2006). (Ver llustración 2.7.)

- Accidentes de tráfico: se trata de la principal causa de lesión en la cabeza en el mundo y, representan el $40-50 \%$ de los casos hospitalizados por TCE. El impacto de los accidentes de tráfico es aún mayor en niños y adultos jóvenes con TCE, en casos de TCE moderada o grave y en pacientes con lesiones múltiples. Cada día mueren unas 3.000 personas y 30.000 personas resultan gravemente heridas en las carreteras del mundo, casi la mitad de ellas con lesiones en la cabeza (World Health Organization, 2006).

- Caídas: son la segunda causa más frecuente de TCEs. Las personas mayores de 70 años presentan una incidencia relativamente alta de lesiones en la cabeza, siendo las caídas la causa más común en estos pacientes. Entre los factores que contribuyen al aumento del 
riesgo de caídas en personas mayores se encuentra el deterioro de la marcha, mareos, accidente cerebrovascular previo, deterioro cognitivo, hipotensión postural, mala agudeza visual y múltiples medicamentos (Thornhill et al., 2000).

- Violencia: la violencia interpersonal es la causa del 2-15\% de los casos de TCE (Thornhill et al., 2000). La mayoría de los TECs son el resultado de un traumatismo cerrado, pero en algunos países hay un alto porcentaje de lesiones penetrantes, como por ejemplo en Estados Unidos donde las heridas de bala son la principal causa y representan el $40 \%$ de todas las muertes por lesiones en la cabeza (Adekoya, Thurman, White, \& Webb, 2002).

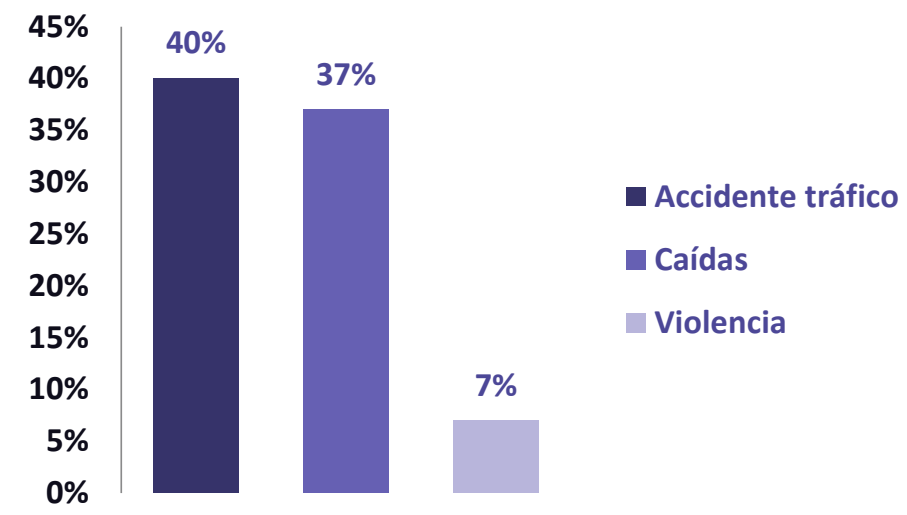

Ilustración 2.7. Causas externas de TCE en Europa

Aunque como hemos comentado anteriormente es frecuente encontrarnos con un cierto grado de discapacidad tras un TCE leve, la mayoría de los pacientes realizan una buena recuperación con la provisión de información necesaria y sin requerir grandes intervenciones específicas adicionales (Taricco \& Liberati, 2006; L. Turner-Stokes, Nair, Sedki, Disler, \& Wade, 2005). Por su parte, los pacientes con TCE de 
moderado a grave deben someterse a una evaluación rutinaria para valora las necesidades específicas de rehabilitación, pues existe gran evidencia de los beneficios que aportan las intervenciones formales, particularmente los programas intensivos que comienzan cuando los pacientes se encuentran todavía en la sala u hospital de agudos. El equilibrio entre intensidad y coste-efectividad no se ha determinado (Taricco \& Liberati, 2006; L. Turner-Stokes et al., 2005), de hecho la importancia de la rehabilitación se subestima constantemente. Lamentablemente esta parte del tratamiento no se considera tan importante como el tratamiento primario o inicial y por lo que resulta más complicado financiarlo. No obstante, es de gran importancia, ya que el TCE también afecta a los jóvenes, para quienes la rehabilitación es tan importante para la recuperación de la función como tratamiento primario es para el ahorro de la vida (World Health Organization, 2006)

\section{CONSECUENCIAS DEL DAÑo CEREBRAL ADQUIRIDO:}

A pesar de que los cambios físicos suelen ser los más evidentes en los pacientes con DCA, las secuelas cognitivas y conductuales son más frecuentes y persistentes en el tiempo. Muchos son los estudios que han demostrado la presencia de diversos déficits resultantes de algún tipo de daño cerebral adquirido, entendidos como pérdida de funciones cerebrales previamente desarrolladas. Entre éstas se encuentran, funciones cognitivas y de la comunicación, habilidades para la regulación conductual y emocional así como destrezas motoras y sensoriales, que suponen en ocasiones, una disminución en la percepción de 
recuperación, satisfacción y calidad de vida (Carlsson, Möller, \& Blomstrand, 2004; Edwards, Hahn, Baum, \& Dromerick, 2006; Jaillard, Grand, Le Bas, \& Hommel, 2010; Mansueti, De Frias, Bub, \& Dixon, 2008; Ríos-Lago, Benito-León, Paul, \& Tirapu-Ustárroz, 2008; Schmidt et al., 2004; Srikanth et al., 2003). Otro de los aspectos que se ven mermados en los pacientes con DCA es la independencia funcional respecto al estado premórbido, suponiendo una situación de discapacidad, entendida como una disminución del nivel de actividad y grado de participación, con la consiguiente sobrecarga de su entorno más próximo, generalmente la familia (M. D. Lezak, 1988)

En el presente apartado se describen brevemente estas posibles consecuencias del daño cerebral adquirido.

\subsection{ALTERACIONES COGNITIVAS:}

Los principales trastornos cognitivos que pueden aparecer tras un DCA están relacionados con la atención, la memoria, el lenguaje, el movimiento, la percepción, las funciones ejecutivas y la velocidad de procesamiento de la información (Machuca, León-Carrión, \& Barroso, 2006; Silver, MaCallister, \& Yudofsky, 2004). Entre las dificultades de atención es frecuente encontrar incapacidad para la detección de estímulos, focalización y mantenimiento de la vigilancia, distractibilidad y disminución de la resistencia a la interferencia, dificultad para atender a estímulos de manera simultánea o sucesiva (atención dividida y alternante) y presencia de heminegligencia. Relacionado con la función mnésica se observan dificultades tanto para el registro, mantenimiento, consolidación y recuperación de la información, así como para el aprendizaje y adquisición de material nuevo (FEDACE, 2006). 
Los trastornos del lenguaje generalmente se observan en los ACVs izquierdos (Elber Tafur C, 2012), dando lugar entre otros, a diferentes tipos de afasia. Entre las más frecuentes se encuentran la Afasia de Broca, la de Wernicke, la Afasia de Conducción y la Afasia Global. La primera se caracteriza por un lenguaje espontáneo no fluente y dificultad en la repetición y denominación, no obstante la comprensión está relativamente preservada; generalmente se acompaña de apraxia orofacial, agrafia y alexia. La Afasia de Wernicke, por lo contrario presenta un lenguaje fluente, aunque con dificultades en la repetición y en la comprensión auditiva; ésta puede ir acompañado de alexia, acalculia o apraxia dependiendo de la extensión de la lesión. La afasia de Conducción es similar a la Afasia de Broca aunque el lenguaje es fluente, manteniéndose relativamente preservada la comprensión y alterada la repetición y denominación. En la Afasia Global, como su nombre indica la alteración es generalizada y todos los aspectos del lenguaje (fluencia, comprensión, repetición y denominación) se encuentran alterados (Elber Tafur C, 2012).

A nivel perceptivo y motor pueden darse agnosias y apraxias. La agnosia se trata de un fallo en el reconocimiento que no puede ser debido a un problema o limitación sensorial, deterioro mental, trastorno atencional, dificultades en la denominación o falta de familiaridad con el estímulo presentado o el canal sensorial a través del cual se presenta. La apraxia consiste en una alteración en la ejecución intencionada de una acción motora llevada a cabo deliberadamente y en general fuera de contexto, sin una alteración sensorial, motora, perceptiva, de la comprensión verbal, desinterés o trastorno mental grave que lo justifique (Peña-Casanova, 2007).

La alteración de las funciones ejecutivas pueden manifestarse de manera muy amplia dando lugar a dificultades cognitivas y conductuales. 
La capacidad de planificación, organización, anticipación, selección de conducta, memoria de trabajo, razonamiento o fexibilidad mental, fluidez verbal, secuenciación de órdenes, autorregulación o automonitorización, son algunas de ellas (M. Lezak, Howieson, \& Loring, 2004; Sholberg \& Mateer, 1989)

Por lo que respecta al tiempo de reacción, las personas con DCA especialmente aquellos que han sufrido un TCE presenta mayor lentitud en la velocidad de procesamiento de la información y tiempos de reacción más elevados, debido a lesiones focales en ganglios basales, las fuerzas de rotación ejercidas sobre los nervios y a la pérdida consecuente de sustancia blanca (Prieto et al., 2009)

\subsection{ALTERACIONES CONDUCTUALES-EMOCIONALES:}

Como ya se ha comentado anteriormente algunas de las consecuencias del DCA son las alteraciones de conducta y trastornos emocionales, manifestándose como desinhibición, euforia, falta de control conductual, apatía, falta de conducta autoiniciada o indiferencia o desinterés (FEDACE, 2006). Estas alteraciones están relacionadas con la Corteza Prefrontal (CPF), una de las áreas anatómicas más afectadas en los TCEs, por el efecto conocido como "golpe contra golpe" que está interconectada con multitud de regiones corticales y subcorticales, resultando imprescindible para el rendimiento de otras áreas cerebrales mediante procesos de control, organización y coordinación. Estas alteraciones prefrontales se conocen en la práctica clínica como Síndrome orgánico de la personalidad (FEDACE, 2006; Sánchez-Cubillo, Lertxundi, Quemada, \& Ruiz-Ruiz, 2007) Desde los modelos de procesamiento centralizado en la CPF se ha estudiado el funcionamiento anómalo bajo la 
denominación de "Síndrome Disejecutivo"(Burgess, 1997), asociado a dificultades en la planificación, autorregulación, desinhibición, flexibilidad cognitiva, impulsividad, falta de juicio social, regulación conductual y emocional, déficit de memoria de trabajo y dificultad para centrarse en la tarea y finalizarla sin un control ambiental externo, entre otras (Baddeley \& Wilson, 1988).

Los cambios comportamentales asociados al daño cerebral adquirido pueden aparecer por exceso, por defecto o por inadecuación. Entre las primeras se encuentran la impulsividad, desinhibición, perseveración, verborrea, agresividad, irritabilidad, impulsividad, confabulación, distractibilidad, inflexibilidad y conductas de riesgo. Las alteraciones que aparecen por defecto son la apatía y falta de iniciativa, falta de motivación, de espontaneidad, de autocontrol, indiferencia afectiva, falta de habilidades sociales, de conciencia de déficit y despreocupación. Se consideran conductas inadecuadas en el DCA el egocentrismo, la puerilidad, falta de juicio social, rigidez del patrón de respuestas, conducta indiscreta, jocosidad y aislamiento social (FEDACE, 2006; FEVADACE, 2004).

A nivel emocional, en las personas con DCA es frecuente encontrar irritabilidad, explosiones de ira, síntomas de depresión y bajo estado de ánimo o cierta labilidad emocional (FEVADACE, 2004). Los cambios de personalidad y humor, con aumento de la agresividad e irritabilidad, pérdida de las normas de comportamiento social y falta de responsabilidad se han asociado al daño cerebral adquirido debido a la afectación de conexiones fronto-parietales que suponen falta de control emocional e intencional (Sánchez-Cubillo et al., 2007).

Entre los diferentes tipos de dificultades presente en los pacientes con lesión cerebral las alteraciones conductuales son las que a largo plazo provocan más estrés en el entorno familiar así como las que más dificultan 
la integración del paciente en el entorno laboral y social. Incluso, las alteraciones conductuales pueden afectar de manera tan importante en el proceso rehabilitador que el correcto manejo de las mismas es determinante para que la recuperación funcional del paciente se óptima. Por ello, la intervención y el manejo adecuado de este tipo de alteraciones consecuencia del DCA es imprescindible tenerlo en cuenta en la rehabilitación de estos pacientes (FEDACE, 2009).

\subsection{ALTERACIONES FUNCIONALES:}

La disminución o pérdida de independencia funcional respecto al nivel previo a la lesión en los pacientes con DCA supone una situación de dependencia en el mismo individuo y una sobrecarga para su entorno social, principalmente para el sistema familiar (M. D. Lezak, 1988).

Varios son los pacientes que tras un traumatismo grave que presentan diferentes tipos alteraciones, discapacidades y minsuvalías, de hecho, el grado de independencia funcional al año o más de haber sufrido la lesión se sitúa muy por debajo de las normas de la población. Al menos la mitad de los pacientes que han sufrido un TCE tienen uno o varios problemas residuales, y al menos un cuarto de ellos no retoman su actividad laboral anterior (Wouter et al., 2005).

Como se ha ido comentando en los puntos anteriores, las personas con DCA presenta secuelas motoras, sensoriales, cognitivas, conductuales y emocionales. Estos déficits afectan al correcto desempeño de las actividades de la vida diaria (Nilsen, Gillen, DiRusso, \& Gordon, 2012) y tienen un impacto significativo en la calidad de vida, pues dificultan la reinserción social, académica y ocupacional, incluso en mayor grado que 
las secuelas físicas (Mateer, 2003). Tanto el nivel de dependencia para la realización de estas actividades como el grado de participación del individuo se ven afectadas, llegando incluso a producirse el abandono de las mismas. Por ello, uno de los objetivos primordiales de la rehabilitación se centra en alcanzar la mayor independencia posible, tanto en su hogar como en su comunidad (Huertas Hoyas, Pedrero Perez, Águila Maturana, García López-Alberca, \& González Alted, 2015).

\section{REHABILITACIÓN DEL DAÑO CEREBRAL ADQUIRIDO: MEDIDAS DE RESULTADO}

La rehabilitación es el proceso a través del cual los profesionales de las distintas áreas y la persona con lesión cerebral trabajan de manera conjunta para conseguir el máximo nivel de funcionamiento físico, social, psicológico y vocacional. Así mismo, se pretende que tanto el paciente como los familiares con los que convive puedan reducir, manejar y sobrellevar estos déficits (Wilson, 1999), aunque no es tarea fácil. Los distintos factores que afectan al proceso rehabilitador tales como la complejidad de la lesión, del individuo y del sistema de apoyo suponen que el diseño del tratamiento se haga de manera individual y precisa para cada uno de los pacientes, resultando en un proceso tremendamente complejo (Ben-Yshay, 1993). Debido a esta complejidad que rodea al daño cerebral, el tipo de rehabilitación que ha demostrado tener mayor efectividad es aquella que combina diferentes técnicas destinadas a mejorar la capacidad funcional del paciente con el esfuerzo conjunto de terapeutas, pacientes y familiares y que se conoce como modelo comprensivo-holístico (Ylvisaker, Turkstra, \& Coelho, 2005). 
Un factor importante en esta rehabilitación es iniciarla tan pronto como sea posible después del inicio de la lesión; en aquellos pacientes con grave disminución de la conciencia la intervención es pasiva y es en el momento en que la conciencia está preservada cuando la rehabilitación se torna activa. Existen varios modelos organizacionales de rehabilitación, generalmente se inicia en el hospital y continúa a corto plazo en la misma unidad (unidades completas de ictus o de daño cerebral), clínicas de rehabilitación o centros ambulatorios. El enfoque multidisciplinar del equipo de rehabilitación y la participación y el apoyo a los cuidadores son características clave también en la recuperación a largo plazo. Varios estudios han demostrado que los diferentes tipos de servicios de rehabilitación mejoran el resultado, pero se sabe menos acerca de la intensidad y duración óptimas de las intervenciones específicas (World Health Organization, 2006)

La recuperación de las funciones perdidas en los pacientes con lesión cerebral es un proceso complejo que, puede ser en parte espontáneo aunque necesita los efectos que proporciona las intervenciones terapéuticas específicas para la correcta recuperación. El conocimiento sobre las intervenciones que promueven los mejores resultados en esta recuperación puede ayudar a optimizar los servicios de atención de salud. La recuperación exitosa de un accidente cerebrovascular debe resultar en una mejor calidad de vida y mayor grado de participación en la comunidad similar a la que tenía previamente a la lesión (Obembe \& Eng, 2016). La participación social es, por tanto, uno de los objetivos más importantes de la rehabilitación de pacientes con DCA y se sitúa generalmente en el último lugar (Obembe \& Eng, 2016). No obstante muchas son las investigaciones que estudian cuáles deberían ser los objetivos principales de la rehabilitación del daño cerebral, aunque no parece existir un acuerdo claro. Los factores que predicen con precisión los resultados funcionales después del daño son importantes para el 
manejo temprano del mismo con el fin de establecer metas adecuadas de rehabilitación, planificar el momento apropiado del alta e informar correctamente a los pacientes y familiares (Weimar, König, Kraywinkel, Ziegler, \& Diener, 2003).

En el campo de la rehabilitación, el término resultado (outcome, en inglés) se refiere a los cambios esperados o previstos en alguna medida o estado. Esto es, si un paciente entra en programa de tratamiento de una determinada manera y al cabo de un tiempo ese estado ha cambiado como resultado de la terapia recibida, el nuevo estado sería el resultado.

Establecer una medida de resultado inicial tras el daño cerebral está determinado generalmente por las variables indicadoras de la gravedad del daño, sin embargo, predecir el resultado a largo plazo resulta más complicado. De hecho, la gravedad de la lesión explica sólo una pequeña parte del daño, la actividad, la participación y la calidad de vida tras la lesión (Azouvi et al., 2016) y se considera junto con la edad una medida de resultado principalmente en la fase aguda del accidente cerebrovascular (Kwakkel \& Kollen, 2013). El resultado a largo plazo está determinado por varias variables previas a la lesión (p.ej. trastornos psiquiátricos, edad), por la gravedad de la misma (p.ej. tiempo en coma, amnesia post-traumática) y por las consecuencias que comporta (p.ej. alteración cognitiva, uso de ayudas técnicas) (Schönberger, Ponsford, Olver, Ponsford, \& Wirtz, 2011).

Para estudiar la medida de resultado es importante trabajar dentro de un marco o modelo de enfermedad que permita categorizar y clasificar todo los datos que se recogen. En este sentido, el modelo más utilizado y comúnmente aceptado ha sido la Clasificación Internacional de Deficiencias, Discapacidades y Minusvalías -CIDDM- de la OMS (World Health Organization, 1980) y posteriormente sus versiones actualizadas, la Clasificación Internacional de Deficiencias, Discapacidades y 
Minusvalías -CIDDM-2-(World Health Organization, 1999) y la Clasificación Internacional de Funcionamiento, de la Discapacidad y de la Salud-CIF- (OMS. Organización Mundial de la Salud, 2001; World Health Organization., 2002). En este sentido la CIF proporciona un marco multidimensional para la salud y discapacidad adecuado para clasificar los instrumentos de medida de resultado (Salter et al., 2005).

Dentro de la segunda versión de la CIDDM el resultado podía ser medido en diferentes niveles (Tabla 2.2) y, ante cualquier intervención sería esperable observar algún tipo de cambio. Por ejemplo, el resultado anatómico o estructural del cerebro resultado de un accidentecerebrovascular sería un efecto a nivel de patología, sin embargo, el paciente probablemente valorará más su habilidad para realizar una determinada actividad o para participar en un entorno social (Roberts \& Counsell, 1998).

Tabla 2.2. Resultados del daño según la Clasificación CIDDM-2. Adaptado de (Salter et al., 2005)

\begin{tabular}{|c|c|c|}
\hline & Descripción & Nivel de descripción \\
\hline $\begin{array}{l}\text { Enfermedad } \\
\text { Patología } \\
\text { Daño/déficit } \\
\text { Actividad (antes } \\
\text { discapacidad } \\
\text { Participación (antes } \\
\text { minusvalía) }\end{array}$ & $\begin{array}{l}\text { Trastorno/diagnóstico } \\
\text { Síntomas/signos } \\
\text { Función/conducta } \\
\text { observada } \\
\text { Posición social/roles }\end{array}$ & $\begin{array}{l}\text { Órgano/sistema } \\
\text { Cuerpo } \\
\text { Interacción persona- } \\
\text { ambiente } \\
\text { Persona en su contexto } \\
\text { social }\end{array}$ \\
\hline
\end{tabular}

\section{Ejemplos}

\section{Factores contextuales}

Experiencias

personales

Entorno físico

Entorno social
Función previa, comorbilidades

Hogar

Soporte social de familia y amigos

\section{Comentario}

Factores que pueden afectar a las consecuencias del daño, a la necesidad de ayudas técnicas o modificaciones ambientales así como a las motivaciones. 
Cuando se elige una medida de resultado, los ítems deben estar relacionados con un único nivel de la clasificación, dado que, de pertenecer a más de un nivel resultaría complicado interpretar los resultados (Orgogozo, 1994).

Al tratar de identificar factores y predictores de la CV, objetivo principal de la presente investigación, muchos estudios tienen en cuenta las características específicas de la enfermedad, las variables demográficas o las puntuaciones totales del estado funcional (Alguren et al., 2012). Sin embargo, para poder identificar objetivos adecuados de rehabilitación es importante disponer de información sobre los factores asociados con la CV. Tal y como muestra la revisión de Carod-Artal y Egido (Carod-Artal \& Egido, 2009) sobre los determinantes de CV después del accidente existe una red compleja de factores que afectan a la adaptación de la persona a su vida como son los antecedentes sociales, daño neurológico, discapacidad, cognición, estado de ánimo, estilos de afrontamiento, apoyo social, etc.

En la revisión realiza en el 2000 por Duncan y colaboradores (Duncan, Jorgensen, \& Wade, 2000) sobre las medidas de resultado en accidente cerebrovascular encuentran una gran variabilidad en la selección de medidas. Teniendo en cuenta que de los 51 estudios incluidos en la revisión, únicamente 29 definieron la medida a considerar, el $80 \%$ de éstos incluyeron como medida la discapacidad (sintomatología neurológica, déficit cognitivo, depresión), el $75 \%$ de los estudios la actividad (valorada principalmente con el Índice de Barthel), tan sólo un estudio tuvo en cuenta la calidad de vida y ninguno de ellos prestó atención a la participación. En esta revisión se refleja la falta de coherencia en la selección de las medidas de resultado y en el momento de las evaluaciones así como la falta de acuerdo sobre la definición o la medida de recuperación, destacando la necesidad de un cierto consenso 
sobre la evaluación de los resultados. Estos autores consideran que cualquier estudio debe incluir medidas acerca del nivel de deterioro como medidas de resultado para comprobar que se ha producido la recuperación neurológica esperada. Sin embargo, las medidas de deterioro no deben ser la medida principal de resultado, ya que los pacientes están más preocupados por la actividad. Otros autores (de Haan, Aaronson, Limburg, Hewer, \& van Crevel, 1993) consideran que el principal inconveniente es que la débil relación existente entre el grado de pérdida (en el nivel de patología) y el nivel de actividad, por lo que deben estar influyendo en el resultado otros factores. La calidad de vida se considera una medida de resultado importante dado su multidimensionalidad, ya que incluye constructos que tienen en cuenta los aspectos físico, sociales, y psicológicos de la salud de una persona (Moons, Budts, \& De Geest, 2006). Además, en el campo que nos ocupa de la rehabilitación de pacientes con enfermedades de curso crónico como el daño cerebral se ha demostrado que la calidad de vida es una medida de resultado importante (Fayers \& Machin, 2007; Sturm et al., 2004).

Para mejorar la selección de las medidas de resultado del daño cerebral deben considerarse las siguientes recomendaciones: (1) Las principales medidas de resultado deben estar al nivel de las actividades, teniendo en cuenta no sólo las AVD básicas, sino también las instrumentales. (2) Deberían incluirse medidas de resultado de deterioro cognitivo. (3) Deberían considerar la evaluación de la emoción del individuo, pero debido a que muchas personas no son capaces de responder, se convierte la emoción en una medida deficiente. (4) Todas las medidas de resultado deberían tener propiedades psicométricas establecidas (fiables, válidas y sensibles al cambio) y así como haber sido probadas en individuos con DCA. (5) "La definición de recuperación no debe ser dicotomizada, sino más bien debe evaluar los cambios en la 
discapacidad mediante el uso de estadísticas no paramétricas". (6) Cuando se seleccionan las medidas de resultado, debe considerarse la historia natural de recuperación de la población que se está estudiando. (7) Los principales resultados deben evaluarse a los 6 meses, especialmente en muestras que incluyen un accidente cerebrovascular grave. (8) La recogida de datos debe incluir otras variables que pueden afectar a los resultados (por ejemplo, diabetes, temperatura corporal, niveles de glucosa, depresión y apoyo social) (Duncan et al., 2000).

Establecer una medida de resultado en este contexto es complicado debido a varios factores: (a) normalmente hay varios resultados relevantes, (b) los resultados relevantes se ven afectados por múltiples factores además del tratamiento, y (c) incluso las buenas medidas raramente reflejan el interés específico del paciente o del equipo rehabilitador, dando lugar a discrepancias (Wade, 2003)

Las medidas de resultado son diferentes según el contexto en el que nos movamos, de hecho pueden ser varios los resultados objeto de estudio. En las terapias de rehabilitación tales como la terapia física, la terapia ocupacional, la psicológica o de logopedia en las que hay una relación próxima entre el paciente y terapeuta trabajando sobre la cognición y conducta se suele utilizar las alteraciones en la actividad (desempeño de una tarea) o en el grado de participación (papel del individuo en la comunidad), mientras que en otros ámbitos médicos el principal objetivo son las alteraciones en la función o estructuras corporales, utilizando medidas de rendimiento en las actividades de la vida diaria, sin reflejar aquello que aportan las terapias más cercanas. La rehabilitación es a menudo dependiente del contexto, en términos del CIF esto es que, la situación del paciente depende del entorno físico y de su personalidad, incluyendo creencias y actitudes así como experiencias y expectativas. En otras palabras, los factores físicos, sociales, 
motivacionales y el bagaje personal afectarán al resultado de la rehabilitación y permitirán una mejor generalización de los resultados de posibles ensayos clínicos (Wade, 2003).

Wade (Wade, 2003) argumenta que, los ensayos de rehabilitación deberían recoger datos sobre los dominios de la CIF: información referente a la patología, funciones y estructuras corporales, actividades, participación, contexto personal, físico y social.

La patología determinará la historia natural esperada, informará sobre la elección de las variables pronósticas necesarias para interpretar los hallazgos y asegurar el control de la gravedad, y permitirá que otros hagan conclusiones apropiadas para su práctica, de manera que la patología no sería una variable de resultado.

La información sobre la estructura y función corporal puede tener varios usos; la discapacidad es generalmente el mejor marcador pronóstico y ayuda a la interpretación de otros datos, además los cambios en el grado de discapacidad o deterioro mostraría el efecto de una intervención suponiendo va a haber cambios en el nivel de deterioro, incluso en muchos casos la diminución del deterioro es en sí mismo el objetivos principal.

Reducir la limitación en la actividad es en la mayoría de los estudios el objetivo principal y por tanto la medida de resultado. Las actividades pueden estar dentro o fuera del hogar y podrían incluir las actividades necesarias para participar en el trabajo, pero la principal dificultad es elegir una medida que detecte el cambio esperado.

La mayor parte de la rehabilitación clínica tiene como objetivo potenciar la participación social. Desafortunadamente, las medidas de participación están menos desarrolladas que las medidas de actividades más básicas. Además, muchos factores que están fuera del control del 
equipo de rehabilitación pueden afectar la participación. Por lo tanto, raramente la participación es el foco de los ensayos de investigación en rehabilitación, y apenas se mide.

En cuanto al contexto personal, se sabe que algunas intervenciones están destinadas a trabajar factores personales tales como creencias, expectativas o factores previos al trauma que pueden considerarse como medidas de estado inicial o también como medidas de resultado mostrando el efecto que ha tenido la intervención. Los estudios psicológicos podrían centrarse en la autoeficacia como resultado, pero desde el punto de vista del proceso de rehabilitación como un todo, se desearía evaluar directamente los efectos sobre las actividades. El vínculo conocido entre la autoeficacia y el rendimiento de actividad no es suficientemente fuerte como para permitir su uso como marcador sustituto. Del mismo modo, el conocimiento de los pacientes sobre las prácticas de autocuidado puede ser una medida de proceso importante, pero el desempeño real de estas actividades es aún más importante y (por ejemplo) la reducción de la tasa de complicaciones podría ser el principal objetivo del estudio.

Respecto al contexto físico se pueden investigar los efectos de las ayudas técnicas que se proporcionan a los pacientes (sillas de ruedas, ortesis, paneles de comunicación...) sobre la participación comunitaria. No obstante se necesita información de estos contextos físicos (i.e. escaleras o rampas) para poder interpretar datos sobre las actividades.

Por último, en relación al contexto social, los estudios podrías investigar los efectos de alterar las actitudes, creencias, conocimientos, habilidades o expectativas de los miembros de la sociedad (familia, amigos, compañeros...) para poder medir este cambio como indicador del proceso de rehabilitación, no obstante resulta complicado realizar esta 
intervención y considerarse el contexto social como medida de resultado. (Wade, 2003).

La versión más reciente de la CIF (OMS. Organización Mundial de la Salud, 2001; World Health Organization., 2002) identifica tres niveles principales del funcionamiento humanos -el cuerpo, la persona y la persona en relación a su contexto social-, a través de los cuales deben ser medidos los resultados. Se tratan de las funciones/estructuras corporales, la actividad y el nviel de participación que se presenta a modo de cuadro resumen en la Tabla 2.3.

Tabla 2.3. Cuadro resumen definiciones CIF. Adaptado de (Salter et al., 2005)

\begin{tabular}{|c|c|c|}
\hline $\begin{array}{l}\text { Término } \\
\text { antiguo }\end{array}$ & $\begin{array}{l}\text { Término } \\
\text { actual }\end{array}$ & Definición \\
\hline Deficiencia & $\begin{array}{l}\text { Cuerpo: } \\
\text { función/ } \\
\text { estructura }\end{array}$ & $\begin{array}{l}\text { Funciones fisiológicas de los sistemas } \\
\text { corporales incluyendo el psicológico. Se } \\
\text { entiende estructura como partes anatómicas o } \\
\text { regiones del cuerpo y sus componentes. La } \\
\text { deficiencia o el daño son los problemas en las } \\
\text { funciones o estructuras corporales. }\end{array}$ \\
\hline Discapacidad & Actividad & $\begin{array}{l}\text { Ejecución que hace la persona de una tarea. } \\
\text { Limitación en la actividad se define como las } \\
\text { dificultades que presenta el individuo podría } \\
\text { experimentar al realizar una tarea } \\
\text { determinada. }\end{array}$ \\
\hline Minusvalía & Participación & $\begin{array}{l}\text { Implicación de un individuo en una situación } \\
\text { de la vida. Las restricciones en la participación } \\
\text { describen las dificultades experimentadas por } \\
\text { el individuo en una situación vital o rol. }\end{array}$ \\
\hline
\end{tabular}

Teniendo esto en cuenta, Salter y colaboradores (Salter et al., 2005) realizaron en el 2005 una revisión sobre los instrumentos más utilizados 
como medida de resultado en la rehabilitación del DCA, clasificados según la categoría CIF que valoraban (Tabla 2.4.).

Tabla 2.4. Clasificación de medidas de resultado. Adaptado de (Salter et al., 2005)

\section{Estructura corporal (daño Actividad (limitación en la o déficit) actividad-discapacidad)}

6. Barthel Index

7. Berg Balance Scale

8. Chedoke McMaster Stroke Assessment Scale

9. Functional Independence Measure (FIM)

4. Modified Ashworth

5. Motor-free Visual Perception Test

10. Frenchay Activities
Participación (restricción en la participaciónminusvalía)

15. Euroqol-5D

16. Medicial Outcomes Study Short Form-36

17. Nottingham Health Profile

18. Sickness Impact Profile (stroke adapted version) Index

11. Modified Rankin Handicap Scale

19. Stroke Impact Scale

20. Stroke Specific Quality of Life

12. Rivermead Motor Assessment

13. Rivermead Mobility Index

14. Timed-Up-and-Go (TUG) 



\section{Calidad de vida en Daño Cerebral Adquirido}

Predictores de Calidad de Vida en pacientes con Daño Cerebral Adquirido: Déficit, Actividad y Participación 



\section{CONCEPTUALIZACIÓN Y EVALUACIÓN DE CALIDAD DE VIDA}

\subsection{CONCEPTO}

La conceptualización de "calidad de vida" (CV) es compleja dado que no existe una definición única general sobre este constructo psicológico. No obstante, la mayoría de definiciones en la actualidad coinciden en incluir dos aspectos: la multidimensionalidad y la valoración subjetiva que el individuo tiene sobre su propia vida.

La propia OMS define la calidad de vida como "percepciones de los individuos sobre su posición en la vida en el contexto de la cultura y sobre el sistema de valores en los que viven, y en relación con sus metas, expectativas, estándares y preocupaciones" ('individuals' perceptions of their position in life in the context of the culture and value system in which they live and in relation to their goals, standards, and concerns') (The WHOQOL Group, 1998). Se trata, por tanto, de un concepto amplio que se ve afectado de manera compleja por la salud física, el estado psicológico, el nivel de independencia, las relaciones sociales y su relación con los estímulos del entorno.

Remontándonos a los inicios de este concepto, ya en los años 70 las ciencias sociales comenzaron a definir indicadores para recoger información relacionada con el bienestar social de una población. Se trataba de datos principalmente objetivos pero, a lo largo de la década de los 70 y 80, fueron incluyéndose aspectos más subjetivos proporcionando al concepto de $\mathrm{CV}$ un carácter multidimensional que incluye información sobre todas las áreas de la vida. Concretamente, en 1976, René Dubos 
(Dubos, 1976) consideró el carácter subjetivo de la CV cuando ésta se relacionaba con la salud, describiéndola como la satisfacción del individuo ante la realización de las actividades de la vida diaria, y relacionándola con la perspectiva personal que cada persona tiene sobre la felicidad. De esta manera el término CV comenzó a emplearse en otros ámbitos, utilizándose tanto en ámbitos de salud, como de servicios, educación y en la toma de decisiones políticas (Gomez \& Sabeh, 2001).

El término "calidad de vida" (CV) ha resurgido y cobrado notable relevancia en las últimas décadas, tal y como puede constatarse al hacer revisiones bibliográficas, por la gran cantidad de literatura reciente que podemos encontrar al respecto. Actualmente coexisten múltiples definiciones para referirse a un mismo constructo: (1) (Oleson, 1990) define la calidad de vida como una "percepción subjetiva de la felicidad o satisfacción con la vida en los aspectos importantes de un individuo"; (2) (Borthwick-Duffy, 1992) formula tres conceptualizaciones según las cuales la CV se define como "calidad de las condiciones de vida de una persona", "satisfacción experimentada por la persona en dichas condiciones de vida" y la "calidad de las condiciones de vida de una persona junto a la satisfacción que ésta experimenta"; finalmente, (Felce \& Perry, 1995) añaden a estos conceptos el de "combinación de las condiciones de vida y la satisfacción personal ponderadas por la escala de valores, aspiraciones y expectativas personales".

A pesar de haber ofrecido una definición de calidad de vida, la OMS no ha incluido este concepto en la nueva CIF, probablemente debido a la falta de acuerdo en la definición del constructo, que contiene además numerosos indicadores subjetivos. De hecho, una manera de conceptualizar la CV es considerar que se trata de la propia evaluación de la persona (el paciente) sobre su vida, incluyendo la percepción de su enfermedad, discapacidad, actividad y participación, interpretada en su 
propio contexto. Si esto se llevara a la práctica, la única manera de establecer la CV de una persona sería preguntarle a ella misma, algo que, por otra parte, suele hacerse con frecuencia (Wade, 2003).

El concepto de "calidad de vida" ha estado estrechamente relacionado con la salud (CVRS) durante muchos años desde que la OMS definiera la salud como un estado de completo bienestar físico, mental y social -y no sólo meramente la ausencia de enfermedad o dolencia(World Health Organization, 1946). A partir de ese momento la CVRS surgió como una forma para profesionales sanitarios e investigadores de describir y medir sistemáticamente la salud y el estado funcional de una persona en múltiples niveles: físicos, emocionales y sociales (K. L. Anderson \& Burckhardt, 1999). Por este motivo, el concepto de CV a menudo se ha relacionado y evaluado en términos de variables relacionados con la salud física (Patrick \& Erickson, 1993), dificultando el avance en el campo de la CV desde la perspectiva de los propios individuos o de la relación entre factores vinculados con la salud, como son los factores contextuales y la CV percibida (Mcdougall, Wright, \& Rosenbaum, 2010). A este respecto, algunos estudios identifican la "paradoja de la discapacidad" que hace referencia a la alta calidad de vida percibida en individuos con un alto grado de discapacidad (Albrecht \& Devlieger, 1999). La explicación que ofrecen estos autores acerca de este fenómeno es que la satisfacción positiva con la vida percibida depende de que la personal logre un equilibrio entre el cuerpo, la mente y el espíritu, de manera que las interrelaciones entre estos factores -en el contexto del entorno más amplio- pueden explicar las aparentes contradicciones planteadas por la paradoja. 


\subsection{EVALUACIÓN}

La calidad de vida se ha definido desde diferentes aproximaciones $y$, en consecuencia, se ha vinculado con la satisfacción de las necesidades (Hörnquist, 1982), con las experiencias subjetivas relacionadas con la salud (Guyatt, Jaeschke, Feeny, \& Patrick, 1996), o con el bienestar físico o psicológico (Wenger, Mattson, Furberg, \& Elinson, 1984). Para resolver el problema que genera la propia conceptualización del término, podemos preguntar directamente al paciente cómo calificaría su calidad de vida actual (Neil K. Aaronson, 1989; Ahlsiö, Britton, Murray, \& Theorell, 1984; Gough, Furnival, Schilder, \& Grove, 1983). Sin embargo, intentar resolver esta cuestión con tan sólo una pregunta no es muy fiable ni válido y tiene poco valor analítico, se hace necesario tener más información para poder interpretar un concepto tan complejo como el que nos ocupa. Por esta razón, la mayoría de los investigadores adoptan un enfoque multidimensional para la evaluación de la CV (N K Aaronson, 1988).

El enfoque actual para la evaluación de la calidad de vida puede caracterizarse por: (1) su naturaleza multidimensional que involucra dominios e indicadores básicos; (2) el uso del pluralismo metodológico que incluye el uso de medidas subjetivas y objetivas; (3) el uso de diseños de investigación multivariante para evaluar las formas en que las características personales y las variables ambientales se relacionan con la calidad de vida evaluada de la persona; y (4) la incorporación de una perspectiva de sistemas que capte los múltiples entornos que afectan a las personas en los niveles micro, meso y macro (Verdugo, Schalock, Keith, \& Stancliffe, 2005)

El interés por obtener una medida más objetiva de CV proviene de tres fuentes. La primera se trata del cambio de enfoque de la creencia que sólo los avances científicos, médicos y tecnológicos mejorarían la CV hacia 
una perspectiva acerca de la interacción entre el bienestar personal, familiar, comunitario y social y los valores, percepciones y condiciones ambientales del individuo. La segunda razón refleja el hecho de que el concepto de CV representa el siguiente escalón para la normalización, haciendo hincapié en los servicios basados en la comunidad como medida de resultado de la integración comunitaria del individuo. Y, por último, la tercera razón se vincula con el creciente movimiento por la planificación centrada en la persona, rendimiento personal y autodeterminación (Verdugo et al., 2005).

Diversos autores que trabajan en la conceptualización y medición de la calidad de vida publicaron entre 2002 y 2004 una seria de principios sobre la manera de medir este aspecto: (I) la medición de la CV implica el grado en que las personas tienen experiencias en la vida que valoran; (II) la medición de la CV refleja dominios que contribuyen a una vida satisfactoria; (III) la medición de la CV considera los entornos físicos, sociales y culturales importantes para la persona; y (IV) la medición de la $\mathrm{CV}$ incluye medidas tanto de experiencias comunes a todos los seres humanos como aquellas únicas para el individuo (Brown, I., Keith, K., \& Schalock, 2004; Schalock et al., 2002)

La relación entre la $\mathrm{CV}$ y los niveles de órgano, persona y sociedad (modelo biopsicosocial) se debe a la definición de salud de la OMS, anteriormente descrita, como "un estado de completo bienestar físico, mental y social y no meramente la ausencia de enfermedad o dolencia" (World Health Organization, 1946).

Así, en la evaluación de CV se habrían de incluir al menos cuatro dimensiones: física, funcional, psicológica y social (de Haan, Aaronson, Limburg, Hewer, \& van Crevel, 1993). La dimensión de salud física se refiere principalmente a los síntomas relacionados con la enfermedad y relacionados con el tratamiento. La salud funcional comprende el 
autocuidado, la movilidad y el nivel de actividad física, así como la capacidad para desempeñar diversos roles en relación con la familia y el trabajo. El funcionamiento cognitivo, el estado emocional (especialmente la depresión post-traumática) y las percepciones generales de salud, bienestar, satisfacción con la vida y felicidad son los componentes centrales del dominio de la esfera psicológica. El funcionamiento social incluye la evaluación de los aspectos cualitativos y cuantitativos de los contactos e interacciones sociales.

Con relación al tema de esta tesis, estudios en personas que han sufrido un ictus indican que las discapacidades físicas a menudo tienen un impacto negativo en la CV, aunque esto no siempre es así. Los pacientes con daño cerebral con poca o ninguna disfunción física también pueden experimentar una disminución en su CV (Labi, Phillips, \& Greshman, 1980; Viitanen, Fugl-Meyer, Bernspång, \& Fugl-Meyer, 1988). Tanto el estado psicológico como la discapacidad física pueden afectar a la calidad de vida (Ahlsiö et al., 1984). En este sentido, hay un gran debate sobre dicho constructo $y$, de hecho, muchos de los instrumentos que se han considerado para su evaluación también miden actividades o emociones (Post, de Witte, \& Schrijvers, 1999). No podemos despreciar otros factores que influyen tanto en la participación como en la calidad de vida como, por ejemplo, el estado de ánimo, la frecuencia de la depresión y su relación con las actividades (Kotila, Numminen, Waltimo, \& Kaste, 1999; Schubert, Taylor, Lee, Mentari, \& Tamaklo, 1992; van de Weg, Kuik, \& Lankhorst, 1999) ni perder de vista el hecho de que muchos pacientes presentan deterioro cognitivo y del lenguaje, lo que puede dificultarles la ejecución adecuada de las pruebas destinadas a la evaluación de la emoción. 


\subsection{INSTRUMENTOS DE MEDIDA}

La selección de un instrumento adecuado para una población y objetivo específico es imprescindible para una buena recogida de información. Para ello, es necesario valorar qué medidas existen, cuáles son sus propiedades psicométricas (fiabilidad, validez, etc.) y las características relacionadas con la aplicación (i.e., modo de administración, tiempo que se emplea en contestarlo, etc.). Una de las características más importantes es la validez aparente y la de contenido (McHorney, 1999), que deben tenerse en cuenta cuando seleccionamos el instrumento apropiado para una patología concreta. Sin embargo, esta propiedad psicométrica en los cuestionarios de calidad de vida para pacientes con ictus raramente ha sido estudiada (Golomb, Vickrey, \& Hays, 2001), por lo que resulta necesario una revisión exhaustiva explorando y comparando los contenidos de las distintas medidas de calidad de vida en este campo (Geyh, Cieza, Kollerits, Grimby, \& Stucki, 2007). Teniendo en cuenta el lenguaje común que emplea la OMS en su sistema de clasificación CIF y debido a su carácter universal, encontramos varios estudios que comparan diferentes medidas de calidad de vida en el caso concreto de DCA (Salter, Jutai, Teasell, et al., 2005a; Salter, Jutai, Teasell, Foley, \& Bitensky, 2005b; Salter, Jutai, \& Bayley, 2005; Stucki, Ewert, \& Cieza, 2002)

La herramienta o instrumento más adecuado para medir la calidad de vida (CV) son los cuestionarios de autoinforme, dada la naturaleza subjetiva del concepto como hemos visto en el apartado anterior. Se trata de un método, más o menos estructurado, de recogida de información a partir de la contestación de una serie de preguntas por el propio sujeto. Generalmente presenta un número determinado de ítems organizados en diferentes apartados, que incluyen los distintos dominios a evaluar y que definen el constructo general, en este caso el de CV. El uso de 
autoinformes o cuestionarios administrados por un profesional experto puede ser complicado en algunos pacientes con DCA debido a las déficits asociados con la lesión, principalmente alteraciones cognitivas como pueden ser la dificultad en la comprensión o problemas de lenguaje. Las medidas genéricas de calidad de vida ofrecen grandes ventajas, especialmente para la comparación de diferentes condiciones de salud. Sin embargo, los instrumentos genéricos disponibles hasta el momento no tienen en cuenta los problemas relacionados con el DCA, como las dificultades cognitivas (Doyle, 2002; Gompertz, Pound, \& Ebrahim, 1993). Para hacer frente a estos desafíos se están desarrollando cada vez más medidas de CV relacionada con la salud específicas para este tipo de pacientes (Geyh et al., 2007).

A finales de los años noventa, se llevaron a cabo diferentes iniciativas con la finalidad de desarrollar nuevos instrumentos específicos para abordar las necesidades que surgían de las limitaciones descritas de los estudios sobre calidad de vida, a partir de las cuales se diseñaron diversos instrumentos como las escalas SS-QOL (Stroke-Specific Quality of Life) y SIS (Stroke-Specific Scale). Estos instrumentos desarrollados desde la perspectiva tanto del paciente como del cuidador incluyen los dominios de deterioro, actividad y participación, junto con otras áreas como el lenguaje, la cognición, la funcionalidad de la mano y movilidad, y presentan buenas propiedades psicométricas (Duncan et al., 1999; Williams, Weinberger, Harris, Clark, \& Biller, 1999).

Posteriormente se llevaron a cabo algunos trabajos muy interesantes, como los de Coons y colaboradores (Coons, Rao, Keininger, \& Hays, 2000)o Geyh y colaboradores(Geyh et al., 2007), que realizaron una revisión exhaustiva de los instrumentos de calidad de vida, incluyendo éstos últimos, un total de seis instrumentos genéricos y cinco específicos para DCA (Coons et al., 2000). En la Tabla 3.1. se presenta una 
visión general de las principales características de las medidas de la CV seleccionadas por estos autores. En la misma tabla se ha incorporado el cuestionario de calidad de vida, satisfacción y placer -QLESQ (Endicott, Nee, Harrison, \& Blumenthal, 1993)- dado la relevancia que supone incluir todos los dominios de participación de la CIF. 

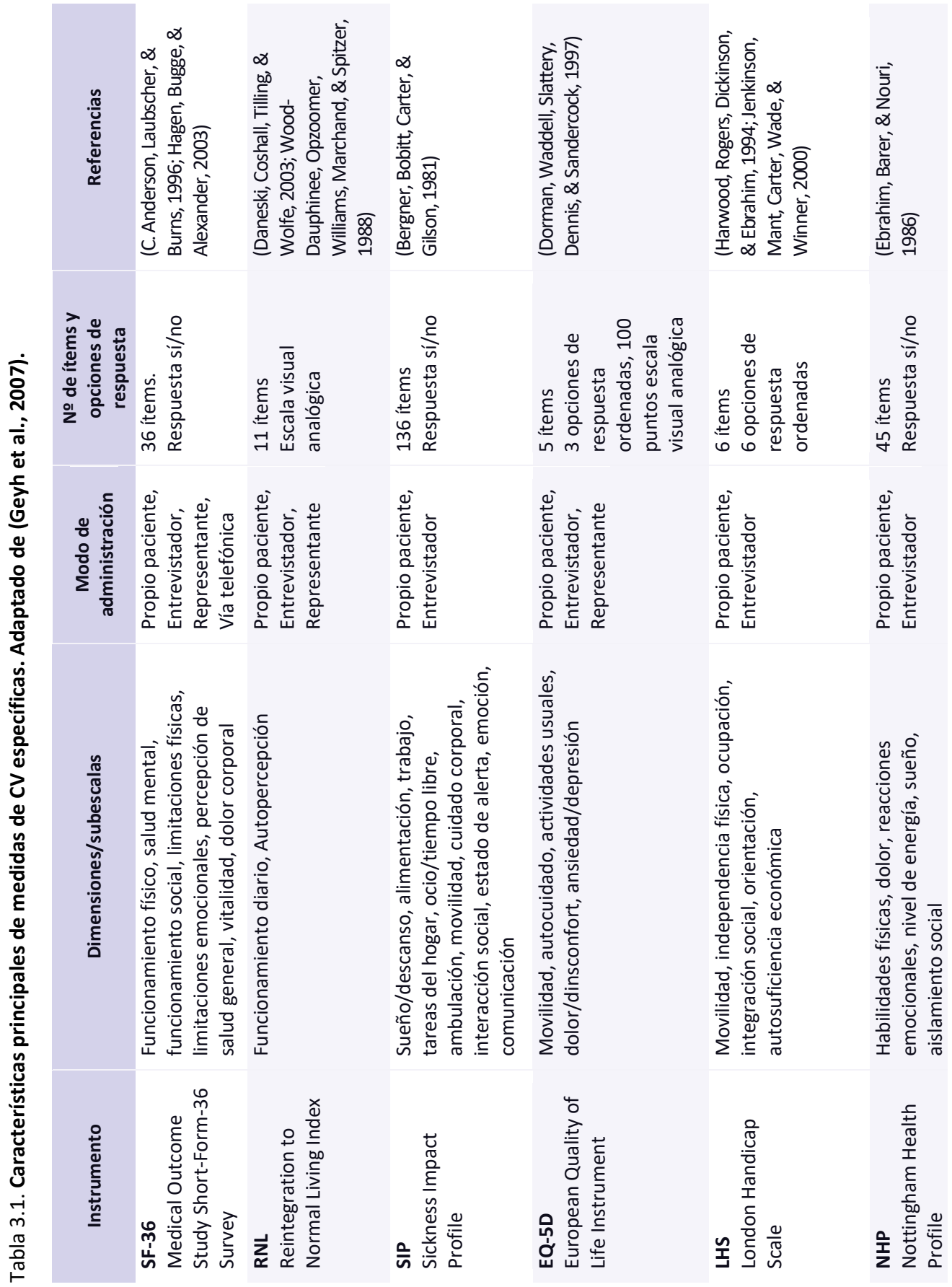


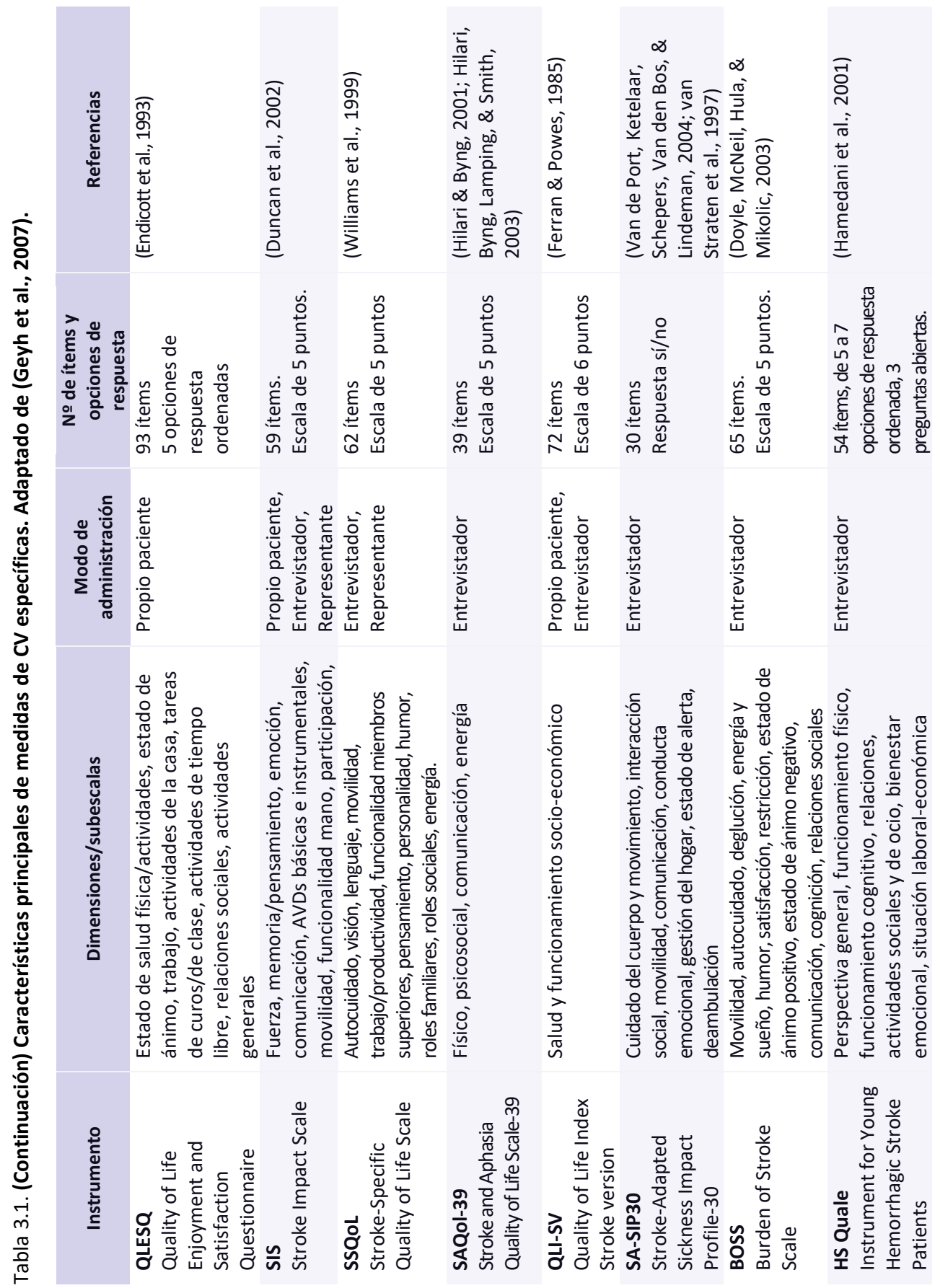


En la revisión realizada por Geyh y colaboradores se observa que pocos instrumentos utilizan al menos un $40 \%$ de las categorías de la $\mathrm{CIF}$; es decir, existen instrumentos que abordan varios e incluso muchos de estos dominios, pero otros autoinformes apenas abordan alguno (Geyh et al., 2007). En consecuencia, algunas de las medidas analizadas en dicha revisión son claramente adecuadas para ciertos propósitos pero no para otros.

Aunque la CIF ha sido criticada por carecer de las dimensiones subjetivas del funcionamiento y la discapacidad (Ueda \& Okawa, 2003; Wade \& De Jong, 2000), los resultados de nuestra revisión muestran que la CIF es capaz de representar los contenidos de las medidas de CV. No obstante, los ítems que contienen conceptos relacionados con los componentes de Actividad y Participación no realizan diferenciación entre ambos ni tienen en cuenta si la actividad o participación se aborda desde la perspectiva de capacidad o desde la perspectiva de desempeño, lo que supone una limitación de las medidas -una limitación en el proceso de relacionar medidas y CIF (Cieza et al., 2005). En la CIF, la capacidad se define como el nivel máximo de funcionamiento ajustado a las influencias del ambiente, y el desempeño o rendimiento como el nivel de funcionamiento teniendo en cuenta las influencias del ambiente así como la participación del individuo en las situaciones de la vida.

La decisión sobre si se debe utilizar una medida de evaluación de CV con un enfoque psicométrico más clásico (por ejemplo, cuestionarios) o un enfoque de utilidad depende de la pregunta de investigación específica que se esté tratando. Si uno está interesado principalmente en generar un cuadro detallado del impacto de la enfermedad y el tratamiento en la CV de los pacientes, entonces un enfoque clásico multidimensional puede ser el más apropiado. $\mathrm{Si}$, por el contrario, la intención es ajustar los datos de supervivencia o generar información de 
coste-utilidad, entonces se preferiría el enfoque de utilidad para la evaluación de la CV. Por supuesto, el uso de un enfoque no excluye el otro. Con recursos suficientes, ambos enfoques podrían incorporarse en un único estudio (de Haan et al., 1993). La elección de una medida de CV versus otra depende, pues, del objetivo que se tenga. En consecuencia, la necesidad de la presente investigación radica en el hecho de valorar la calidad de vida como concepto multidimensional que incluye varios aspectos de la vida del paciente para poder mejorar el resultado del proceso rehabilitador. El Cuestionario de calidad de vida Satisfacción y Placer (QLESQ) recoge las dimensiones de Participación que señala la CIF (es decir, se trata de un modelo hecho acorde al sistema de clasificación (IF). El mayor ámbito de aplicación de este cuestionario se ha realizado en población psiquiátrica (Hope, Page, \& Hooke, 2009; Ritsner, Kurs, Kostizky, Ponizovsky, \& Modai, 2002), por lo que tiene un buen uso de los síntomas y alteraciones neuropsicológicas. Precisamente, este es uno de los principales motivos por los que hemos seleccionado dicho cuestionario en nuestra investigación.

Muchos son los estudios que consideran determinados instrumentos de medida para valorar tanto la CV como la Participación indistintamente (Coons et al., 2000; Geyh et al., 2007; Salter, Jutai, Teasell, et al., 2005a). La definición clásica de calidad de vida (The WHOQOL Group, 1998) -de la que se infiere que existen muchos factores (como, por ejemplo, la salud física, el estado psicológico, el nivel de independencia, las relaciones sociales y su relación con los estímulos del entorno) que pueden comprometerla- se asemeja mucho al concepto de Participación, aunque la CV tiene en cuenta la percepción subjetiva del individuo. Por este motivo, consideramos importante resaltar las diferencias entre ambos conceptos para facilitar una evaluación adecuada de cada uno de ellos. Precisamente, uno de los objetivos de la presente tesis doctoral se centra en dicha cuestión, dado que nos interesa más la 
percepción subjetiva del paciente (atendiendo a la propia definición de CV) que el grado de participación en sí.

En el siguiente apartado se revisan los diferentes factores que se describen en la literatura como posibles predictores o determinantes de calidad de vida, para compararlos posteriormente con aquellas variables explicativas de calidad de vida, según los resultados de nuestro estudio.

\section{DETERMINANTES DE CALIDAD DE VIDA EN DCA}

El bienestar físico, psicológico y social resulta muy afectado a partir del daño cerebral adquirido (DCA). Tal y como se ha revisado en el capítulo anterior, existen numerosas medidas de resultado que se consideran relevantes en la rehabilitación del DCA. Entendemos, por su importancia, la CV como una medida fundamental como demuestra también la literatura científica al respecto. En este apartado, nos centraremos en aquellos factores explicativos que han demostrado tener una mayor relación con la CV en esta población específica de pacientes.

En primer lugar, por lo que se refiere a las características sociodemográficas, los resultados de trabajos previos han demostrado peores niveles de CV en edades más altas (dos Santos Oliveira, Moreno Valdes, D., \& da Silva, 2011; Sturm et al., 2004) cuando la muestra está conformada por mujeres, el estatus socioeconómico es bajo o la persona se encuentra en una institución (Sturm et al., 2004).

Otros autores encuentran que la edad y la duración de la estancia hospitalaria predicen la CV (Weber et al., 2016); (Breed, Flanagan, \& Watson, 2004). Estos estudios sugieren que a mayor edad mejor CV 
percibida por el paciente, puesto que los adultos mayores con TCE consideran que los cambios en su salud están relacionados con el proceso de envejecimiento y no con el DCA que han sufrido. La relación inversa observada entre el tiempo de estancia hospitalaria y la CV se explica por el hecho de que una mayor estancia refleja mayor gravedad del daño afectando directamente a la CV.

La relación entre CV y factores sociodemográficos parece controvertida si atendemos a los resultados de diferentes estudios. Owolabi (Owolabi, 2010) estudió la posible relación entre la calidad de vida y factores sociodemográficos, características clínicas del daño, gravedad y discapacidad y soporte social, observando que ni el género ni el nivel socioeconómico afectaban a la CV. No obstante, otros estudios encuentran que la solvencia económica sí que influye en la CV de los pacientes (Kwok, Pan, Lo, \& Song, 2011). En un estudio reciente (Chou, 2015), además de estos factores, se incluyeron aspectos cognitivos y psicosociales como posibles predictores de CV. Estos autores observaron que los años de educación y de vida laboral, así como el estado civil, se relacionaban con algunos factores de $\mathrm{CV}$.

En cuanto a los aspectos sociosanitarios diversos factores se han visto relacionados con la CV. Así, a nivel clínico, las lesiones más recientes se asocian con peores niveles de CV (dos Santos Oliveira et al., 2011), al igual que sucede con la presencia de demencia o deterioro cognitivo, así como de una discapacidad previa (Sturm et al., 2004). Por otra parte, mientras algunos estudios encuentran que la falta de apoyo social se vincula con un menor estado de salud (Carod-Artal \& Egido, 2009), otros trabajos no encuentran ninguna relación entre la ausencia de apoyo social y la calidad de vida (Teoh, Sims, \& Milgrom, 2009). Finalmente, los datos apuntan a que los factores psicosociales que mejor predicen la CV son el estado de ánimo depresivo, la falta de control percibido y la falta de 
autoestima (Teoh et al., 2009), así como la ausencia de vida social activa (dos Santos Oliveira et al., 2011)

A este respecto, el estudio de Jaracz y colaboradores sugiere que entre los predictores de calidad de vida, el soporte emocional parece ser el que más varianza predice (Jaracz \& Kozubski, 2003), coincidiendo con el estudio de (King, 1996). La sintomatología depresiva, aunque en menor medida, podría ser el segundo factor más importante relacionado con una menor CV, tal y como sugieren numerosas investigaciones (Carod-Artal \& Egido, 2009; dos Santos Oliveira et al., 2011; Kauhanen et al., 2000; King, 1996; Kwok et al., 2006; Teoh et al., 2009). Por último, la discapacidad física sería el tercer factor vinculado con la CV, tal y como muestran otros trabajos (dos Santos Oliveira et al., 2011), aunque presenta una relación mucho más débil comparado con los otros dos factores. En la misma línea, otros trabajos han mostrado que el patrón de marcha y las actividades de la vida diaria -incluyendo el trabajo doméstico-parecen mantener también cierta asociación con la CV (Almkvist Muren, Hütler, \& Hooper, 2008; Langhammer, Stanghelle, \& Lindmark, 2008), al igual que sucede con la disminución en el nivel de funcionalidad general (dos Santos Oliveira et al., 2011).

El tiempo limitado para el ocio y actividades recreativas, la falta de energía y funciones motrices (por ejemplo, la fatiga), así como los patrones deteriorados de la marcha se han considerado factores asociados a una menor $\mathrm{CV}$ principalmente durante el primer año tras el daño cerebral adquirido (Alguren et al., 2012). No obstante, otros estudios (Kwok et al., 2011) no encuentran ninguna relación entre las actividades recreativas y la calidad de vida en las fases tempranas ( 3 meses), pero sí en etapas posteriores (a partir de 12 meses). Contrariamente a lo que observa Scholten y colaboradores (Scholten et 
al., 2015), la capacidad funcional no se relaciona con la CV en el estudio de Weber y colaboradores(Weber et al., 2016).

En diversos estudios se han identificado tanto las funciones mentales como la personalidad como determinantes realmente importantes de CV (Alguren et al., 2012; Haacke et al., 2005; Pan, Song, Lee, \& Kwok, 2008; Visser-Meily, Rhebergen, Rinkel, van Zandvoort, \& Post, 2009).

En el trabajo de Chou anteriormente mencionado (Chou, 2015) en el que, además de los factores sociodemográficos referidos, se incluyeron aspectos cognitivos y psicosociales como posibles predictores de CV, los autores encontraron que la participación social auto-informada, la capacidad de comunicación y la limitación de la actividad resultaron ser fuertes determinantes de $\mathrm{CV}$, así como el nivel de dependencia física para el desempeño de las actividades de la vida diaria. En cuanto a las características clínicas, las que más se relacionaban con CV fueron el número de ictus y si habían recibido tratamiento rehabilitador. Estos autores enfatizan la importante implicación que tiene la participación social, así como la limitación, en el rendimiento de actividades sobre la CV relacionad con el ictus, más que cualquier otra variable relacionada con la función o estructura corporal, coincidiendo con los resultados de (Kwok et al., 2011).

En el estudio de Azouvi y colaboradores en el que se pretendía encontrar predictores e indicadores de discapacidad y de CV establecieron cuatro grupos de variables: (a) datos demográficos, (b) gravedad del daño, (c) alteraciones físicas (dolor, déficit motor y de equilibrio), y (d) estado de ánimo y alteración cognitiva. De estos cuatro grupos, el último fue el que mejor predecía la CV, aunque no especificaron cuánto explicaba cada uno (estado de ánimo vs. alteración cognitiva) dado la fuerte correlación entre ambos factores (Azouvi et al., 2016). 
Además, según estos autores, la discapacidad parece estar más relacionada con la gravedad de la lesión y sus consecuencias a nivel motor y neuroconductual, mientras que la calidad de vida parece estar asociada con el estado de ánimo y la cognición. En esta línea, diversos estudias demuestra también una fuerte relación entre el estado emocional y la CV (dos Santos Oliveira et al., 2011; Koskinen, 1998; Von Steinbuchel et al., 2010)

El mismo objetivo de estudio puede observarse en el trabajo de Chang y colaboradores, quienes observaron que todos los dominios que tiene en cuenta el FIM (Functional Independence Measurement) como medida de independencia funcional explicaban la CV en pacientes con ictus isquémico, mientras que en pacientes con ictus hemorrágico se explicaba principalmente con todas las variables de funcionamiento motor y por la capacidad de comunicación (Chang et al., 2016). Por otra parte, los años de educación, la función motora y la función del lenguaje al alta resultaron buenos predictores de CV.

El área de la CV sobre funcionamiento físico está influida de manera significativa por la edad, las comorbilidades y la funcionalidad de los miembros superiores (Nichols-Larsen, Clark, Zeringue, Greenspan, \& Blanton, 2005).

La presencia de una vida social activa contribuye a una mejor calidad de vida(dos Santos Oliveira et al., 2011; Jönsson, Lindgren, Hallström, Norrving, \& Lindgren, 2005), resultando también un factor explicativo de la CV tanto en fases tempranas como en etapas más avanzadas de la recuperación de pacientes con DCA funcionalmente independientes y buen estado de ánimo (Kwok et al., 2011).

La revisión de la literatura sugiere que debemos considerar múltiples determinantes de CV: el deterioro físico, la discapacidad, la 
depresión, la ansiedad, la institucionalización, las alteraciones cognitivas, la falta de apoyo social, las relaciones sociales y participación, entre otros. Respecto a este último factor sigue resultando todavía muy escaso el número de estudios metodológicamente bien diseñados que consideran este constructo tal y como propone la CIF. Por este motivo lo hemos incluido en la presente tesis doctoral, cuya justificación e hipótesis se describen en el siguiente capítulo. 



\section{PARTE EMPÍRICA}

Predictores de Calidad de Vida en pacientes con Daño Cerebral Adquirido:

Déficit, Actividad y Participación 



\section{Objetivos e hipótesis}

Predictores de Calidad de Vida en pacientes con Daño Cerebral Adquirido: Déficit,

Actividad y Participación 



\section{OBJETIVOS}

El objetivo principal del presente trabajo experimental ha sido analizar los diferentes factores vinculados a las consecuencias asociadas al DCA -como son las alteraciones cognitivas y conductuales, la calidad de vida y la participación- en una muestra de pacientes con Daño Cerebral Adquirido (DCA) en el momento en que se les daba el alta de la intervención neuro-rehabilitadora. Además, se pretendía explorar las posibles relaciones que guardan entre sí estas variables y el poder predictivo de las mismas sobre la Calidad de Vida (CV).

Los objetivos específicos fueron:

I. Describir el Sistema de Clasificación CIF y conocer el estado actual del concepto de CV y su relación con las variables clínicas de la lesión, con la alteración cognitiva y conductual, así como con el grado de actividad y participación. Igualmente, se pretendía explorar el poder predictivo de estas variables en una muestra de pacientes con DCA.

II. Revisar las escalas existentes en la literatura para la evaluación del constructo de participación, tal y como se define desde el modelo CIF de la OMS. De entre las escalas validadas en población española -y utilizadas previamente a nivel experimental en otros estudiosse seleccionarán para nuestra investigación aquellas escalas que incluyan al menos los seis siguientes dominios de la CIF:
a. Habilidades comunicativas y/o cognitivas
b. Capacidad para moverse por su entorno
C. Cuidado personal
d. Relaciones sociales y personales 


\section{e. Actividades de la vida diaria \\ f. Participación social}

III. Conocer a través de un proceso sistemático de recogida de información las variables clínicas de la lesión, las posibles alteraciones cognitivas y conductuales consecuencia de la misma, así como el grado de participación y calidad de vida de un grupo de personas con DCA que han concluido su proceso neurorehabilitador.

IV. Realizar un análisis descriptivo de los datos sociodemográficos de la muestra, del funcionamiento cognitivo y conductual así como del nivel de participación y de la percepción subjetiva de calidad de vida del paciente en el momento de la valoración.

V. Analizar las correlaciones entre las variables neuropsicológicas (cognición y conducta), participación y calidad de vida.

VI. Explorar el poder predictivo de las variables neuropsicológicas (cognición y conducta), y participación sobre la calidad de vida. 


\section{HIPÓTESIS}

H1: Se espera observar una asociación significativa entre algunas variables clínicas de la lesión (tipo de daño, y presencia de trastorno motor) y sociodemográficas (edad y reserva cognitiva) y la calidad de vida. De manera que ante la presencia de ACV, trastorno motor, menor edad y menor reserva cognitiva, menor será la calidad de vida.

H2: Se espera observar una asociación significativa entre los déficits neuropsicológicos (cognición y conducta) y la calidad de vida en una muestra de pacientes con DCA, de manera que a mayor alteración cognitiva-conductual, menor calidad de vida.

H3: Se espera encontrar una asociación significativa entre el grado de participación y la calidad de vida, de esta manera, los pacientes que presenten menor nivel de participación mostrarán menor calidad de vida.

H4: Entre todos los dominios de la CIF (déficit, actividad y participación), la participación será la que mayor valor predictivo tendrá sobre la calidad de vida, de manera que a menor participación, menor calidad de vida.

H5: Entre todos los dominios de participación, las relaciones interpersonales serán las que más predicen la de calidad de vida, de manera que a menor participación social peor calidad de vida. 



\section{Metodología}

Predictores de Calidad de Vida en pacientes con Daño Cerebral Adquirido: Déficit,

Actividad y Participación

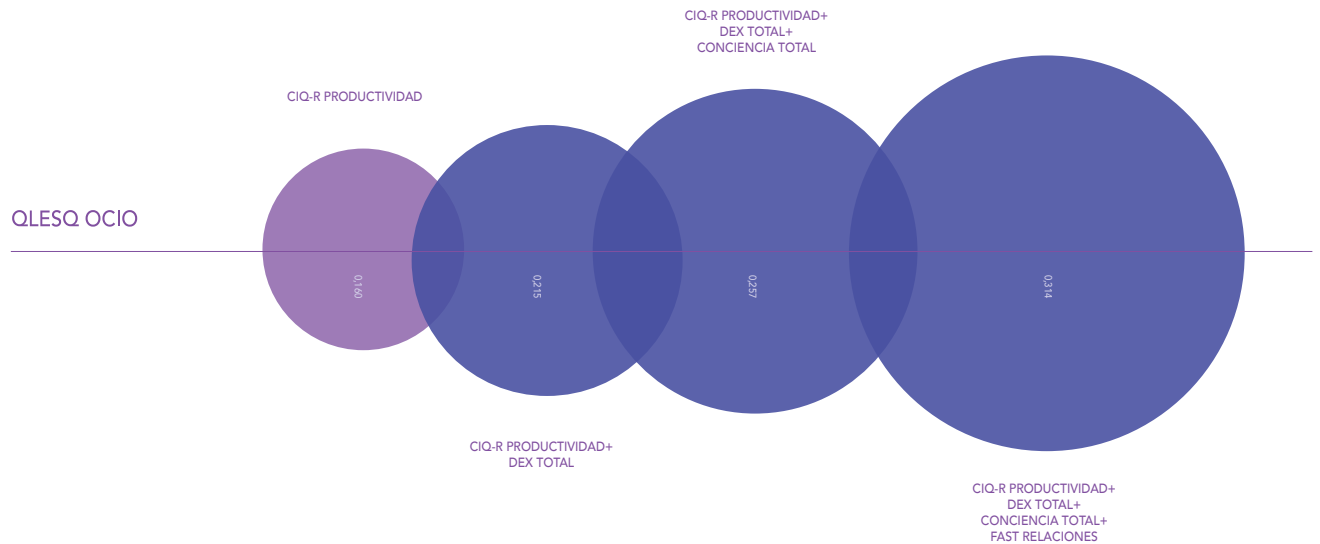





\section{PARTICIPANTES}

La muestra del presente estudio se obtuvo en dos centros geográficos coordinados entre sí: Unidad de Daño Cerebral, Hospital La Magdalena, (Castellón de la Plana) y Reintegra: Centro de Rehabilitación Neurológica (Oviedo). Dicha muestras experimental estaba compuesta por pacientes mayores de dieciséis años con daño cerebral adquirido (DCA) de etiología vascular o traumática. El reclutamiento de los sujetos y recogida de datos se llevó a cabo a través de dos vías. Por una parte, se ofreció participar en el estudio a aquellos pacientes que habían finalizado su tratamiento rehabilitador e iban siendo dados de alta durante el proceso de recogida de datos. En caso de aceptación, se les aplicaba el protocolo de recogida de datos desarrollado para el presente estudio. Por otra parte, se contactó telefónicamente con aquellos pacientes que ya no se encontraban en las unidades de daño cerebral por haber sido dados de alta con anterioridad, para ofrecerles la participación voluntaria en el estudio. A las personas que aceptaron participar se les citaba en la Unidad correspondiente a los pocos días para realizar la valoración y aplicarles el protocolo establecido. Todos los pacientes incluidos en el estudio habían finalizado, por tanto, su tratamiento rehabilitador de las dificultades producidas por la lesión cerebral y cumplían los criterios de inclusión y/o exclusión que se detallan a continuación.

Criterios de Inclusión:

- Haber sufrido un daño cerebral adquirido de gravedad suficiente para provocar su ingreso hospitalario en los dos años anteriores a la realización del presente estudio. 
- Haber sido atendido en una de las unidades de captación dedicadas específicamente a la rehabilitación neuropsicológica y física de las secuelas de daño cerebral adquirido.

- Tener una edad superior a 16 años y menor de 75 años.

- Aceptar participar voluntariamente en el estudio tras ofrecer información detallada del mismo y de sus objetivos (el paciente, o el familiar de referencia si el paciente no estaba en condiciones de dar consentimiento informado).

- Contar con un familiar u otra persona que ejerciera el rol de cuidador, que estuviera disponible y dispuesto a colaborar con el proceso de recogida de información sobre la autonomía del paciente.

Criterios de Exclusión:

- Tener un diagnóstico previo de otra patología neurológica o de enfermedad mental, de carácter grave.

- Poseer un grado de discapacidad moderada en adelante según valoración del WHO-DAS, por alguna circunstancia previa diferente al ACV o TCE.

\section{VARIABLES E INSTRUMENTOS DE MEDIDA}

En el presente trabajo se analizaron diferentes variables de carácter sociodemográfico, así como variables relativas a la lesión cerebral y también neuropsicológicas, que se obtuvieron tras aplicar el 
protocolo de evaluación diseñado para el estudio. A continuación, se presenta una relación de las variables evaluadas y cómo se recogieron.

\subsection{VARIABLES SOCIODEMOGRÁFICAS}

En nuestro estudio se tuvieron en cuenta las siguientes variables sociodemográficas: edad, género (hombres/ mujeres), estado civil (casado/ divorciado/ separado/ soltero/viudo/ unión/ otros), años de educación, nivel de estudios (analfabeto/ lee y escribe/ primarios/ bachiller-FP/ superiores), ocupación previa (sin actividad remunerada/ empleado sin cualificar/ empleado cualificado/ profesional-directivo/ autónomo-empresa familiar/ empresario con empleados), situación laboral actual (pensión de invalidez/ paro sin subsidio/ paro con subsidio/ pensión jubilación/ dedicación al hogar/ estudiante/ incapacidad temporal/ en activo), idioma materno (castellano, valenciano, rumano, árabe, francés, otros), personas de convivencia (pareja/ pareja e hijos/ solo/ padres/ hijos/ hermanos/ institución/ otros) y posibles adaptaciones realizadas en la vivienda como consecuencia del DCA (requiere grandes adaptaciones/ pequeños problemas/adaptada).

Las variables con distintas opciones de respuesta cerrada (estado civil, nivel de estudios, ocupación previa, situación laboral, personas de convivencia) se recogieron de forma categórica, mientras aquellas variables como la edad, o los años de escolarización como variable cuantitativa continua. 


\subsection{VARIABLES DE LESIÓN CEREBRAL}

Este conjunto de variables fueron proporcionadas por los médicos especialistas que colaboraron en el estudio en el momento de la valoración neuropsicológica, o bien fueron obtenidas a partir de los informes hospitalarios (proporcionados por el servicio de neurología). Estas variables hacen referencia a la propia lesión cerebral y, por otra parte, a las secuelas del daño (teniendo en cuenta, además, el nivel de funcionalidad previo a la lesión del paciente).

Entre las variables relacionadas con la lesión cerebral se encuentran la fecha de la lesión, tanto el diagnóstico principal como el secundario, así como la información específica vinculada con la etiología del daño (vascular o traumático). En el caso de los pacientes con DCA vascular se tuvo en cuenta la naturaleza del daño (isquémico/hemorrágico) y el tipo (embólico/ malformación artereovenosa o MAV/ trombótico/ hemodinámico/ hemorrágico/ lacunar/ isquémico con transformación hemorrágica/ indeterminado). Para los pacientes con DCA traumático se obtuvo información sobre la causa (accidente laboral/ accidente deportivo/ accidente de tráfico/ agresión/ otros), y sobre el tipo de lesión (difusa/ multifocal/ focal evacuada/ focal no evacuada).

\subsection{VARIABLES COGNITIVAS}

En el presente estudio se han valorado los siguientes dominios cognitivos: atención y procesamiento de la información, aprendizaje y memoria, memoria +de trabajo y funcionamiento ejecutivo. Las pruebas que componen el protocolo de valoración se describen en los siguientes 
apartados -agrupadas según la función que evalúan- y se resumen en la Tabla 5.1.

Tabla 5.1. Pruebas neuropsicológicas según el dominio evaluado.

Función evaluada

Atención y procesamiento de la información

\section{Prueba neuropsicológica}

Dígitos, orden directo (WAIS)

Localización espacial, orden directo (WMS)

Test de cancelación de campanas

Test de trazados de colores, parte I

Continuous Performance Test-II (tiempo reacción)

Test Auditivo Verbal España Complutense

Dígitos, orden inverso (WAIS)

Localización espacial, orden inverso (WMS)

Test de trazados de colores, parte II

Test de clasificación de cartas de Wisconsin

Test de Asociación controlada de palabras Matrices (WAIS)

Test de Brixton

Test de búsqueda de la llave (BADS)

Continuous Performance Test-II

(comisiones)

\subsubsection{ATENCIÓN Y PROCESAMIENTO DE LA INFORMACIÓN}

\subsubsection{DÍGITOS EN ORDEN DIRECTO (WAIS)}

La prueba de dígitos es uno de los subtests incluidos en la escala de inteligencia Wechsler para Adultos-III (Wechsler, 1999) que conforma, junto con otros tests (i.e., Letras y números y Aritmética), el índice de 
memoria de trabajo de la escala verbal. Consta de dos partes independientes: dígitos en orden directo y dígitos en orden inverso. En ambos casos, el sujeto debe repetir una secuencia de números en el mismo orden en que el examinador se los dice, o bien en orden inverso a cómo se le ha presentado. El número de elementos que se van ofreciendo van aumentando, empezando por dos dígitos hasta un total de nueve, de manera que evalúa la concentración y capacidad atencional de carácter auditivo del sujeto. La prueba termina cuando se el sujeto comete dos errores del mismo número de elemento.

Para puntuar esta prueba, en el manual de aplicación y corrección del WAIS-III encontramos unas tablas con las puntuaciones directas en cada prueba y sus correspondientes puntuaciones escalares (Media = 10 y DT = 3). Las tablas se presentan por grupos de edad (16-19 años, 20-24 años, 25-34 años, 35-54 años, 55-69 años, 70 y más años). En este mismo manual encontramos una tabla con los porcentajes acumulados de la serie recordada más alta en dígitos para la muestra total y por subgrupos de edad, especificando para cada uno de ellos la media, desviación típica y mediana. De este modo podemos conseguir puntuaciones transformadas separadas para cada una de las dos subpruebas (dígitos en orden directo y dígitos en orden inverso), independientemente del valor asignado al subtest Dígitos que incluyen las dos pruebas.

\subsubsection{LOCALIZACIÓN ESPACIAL, ORDEN DIRECTO (WMS)}

La prueba de localización espacial es uno de los subtests incluidos en la escala de memoria Wechsler para adultos-III (Wechsler, 1997), traducida y adaptada por TEA Ediciones en 2007, que conforma junto con el subtest Letras y números el índice de memoria de trabajo. Esta prueba es una versión visual del test de Dígitos de la WAIS explicado en el apartado anterior. 
En esta prueba, el examinador toca por orden ciertos cubos que se presentan sobre un tablero y el sujeto debe repetir los mismos movimientos. El número de cubos que tiene que tocar va aumentando, empezando por dos hasta un total de nueve. La prueba termina cuando el sujeto comete dos errores del mismo número de elementos. Las puntuaciones directas que se obtienen en los tests de la WMS-III se transforman en puntuaciones escalares (Media = 10 y DT $=3$ ) ajustadas al grupo de edad del sujeto a través de las tablas proporcionadas en el manual de corrección de la escala.

\subsubsection{TEST DE CANCELACIÓN DE CAMPANAS}

En el test de cancelación de campanas (Gauthier, Dehaut, \& Joanette, 1989) se presenta al paciente una lámina con 35 estímulos "objetivo" (campanas) y 280 estímulos distractores (llaves, manzanas, caballos, etc). La prueba consiste en señalar todas las campanas que aparecen en la lámina valorando de esta manera la capacidad atencional del sujeto y la estrategia de exploración que emplea (a través de un rastreo ordenado o de manera aleatoria). Esta prueba también permite observar la presencia de heminegligencia en aquellos casos en los que el sujeto únicamente cancele las campanas de la mitad derecha o izquierda de la lámina.

\subsubsection{TEST DE TRAZADOS DE COLORES PARTE I}

Esta prueba diseñada por D'Elia y cols. (D'Elia, Satz, Uchiyama, \& White, 1996) permite evaluar velocidad de búsqueda visual, atención, secuenciación visuoespacial, flexibilidad mental y función motora. La prueba consta de dos partes, la segunda de mayor complejidad. Se trata de una adaptación del Trail Making Test-I (TMT) (Reitan, 1958) que en lugar de ser todos los números del mismo color, en el Color Trail-I Test están distribuidos por colores diferentes (rosa y amarillo). Los números 
pares están el color amarillo y los impares en color rosa, de tal forma que realizar la tarea de modo correcta implicaría necesariamente alternar un círculo amarillo y otro rojo. Consiste en pedir al sujeto que conecte los círculos con números en el orden correcto de manera ascendente lo más rápido que pueda. Previamente a la administración de la prueba se hace un examen preliminar donde se le pide al sujeto que cuente en voz alta del número 1 al 25 y que los escriba. En caso de ser incapaz de completar esta prueba no se podrá administrar el test.

Para la corrección de la prueba el manual profesional ofrece datos normativos corregidos según criterios demográficos (edad y nivel de educación), de manera que la puntuación directa obtenida en la prueba con el tiempo en segundos como unidad de medida, queda transformada según la edad y años de educación del sujeto evaluado en puntuaciones $\mathrm{T}($ Media $=10, \mathrm{DT}=50)$.

\subsubsection{CONTINUOUS PERFORMANCE TEST (CPT-II)}

El Continuous Performance Test (CPT-II) (Conners \& Staff, 2000) consiste en una prueba informatizada que permite valorar la capacidad atencional del sujeto, principalmente la atención sostenida y selectiva. El programa va presentando letras blancas en el centro de la pantalla del ordenador (sobre un fondo negro), una detrás de otra, pero de manera aleatoria. La tarea consiste en apretar la barra espaciadora del teclado tan pronto como vayan apareciendo los estímulos "señal" (letras) excepto cuando se presente la letra "ruido" (" $X$ "), ante las que se debe inhibir la respuesta. Esta prueba evalúa las dimensiones de inatención, impulsividad y vigilancia a partir de diferentes índices: omisiones, comisiones, tiempo de reacción, variabilidad y detectabilidad (para la dimensión de inatención); omisiones, tiempo de reacción y perseveraciones (para la impulsividad); tiempo de reacción y cambio de 
consistencia en la respuesta (para la dimensión de vigilancia). En nuestro estudio se han utilizado los siguientes índices como medidas de atención:

- Omisiones: falta de respuesta ante los estímulos "objetivo" ("señal").

- Hit Reaction Time-Overall (Hit RT): velocidad media de respuestas correctas durante toda la prueba.

Es el mismo programa el que, una vez ha finalizada la prueba, ofrece las puntuaciones directas y las puntuaciones transformadas para cada variable, teniendo en cuenta la edad del paciente y el nivel educativo que previamente se ha introducido en el programa informático.

\subsubsection{APRENDIZAJE Y MEMORIA}

\subsubsection{TEST AUDITIVO VERBAL ESPAÑA COMPLUTENSE (TAVEC)}

El Test de Aprendizaje Verbal España-Complutense (TAVEC) (Benedet \& Alexandre, 1998)propone una evaluación detallada de las habilidades de aprendizaje y memoria. Se trata de la adaptación a nuestro país del California Verbal Learning Test (CVLT)(Delis, Kramer, Kaplan, \& Thomkins, 1987). La prueba consta de tres listados de palabras que se presentan al sujeto como "listas de la compra". La primera de ellas (lista A) se conoce como "lista de aprendizaje", la segunda (lista B) se denomina "lista de interferencia" y la última (lista C) es la "lista de reconocimiento". Las listas A y B constan de 16 palabras agrupables en cuatro categorías (especias, frutas, herramientas y prendas de vestir para la lista $A$; especias, frutas, utensilios de cocina y pescados para la lista B). La lista $C$ consta de 44 palabras: a) las 16 de la lista diana; b) 2 palabras de cada una de las categorías semánticas que comparten la lista diana y la lista de interferencia; c) 2 palabras de cada una de las categorías semánticas específicas de la lista de interferencia; d) 1 palabra "prototípica" (de 
elevada frecuencia de uso) de cada una de las cuatro categorías semánticas que integran la lista diana; e) 8 palabras (dos por categoría semántica) relacionadas sólo fonéticamente con otras tantas palabras de la lista diana; y f) 8 palabras no relacionadas con ninguna lista.

Al inicio de la prueba se le pide al sujeto que escuche atentamente la lista de palabras que se le va a leer a continuación y que posteriormente repita todas las que recuerda. Este ejercicio se repetirá durante cinco ensayos se irá recogiendo en cada uno de ellos las palabras y orden de las mismas en que va diciendo el examinado, de manera que podremos observar la curva de aprendizaje, el efecto de primacía y el efecto de recencia. Tras ello, se leerá al sujeto la lista de interferencia y ser registrará de la misma manera que anteriormente las palabras que recuerda el sujeto, esta vez durante únicamente un ensayo. Una vez no recuerda ninguna palabra más de esta lista de interferencia se le pide al sujeto que diga las palabras que recuerda de la lista anterior (lista A), y dicho número nos indicará el recuerdo libre a corto plazo (RL-CP). Después del recuerdo libre se le ofrecerá al examinado las categorías semánticas para que vaya diciendo de cada una de ellas las palabras que recuerda, siendo éste número el índice correspondiente al recuerdo con claves a corto plazo ( $\mathrm{RCl}-\mathrm{CP})$. Llegado este momento se realizan durante 20 minutos otras pruebas de evaluación de componente no verbal para evitar interferencias y tras ello se vuelve a preguntar primero por las palabras que recuerda libremente de la lista A (recuerdo libre a largo plazo RL-LP) y las que recuerda proporcionando las claves semánticas (RCl-LP). Finalmente se lee la lista de reconocimiento y se registran las palabras que el examinado considera sí se han presentado anteriormente y las que no.

Para la puntuación de esta prueba el manual ofrece tablas de conversión baremadas por grupos de edad (16-24; 25-34; 35-44; 45-54; 
55-64; 65-74; mayores de 74) incluyendo la media y desviación típica para cada una de las variables, pudiendo así calcular las puntuaciones típicas para cada una de las medidas.

\subsubsection{MEMORIA DE TRABAJO}

\subsubsection{DÍGITOS, ORDEN INVERSO (WAIS)}

Como se ha introducido anteriormente al describir la prueba de Dígitos en orden directo, inmediatamente después se administran los Dígitos en orden inverso. En esta prueba el sujeto reproduce en orden inverso aquellos dígitos que el examinador le ha presentado oralmente. De esta manera, la prueba mide la capacidad del sujeto de mantener y manipular la información mientras se retiene hasta la evocación posterior. Esta habilidad se conoce como "memoria de trabajo" o “memoria operativa" (Baddeley \& Hitch, 1974).

La puntuación directa de esta prueba es transformada en puntuación escalar a través de las tablas de conversión que ofrece el manual de aplicación y corrección de la Escala WAIS-III (ver apartado 2.1.1.1).

\subsubsection{LOCALIZACIÓN ESPACIAL, ORDEN INVERSO (WMS)}

Tal y como se ha explicado en el apartado de medidas de atención, la prueba de localización espacial se trata de la versión visual del test de Dígitos de la WAIS explicado anteriormente. En esta prueba, el examinador toca por orden ciertos cubos que se presentan sobre un tablero y el sujeto debe repetir los mismos movimientos en el orden inverso a cómo se le han presentado. El número de cubos que tiene que tocar va aumentando, empezando por dos hasta un total de nueve. La prueba termina cuando el sujeto comete dos errores del mismo número de elementos. 
Las puntuaciones directas que se obtienen en los tests de la WMSIII se transforman en puntuaciones escalares (Media $=10$ y DT $=3$ ) ajustadas al grupo de edad del sujeto a través de las tablas proporcionadas en el manual de corrección de la escala.

\subsubsection{COLOR TRAILS TEST-II}

El Color Trails Test-II (D'Elia et al., 1996), al igual que el I, también es una adaptación del Trail Making Test (Partington \& Leiter, 1949) aunque en este caso en lugar de unir números y letras (1A, 2B, 3C, 4D...) se han de unir los números alternando los colores (1-rosa-, 2-amarillo, 3rosa, 4-amarillo, 5-rosa...). Todos los números aparecen por duplicado en dos círculos de diferente color, rosa y amarillo (para la primera parte, ver apartado 3.1.1.4). El sujeto debe unir los números de manera correcta en orden ascendente alternando los colores, de manera que el número 1 en rosa lo unirá con el 2 en amarillo, éste con el 3 en rosa, que a su vez lo unirá con el 4 amarillo y así sucesivamente hasta el número 25 donde finaliza la prueba.

Para la corrección de la prueba el manual profesional ofrece datos normativos corregidos según criterios demográficos (edad y nivel de educación), de manera que la puntuación directa obtenida en la prueba con el tiempo en segundos como unidad de medida, queda transformada según la edad y años de educación del sujeto evaluado en puntuaciones T cuya media es 10 y la desviación típica 50.

\subsubsection{FUNCIONAMIENTO EJECUTIVO}

\subsubsection{WISCONSIN CARD SORTING TEST (WCST)}

En el presente trabajo se ha utilizado la adaptación española baremada y validada en nuestro país del test de clasificación de tarjetas de Wisconsin (WCST) de Heaton y cols. (Heaton, Chelune, Talley, Hay, \& 
Curtiss, 2001). El WCST es una prueba desarrollada como medida de función ejecutiva que requiere estrategias de planificación, indagaciones organizadas y utilización del "feedback" ambiental para cambiar esquemas. Es una prueba muy sensible a alteraciones de procesos dependientes de las funciones ejecutivas, como flexibilidad cognitiva y auto-regulación de la cognición y conducta.

La prueba está formada por un conjunto de 4 tarjetas-estímulo y 128 tarjetas-respuesta que contienen figuras de varias formas (estrella, triángulos, círculos y cruces), colores de las figuras (rojo, amarillo, verde y azul) y número de figuras (uno, dos, tres y cuatro). El modo de realizar la prueba consiste en colocar delante del paciente las cuatro tarjetasestímulo e ir presentándole una detrás de otra las tarjetas-respuesta para que indique con qué tarjeta-estímulo debe emparejarse. Cada vez que el examinado coloque la tarjeta se le indicará si lo ha hecho de forma correcta o errónea, y se omite cuál es la categoría con la que debería asociarla. Cuando el sujeto ha logrado emparejar 10 tarjetas consecutivas de acuerdo a la categoría de clasificación establecida (color-C), se cambia dicha categoría de clasificación (forma-F) sin previo aviso, de manera que el sujeto ha de utilizar este "feedback" para establecer nuevo criterio de clasificación. De la misma manera que con la categoría anterior, una vez ha logrado clasificar 10 tarjetas consecutivas según esta segunda categoría, el examinador vuelve nuevamente a cambiar el criterio de clasificación (número-N). La prueba se desarrolla de esta manera hasta que el sujeto ha logrado completar de manera satisfactoria dos bloques de los tres criterios de clasificación (CFNCFN), o que el sujeto agote las 128 tarjetas-respuesta.

Dadas estas características de la prueba, nos permite evaluar la flexibilidad mental y la auto-regulación conductual. 
Para la corrección de la prueba el manual de aplicación y corrección ofrece datos normativos corregidos según criterios demográficos (edad y nivel de educación), aunque las tablas de conversión para sujetos menores de 19 años no distinguen nivel educativo. Las tablas correspondientes a las edades comprendidas entre 20 y 89 años están organizadas por grupos de 10 años de edad (por ejemplo, "40 años, 0 meses y 0 días hasta 49 años, 11 meses y 30 días") y cinco grupos de nivel educativo (escolarización hasta los 8 años, 9-11 años, 12 años, 13-15 años, 16-17 años, hasta 18 años).

\subsubsection{TEST DE ASOCIACIÓN CONTROLADA DE PALABRAS (FAS)}

El test de asociación controlada de palabras (Spreen \& Strauss, 1998)fue denominado al principio Verbal Associative Fluency Test y posteriormente Controlled Word Association Test. Consiste en evocar palabras a partir de la letra inicial durante tres ensayos de un minuto cada uno. El sujeto debe decir el máximo número de palabras posible en ese tiempo utilizando las letras F-A-S en el primero, segundo y tercer ensayo respectivamente excluyendo nombres propios, números y palabras derivadas de otras ya dichas anteriormente. Para transformar las puntuaciones directas en puntuaciones tipificadas se emplearon los baremos derivados de un estudio en marcha con más de 500 sujetos sanos distribuidos por grupos de edad (16-59 años, 60-79 años y 80-95 años) y años de educación (0-8, 9-12, 12-21) con un valor medio y una desviación estándar para cada uno de ellos.

\subsubsection{TEST DE MATRICES (WAIS)}

La prueba de matrices es uno de los subtests incluidos en la escala de inteligencia Wechsler para adultos-III (Wechsler, 1999) que conforma junto con otros (Figuras incompletas y Cubos) el índice de organización perceptual de la escala manipulativa. El test consta de cuatro tipos 
distintos de razonamiento no verbal: completamiento, clasificación, analogías y razonamiento serial, tal y como explica el manual. El sujeto debe observar una matriz incompleta e identificar cuál de las opciones mostradas debajo de la misma considera la adecuada para completar la matriz de manera que tenga sentido. La prueba comienza con unos ejemplos que permiten al sujeto comprender la instrucción, de manera que si falla en alguno de ellos se le muestra la solución explicándole el razonamiento. Cada elemento de evaluación contestado de manera correcta puntúa un punto. La prueba finaliza después de cuatro fallos consecutivos o cuatro puntos en cinco elementos consecutivos.

Tal y como se ha comentado anteriormente en el apartado 2.1.1.1, el manual de corrección nos ofrece una tablas para convertir la puntuación directa obtenida a una puntuación escalar según el grupo de referencia al que pertenece el sujeto que estamos evaluando.

\subsubsection{TEST DE ANTICIPACIÓN ESPACIAL DE BRIXTON}

Los tests de Hayling y Brixton (P. Burgess \& Shallice, 1997) han sido diseñados para valorar disfunciones ejecutivas. En concreto, el test de anticipación de Brixton consiste en detectar una regla y seguir esa regla durante una tarea. El test de anticipación espacial de Brixton consiste en un cuaderno con 56 páginas, todas ellas con el mismo diseño: un recuadro con 10 posiciones y una de ellas pintada de azul. Para la realización de la prueba se le explica al sujeto que la coloreada se va moviendo de acuerdo a un patrón determinado que va variando durante la prueba, sin ningún aviso al sujeto, y que los números están únicamente para señalar la posición, sin que haya ninguna regla matemática ni nada complicado. La tarea consiste en a medida que se van pasando las páginas, averiguar la regla tan bien como se pueda, y señalar dónde cree que estará la figura azul en la siguiente página. Por tanto, para dar la respuesta apropiada, el sujeto ha de ser capaz de reconocer el patrón de movimiento del círculo 
azul. De esta manera, el test de anticipación de Brixton requiere la puesta en marcha de procesos tales como memoria de trabajo, flexibilidad cognitiva, auto-supervisión y auto-regulación conductual.

La puntuación de esta prueba se obtiene a partir del número de errores cometidos por el sujeto. El manual ofrece una tabla de conversión de la puntuación bruta (número de errores) a una puntuación escalar del 1 al 10 donde cada número equivale a una percentil determinado.

\subsubsection{TEST DE BÚSQUEDA DE LA LLAVE (BADS)}

El test de búsqueda de la llave es una prueba que se incluye en la batería BADS (Behavioural Assessment of the Dysexecutive Syndrome) (Wilson, Emsile, Evans, Alderman, \& Burgess, 1996)en la que se le pide al sujeto que imagine que el cuadrado que se le presenta en un papel es un campo el que ha estado anteriormente y que en algún lugar de éste se le ha perdido las Ilaves. Una vez nos aseguramos que el sujeto ha entendido el mensaje que le señala un punto abajo del cuadrado al mismo tiempo que se le dice que partiendo de ese punto su tarea consiste en dibujar una línea con el lápiz que represente el camino que realizaría para asegurarse de que encontrará la llave sin importar dónde se encuentra.

\subsubsection{CONTINUOUS PERFORMANCE TEST (CPT-II)}

El Continuous Performance Test (Conners \& Staff, 2000) ya explicado anteriormente como medida de atención permite al mismo tiempo valorar algunos aspectos de las funciones ejecutivas como es la impulsividad medida a través del índice de "Comisiones" que se considera como la respuesta incorrecta a los estímulos no "objetivo" (ruido). 


\subsection{VARIABLES CONDUCTUALES Y EMOCIONALES}

Las alteraciones conductuales y emocionales son otras de los síntomas habituales que se pueden observar en los pacientes con daño cerebral. La frecuencia y gravedad de estas alteraciones se han valorado en el presente estudio a través del cuestionario que se explica continuación.

\subsubsection{DYSEXECUTIVE QUESTIONNAIRE -DEX- (BADS)}

EI DEX es un cuestionario que se incluye en la batería BADS (Wilson et al., 1996) que propone a través de 20 ítems con cuatro alternativas de respuesta $(0=$ nunca, 1 = ocasionalmente, 2 = algunas veces, $3=$ a menudo y 4 = muy a menudo) una estimación de la función ejecutiva aplicada a aspectos de la vida cotidiana. Algunas alteraciones conductuales y emocionales que la persona puede experimentar un su vida diaria se organizan en cuatro grandes áreas: cambios emocionales o de personalidad, cambios motivacionales, cambios de comportamiento y cognitivos. El cuestionario tiene dos versiones con los mismos ítems, una versión autoinformada que la cumplimenta el propio paciente y otra versión para un evaluador independiente que ha de cumplimentar alguna persona del entorno próximo y significativo, preferiblemente con un contacto diario. Las puntuaciones del DEX heteroaplicado se consideran más válidas dado la baja conciencia de los déficits que presentan los pacientes con Síndrome Disejecutivo (P. W. Burgess, Alderman, Evans, Emslie, \& Wilson, 1998).

Varios son los estudios que realizan análisis factoriales de estos cuestionarios. Autores como Burgess y colaboradores (P. W. Burgess et al., 1998) revelan la existencia de cinco factores: inhibición, intencionalidad, memoria ejecutiva y dos factores relacionados con la 
emocionabilidad y los cambios de personalidad denominados afecto positivo y negativo. El estudio de Mooney colaboradores (Mooney, Walmsley, \& McFarland, 2006) encuentra cuatro factores: inhibición intencionalidad, regulación social y resolución de problemas abstractos, mientras que Chaytor y Schmitter-Edgecombe (Chaytor \& SchmitterEdgecombe, 2007) proponen tres factores nombrados como inhibición conductual, intencionalidad/conducta dirigida a un fin, cognición/memoria ejecutiva. Pedrero y colaboradores (Pedrero-Pérez et al., 2011) muestran la existencia de dos factores con adecuados índices de consistencia y validez interna, por una parte ítems que exploran dificultades en el inicio, mantenimiento y organización de la conducta (desorganización/ apatía) y por otra ítems relacionados con la dirección o interrupción de la conducta en una situación determinada (desinhibición/ impulsividad). En el estudio de Luna-Lario y colaboradores (Luna-Lario, Seijas-Gómez, Tirapu-Ustárroz, Hernáez-Goñi, \& Mata-Pastor, 2012) se realizan diferentes análisis factoriales de dos, tres, cuatro y cinco factores, considerando éste último como el más apropiado. Nombran los factores como solución de problemas, control cognitivo, inhibición, conciencia social e impulsividad. Los análisis realizados por otros autores (Gerstorf, Siedlecki, Tucker-Drob, \& Salthouse, 2008; McGuire et al., 2014) ofrecen un único factor indicando que todos los ítems del cuestionario representan el constructo de disfunción ejecutiva.

Varios son los estudios que realizan un análisis factorial de este cuestionario aunque existe falta de consenso en cuanto al número de factores resultantes, desde tres hasta cinco. Como comentan Pedrero y colaboradores (Pedrero-Pérez et al., 2011) en su estudio, esta variablidad estructural puede ser debido al tamaño muestra diferente entre los estudios, el reducido número de ítems o la complejidad de la repercusión cotidiana de los síntomas englobados bajo el término "disejecutivo". 


\subsection{VARIABLES DE ACTIVIDAD Y PARTICIPACIÓN:}

Son muchas las variables descritas en la literatura que para medir el grado de independencia funcional en pacientes con daño cerebral adquirido tales como variables de movilidad, cuidado personal como el vestido, la alimentación o la higiene funciones cognitivas, estado emocional, ajuste psicosocial, nivel ocupacional, empleo, comunicación o supervisión de terceras personas en determinados ambientes (Domínguez-Morales, Balmaseda Serrano, León Carrión, \& García Bernal, 2000; León Valenzuela, 2011; Machuca, León-Carrión, \& Barroso, 2006).

Uno de los instrumentos de medida de independencia funcional que se utiliza con frecuencia en el ámbito del daño cerebral adquirido es la escala FIM-FAM que presta atención no sólo a las actividades tradicionales relacionadas principalmente con la independencia física sino que incluyen otras medidas que tienen que ver con la función de comunicación, ajuste psicosocial y funcionamiento cognitivo, abarcando así más áreas de funcionamiento que las clásicas relacionadas específicamente con la función motora.

La evaluación de la actividad y del grado de participación de los pacientes se ha realizado a través de los cuestionarios que se describen en los siguientes apartados.

\subsection{1 ÍNDICE DE BARTHEL}

En el presente estudio, el nivel de independencia necesario para el desempeño de las actividades básicas de la vida diaria se ha valorado a través del Índice de Barthel (Mahoney \& Barthel, 1965). Se trata de un cuestionario heteroadministrado con 10 ítems relacionados con las actividades básicas (comer, lavarse-bañarse, vestirse, arreglarse, 
deposición, micción, ir al retrete, trasladarse sillón/cama, deambulación, subir y bajar escaleras). Consiste en asignar a cada paciente una puntuación en función de su grado de dependencia para la realización de la actividad que describe el ítem, a partir de un sistema de respuesta tipo Likert con intervalos de 5 puntos cada opción. De manera que, a mayor independencia, mayor puntuación. Por ejemplo para el ítem correspondiente a la actividad de comer, si el paciente es independiente siendo capaz de utilizar cualquier instrumento necesario, de desmenuzar la comida, extender condimentos, etc. y comer en un tiempo razonable le corresponderían 10 puntos, si por el contrario necesita ayuda para cortar o extender condimentos pero es capaz de comer solo se le asignarían 5 puntos y si necesita ser alimentado por otra persona serían 0 puntos. En el ítem elacionado con el control de la micción, serían 10 puntos en caso de ser continente, 5 puntos si presenta accidentes ocasionales (menos de una vez por semana o necesita ayuda para enemas o supositorios) y 0 puntos si es incontinente o son incapaces de manejarse con la sonda en caso de llevarla.

La puntuación total de la escala varía entre 0 y 100 puntos: puntuaciones entre 0 y 20 sugieren dependencia total, entre 21 y 60 dependencia severa, entre 61 y 90 dependencia moderada, entre 91 y 99 escasa dependencia y una puntuación total de 100 supone independencia completa.

\subsubsection{COMMUNITY INTEGRATION QUESTIONNAIRE, REVISED (CIQ-R)}

El Community Integration Questionnaire fue creado por Barry Willer junto con un grupo de profesionales en 1993 (Willer, Rosenthal, Kreutzer, Gordon, \& Rempel, 1993) como medida de integración comunitaria tras un daño cerebral traumático. Incluso se ha convertido 
en el instrumento más utilizado a nivel internacional para valorar la integración en el hogar, integración social y productividad en el ámbito del daño cerebral adquirido (Kaplan, 2001; Ritchie, Wright-St Clair, Keogh, \& Gray, 2014). Esta versión constaba de 15 ítems relacionados integración en el hogar, integración social y actividades productivas, pudiendo obtener a partir de la suma de todos los ítems una puntuación global de integración comunitaria.

En 1999, Sander y colaboradores (Sander et al., 1999) plantearon una nueva versión con menor número de ítems, que es la que empleamos en el presente estudio. Se trata de un cuestionario administrado en el contexto de una entrevista preferiblemente contestado por el familiar o cuidador del paciente, que mide el grado de participación a través de 13 ítems agrupados en tres dominios: Competencia en el hogar, Integración social y Habilidades productivas. La primera escala hace referencia a quién realiza determinadas actividades de la casa como las compras, comidas, finanzas o actividades sociales. La escala de Integración Social pregunta acerca de cuántas veces al mes el paciente realiza determinadas actividades sociales como ocio, visitas a familiares o amigos... $Y$ por último, la escala de Actividades Productivas se refiere a la situación laboral actual, actividades formativas o de voluntariado.

Las escalas de "Competencia en el Hogar" y la de "Integración Social" se pueden puntuar con un máximo de 10 puntos mientras que la de "Actividades Productivas" con 5 puntos, de manera que la puntuación total en la escala oscila entre 0 y 25 puntos donde, a mayor puntuación, mayor nivel de integración. 


\subsubsection{CRAIG HANDICAP ASSESSMENT AND REPORTING TECHNIQUE (CHART)}

El Craig Handicap Assessment and Reporting Technique (CHART) (Whiteneck, 1992) fue diseñado de acuerdo a la Clasificación Internacional de Deficiencias, Discapacidades y Minusvalías para ofrecer una medida simple y objetiva sobre el grado en el que las deficiencias y discapacidades resultan en dificultades (hándicaps) así como para evaluar cómo las personas con discapacidades funcionan como miembros activos de sus comunidades.

Teniendo en cuenta el Sistema de Clasificación Internacional de Funcionamiento, Discapacidad y Salud (CIF) como marco teórico en el que nos movemos, las deficiencias y discapacidades a las que se hacía referencia en la nomenclatura antigua se tratan de los déficits y la actividad según este modelo y las dificultades (hándicaps) se traducen en el grado de participación, objetivo de evaluación del presenta trabajo.

Esta escala incluía inicialmente 5 dominios, pero fue revisada para incluir la independencia cognitiva, resultando en 6 dominios con 32 ítems totales: a) independencia física; b) independencia cognitiva; c) movilidad/accesibilidad a actividades y recursos dentro y fuera del hogar; d) ocupación, incluyendo actividades del hogar, cuidado de otras personas, actividades de voluntariado, de ocio, etc.; e) cantidad y calidad de las relaciones interpersonales, y f) independencia económica. No obstante en nuestro estudio los ítems correspondientes a este último dominio no se administraron dado que las tablas de conversión para esta escala están diseñadas según los ingresos americanos, además que el equipo investigador consideró que podría resultar invasivo para los familiares.

La puntuación de cada subescala se sitúa entre 0 y 100 puntos, pudiendo obtener entre 0 y 600 puntos en la puntuación total del CHART. 
Las puntuaciones más altas indican un menor grado de discapacidad o mayor grado de participación social y comunitaria.

El domino de la CIF que explora esta escala es el de Participación, dado que pregunta sobre la frecuencia o ayuda que precisa la persona para desarrollar ciertas actividades funcionales, y no sobre la capacidad o competencia del individuo para realizarlo, que sería correspondería al dominio de Actividad, tal y como lo hacen otras escalas como el Índice de Barthel o las Medidas de Evaluación Funcional (Functional Assessment Measures FIM+FAM).

\subsubsection{PRUEBA BREVE DE EVALUACIÓN DEL FUNCIONAMIENTO (FAST)}

La FAST (Ribero Rosa et al., 2008) es un instrumento sencillo, de fácil aplicación y de respuesta objetiva que se desarrolló para valorar clínicamente las limitaciones que presentaba una población de enfermos psiquiátricos. Se trata de una escala heteroaplicada con criterios operativos de puntuación en la que se valoran las limitaciones que presenta el paciente teniendo en cuenta el funcionamiento normal esperado en una persona del mismo sexo, edad y situación sociocultural durante los últimos quince días. Está compuesta de un total de 24 ítems que evalúan seis áreas específicas de funcionamiento: autonomía (capacidad de la persona para hacer las cosas por sí mismo, concretamente encargarse de la tareas de la casa, vivir solo, hacer la compra y cuidar su aspecto e higiene), funcionamiento laboral (capacidad del paciente para trabajar), cognitivo (capacidad del paciente para la concentración, atención, capacidad de aprendizaje y memoria, resolución de problemas...), manejo de finanzas (capacidad para la gestión económica y realización de compras proporcionadas), relaciones personales (habilidad para las relaciones sociales bien familiares o de 
amistad y participación en las mismas) y ocio (capacidad para la práctica de ejercicio físico y adquisición y mantenimiento de aficiones).

Para cada uno de los ítems incluidos en los dominios anteriores la persona responsables del cumplimiento del cuestionario, en nuestro caso, el familiar o cuidador principal, responde de acuerdo a cuatro opciones según el grado de dificultad que presenta el paciente para el desempeño de la actividad a la que hace referencia el ítem. Las opciones de respuesta serían las siguientes: (0) ninguna dificultad, el funcionamiento del paciente se ajusta a las normas de su grupo de referencia; (1) poca dificultad, se detecta desviación de la norma un una o más de las actividades o funciones; (2) bastante dificultad, presenta desviación muy marcada respecto a la norma encontrándose el paciente con una discapacidad moderada-severa y (3) mucha dificultad, en la que la desviación de la norma es tan grande que el paciente se encuentra gravemente discapacitado la mayor parte de tiempo.

\subsection{VARIABLES DE CALIDAD DE VIDA}

Debido a que la calidad de vida de los pacientes que han sufrido una lesión cerebral puede verse afectada, en la presente investigación se ha administrado el cuestionario que se detalla a continuación para valorar esta variable.

\subsubsection{CUESTIONARIO SOBRE CALIDAD DE VIDA SATISFACCIÓN Y PLACER (Q-LES-Q)}

El cuestionario de Calidad de Vida, Satisfacción y Placer (Endicott, Nee, Harrison, \& Blumenthal, 1993) es una de las medidas de resultado 
auto-informado más importantes para valora cómo el paciente percibe el impacto que tiene en su vida diaria una determinada condición de salud. Se ha demostrado que esta escala presenta fiabilidad y validez para numerosas condiciones psiquiátricas, y se ha utilizado como medida de la calidad de vida en más de un centenar de publicaciones(Endicott, Krithika, Margaret, \& Wayne, 2007; Hope, Page, \& Hooke, 2009; Mick, Biederman, Spencer, Faraone, \& Zhang, 2006; Ritsner, Kurs, Kostizky, Ponizovsky, \& Modai, 2002). Se trata de un cuestionario genérico, autoadministrado y que consta de 93 ítems distribuidos en varios dominios:

- Estado de salud física. Pretende conocer la frecuencia con que experimentó el paciente durante la semana pasada distintas condiciones de salud física como dolor, cansancio, energía y vitalidad, buena coordinación en los movimientos o buen rendimiento mnésico, entre otros.

- Estado de ánimo. Dimensión que igual que la anterior pretende indagar sobre el estado de ánimo del paciente, preguntando la frecuencia con la que se sentía alegre, a gusto con su aspecto físico, satisfecho, relajado, capaz de cuidar de sí mismo, etc.

- Trabajo. Dimensión cuyo objetivo es conocer la opinión del paciente respecto a su trabajo. Como son muchas las condiciones de salud en la que los pacientes son incapaces de realizar un trabajo remunerado, se les pregunta previamente dentro del mismo cuestionario si trabaja. Si es que sí puede responder a las preguntas (frecuencia con la que se sintió a gusto en el trabajo, con la que logró lo que se propuso, con la que trabajó cuidadosamente...) y si es que no ha de especificar el motivo (demasiado enfermo físicamente, demasiado alterado emocionalmente, jubilado u otra razón). En nuestro estudio por la baja prevalencia de pacientes que 
se encontraban laboralmente activos en el momento de la evaluación evitamos estudiar este domino.

- Actividades de la casa. Al igual que en la dimensión anterior se pregunta previamente si es responsable de alguna tarea del hogar como limpieza, compras, lavar platos u otras y dependiendo de la respuesta ofrece el motivo o por el contario se dispone a contestar las preguntas (frecuencia de satisfacción en cuanto a la manera de limpiar, en cuanto a la manera de comprar, en la toma de decisiones respecto a tareas domésticas...)

- Tareas de curso o clase. Se responde de igual manera que las dos dimensiones anteriores. En caso de que el paciente haya asistido algún curso o haya participado en alguna clase se le formulan preguntas relacionadas con la frecuencia con la que disfrutó de las tareas, la frecuencia con la que pensó con claridad sobre las tareas, o la frecuencia con la que se interesó sobre las mismas.

- Actividades de tiempo libre. Las preguntas de esta dimensión se refieren a las actividades de tiempo libre durante la semana anterior, tales como ver la televisión, leer el periódico o revistas, ocuparse de las planta o el jardín, pasatiempos, ir a museos o actos deportivos, etc.

- Relaciones sociales. Esta dimensión está relacionada con la frecuencia con que el paciente desea, disfruta, se interesa, se divierte... en las relaciones sociales con amigos, familia $u$ otras personas, así como si se lleva bien o si siente cariño por ellas.

- Actividades generales. En esta dimensión se pretende conocer el nivel global de satisfacción que tiene el paciente respecto a las actividades generales que hacen referencia a los dominios anteriores. Se le pregunta al paciente cómo evaluaría su nivel de 
satisfacción durante la semana anterior en cuanto al estado de salud física, el estado de ánimo, el trabajo, las relaciones sociales, el tiempo de ocio, la capacidad de participar en la vida diaria, y otros aspectos relacionados.

Cada una de las dimensiones incluyen ítems con un sistema de respuesta cerrada a partir de cinco alternativas de respuesta con una puntuación de 0 a 5: (1) nunca, (2) casi nunca, (3) a veces, (4) a menudo o la mayor parte del tiempo y (5) muy a menudo o siempre. El sistema de respuesta de la última dimensión (actividades generales) es diferente siendo: (1) muy malo, (2) malo, (3) regular, (4) bueno y (5) muy bueno.

Adoptando el modelo CIF como marco de referencia, las diferentes dimensiones que valora este cuestionario se asemejan a los dominios de Participación propuestos por la OMS en su sistema de Clasificación del Funcionamiento. Concretamente el dominio 1, "Aprendizaje y aplicación de conocimiento", podría valorarse a través de la dimensión "Tareas curos/clase"; el dominio 2, "Tareas y demandas generales" a través de la dimensión "Actividades generales"; el dominio 3 "Comunicación" a través de algunos ítems de las dimensiones "Estado de ánimo", y "Relaciones sociales"; el domino 4 "Movilidad", a través de "Estado de salud física"; el dominio 5 relacionado con el "Autocuidado" mediante algunos ítems de "Estado de ánimo"; la "Vida doméstica" del dominio 6 con la dimensión "Actividades de la Casa"; el dominio 8 sobre "Áreas principales de la vida" se podría valorar a través de la dimensión "Actividades generales" y por último, la "Vida comunitaria, cívica y social" del dominio 9 se mediría con los ítems de los dominios "Actividades de ocio" y "Relaciones sociales".

Al ser el Q-LES-Q un cuestionario autoadministrado la calidad de la respuesta es subjetiva y por tanto indicadoras de lo que pretende medir el test, es decir, un constructo psicológico sujeto a la propia percepción 
del paciente como es la calidad de vida, la satisfacción y el placer. Además, en relación con los objetivos de este trabajo se trata, como acabamos de ver, de una escala muy exhaustiva al abordar todos los dominios de Participación de la CIF.

\subsection{OTRAS VARIABLES NEUROPSICOLÓGICAS}

Además de las variables cognitivas, conductuales, de independencia funcional y de calidad de vida, en el protocolo de evaluación del presente estudio se han recogido otras variables neuropsicológicas como la conciencia de déficit y la reserva cognitiva. En los siguientes apartados se describen los instrumentos utilizados para evaluar dichas variables.

\subsubsection{CONCIENCIA DE DÉFICIT}

\subsubsection{CUESTIONARIO DE CONCIENCIA DE DÉFICIT FLEMMING}

El cuestionario de autoconciencia de los déficits, adaptado y modificado por Flemming, Strong y Ashton (1996), permite objetivar el grado de conciencia que presenta el paciente con daño cerebral adquirido sobre sus dificultades y limitaciones. El cuestionario se divide en tres bloques que valoran el conocimiento de los déficits, la conciencia de las implicaciones de los déficits y la conciencia de las implicaciones futuras. El evaluador formulas las preguntas abiertas que incluye el cuestionario y puntúa cada una de las partes según se describe a continuación:

I. Conocimiento de los déficits: 0. El paciente muestra buen conocimiento de sus problemas cognitivos y conductuales. 1. El paciente tiene conocimiento de alguno de sus problemas 
pero otros los desconoce, niega o minimiza, centrándose principalmente en las dificultades físicas aunque puede reconocer los problemas cognitivos cuando se le pregunta sobre ellos. 2. Centrado exclusivamente en sus problemas físicos desconociendo los cognitivos/conductuales. 3. Desconocimiento de sus déficits.

II. Conciencia de las implicaciones de sus déficits: 0 . El paciente describe de manera adecuada su situación funcional, y especifica qué limitaciones le ha producido el daño cerebral y qué medidas compensatorias ha tomado para resolver las deficiencias. 1. Describe algunas alteraciones funcionales, pero cuando se le pregunta parece no estar seguro por el motivo por el que no puede realizar algunas actividades. 2 . Conoce algunas implicaciones pero las niega o minimiza. 3 . Ningún conocimiento de las consecuencias de sus limitaciones.

III. Implicaciones futuras: 0 . El paciente presente objetivos realistas, 1. Objetivos parcialmente realistas, reconociendo alguna posible dificultad, 2. Objetivos poco realistas creyendo el paciente que pronto volverá la situación premórbida, 3. El paciente no plantea ningún problema presente ni futuro.

\subsubsection{RESERVA COGNITIVA}

\subsubsection{CUESTIONARIO DE RESERVA COGNITIVA}

La reserva cognitiva hace referencia a la capacidad del cerebro para tolerar las diferentes manifestaciones clínicas de los cambios cerebrales asociados a un proceso degenerativo. Se trata del resultado de las 
experiencias vividas tales como la ocupación laboral, la actividad lectora, el nivel de educación, y otras actividades intelectuales y cognitivas realizadas a lo largo de la vida (Stern, 2002). Bajos niveles de reserva cognitiva se vinculan con mayor deterioro cognitivo (Adell-Serrano et al., 2013).

El Cuestionario de Reserva Cognitiva (CRC) (Rami et al., 2011)se divide en 8 secciones que se valoran de 0 a 5 puntos dependiendo del número de alternativas de respuesta, siendo la puntuación máxima que se puede obtener, de 25 puntos. La variable escolaridad puede sumar hasta cinco puntos $(0=\sin$ estudios, $1=$ lee $y$ escribe de manera autodidacta, $2=$ básica $<6$ años, 3= primaria $\geq 6$ años, $4=$ secundaria $\geq 9$ años, 5 = superior diplomatura/licenciatura). La variable escolaridad de los padres puede sumar hasta 3 puntos $(0=$ no escolarizados, $1=$ básica 0 primaria, 2= secundaria o superior); cursos de formación hasta tres puntos ( 0 = ninguno, $1=$ uno o dos, $2=$ entre dos y cinco, 3= más de cinco), mientras que formación musical hasta 2 puntos $(0=$ no toca ningún instrumento ni escucha música frecuentemente, $1=$ toca poco o escucha música frecuentemente, 2 = formación musical reglada). Por su parte, el nivel de idiomas como para mantener una conversación puede sumar hasta 3 puntos $(0=$ solamente idioma materno, $1=$ dos idiomas -incluye catalán, gallego, euskera, castellano-, 2=dos/tres idiomas -uno diferente al catalán, gallego o euskera-, 3= más de dos idiomas), mientras que la actividad lectora puede sumar hasta 4 puntos $(0=$ nunca, 1 : ocasionalmente, 2 = entre dos y cinco libros al año, 3= de cinco a diez libros al año, 3: más de diez libros al año). Finalmente, la realización de juegos intelectuales puede sumar hasta 2 puntos $(0=$ nunca o alguna vez, $1=$ entre uno y cinco al mes, $2=$ más de cinco al mes).

Una puntuación global de igual o menor de 6 puntos situaría el grado de reserva cognitiva del sujeto en el rango inferior, entre 7 y 9 
puntos en el rango medio-bajo, entre 10 y 14 en el rango medio-alto; finalmente, puntuaciones superiores a 14 se corresponden con una reserva cognitiva de un rango superior.

\section{PROCEDIMIENTO}

En primer lugar, se elaboró el protocolo de recogida de datos, teniendo en cuenta las variables e instrumentos de medida a aplicar. Una vez diseñado, tal y como se ha explicado anteriormente, se seleccionaron aquellos pacientes que cumplían los requisitos de inclusión y se contactó telefónicamente o bien desde la misma Unidad con aquellos que ya habían sido dados de alta con anterioridad o iban a finalizar el proceso rehabilitador en los próximos días, respectivamente. A los pacientes que aceptaron participar se les citaba en la Unidad correspondiente a los pocos días para realizar la valoración y aplicarles el protocolo establecido.

Una vez acudían a la Unidad, se les explicaba de nuevo y de manera detallada el motivo del estudio, asegurando que había sido entendido y no les quedaran dudas al respecto, y se recogía por escrito en la historia clínica el consentimiento informado. El mismo día se entregaba al familiar o cuidador los cuestionarios de Participación (FAST, CIQ-R, CHART) para que pudieran cumplimentarlos en una sala adjunta donde el paciente era evaluado. La administración de las pruebas se llevó a cabo por parte de un neuropsicólogo con competencia suficiente en la aplicación de las mismas. El tiempo que empleaba el familiar en cumplimentar los cuestionarios era de 45 minutos aproximadamente, mientras que la evaluación con el paciente ser realizó durante unas tres horas. Las pruebas se administraron en dos sesiones que tuvieron lugar en días 
diferentes, o bien en un mismo día para aquellos pacientes con dificultades para trasladarse dos días a la Unidad, facilitando los descansos necesarios para el correcto rendimiento del paciente.

En general, el orden de administración de las pruebas fue el mismo para todos los participantes. No obstante, algunas diferencias individuales entre los pacientes -como limitaciones sensoriales, velocidad de procesamiento o cansancio- podían introducir algunas modificaciones en el protocolo de evaluación. En primer lugar, se administraba la prueba de aprendizaje y memoria verbal (TAVEC) y, durante los veinte minutos que deben pasar para valorar el recuerdo a largo plazo, se administraban algunas pruebas de atención y de funciones ejecutivas (i.e., localización espacial directa e inversa, test de las campanas, test de trazados y colores I y || y matrices). Las pruebas administradas durante este periodo de veinte minutos eran todas visuales -sin ningún componente verbal- para evitar interferencias con las palabras que tenían que recordar en el TAVEC. Pasado este tiempo, se llevaba a cabo la segunda parte de la prueba de memoria donde tenía que recordar las palabras aprendidas anteriormente (ver apartado 2.3.2.1.). A continuación, se administraban el resto de pruebas que componen el protocolo, en el orden siguiente (para la mayoría de los casos): dígitos directos e inversos, CPT-II, FAS, Matrices, Brixton Test, Test de búsqueda de la llave y WCST. Por último, se administró el cuestionario de calidad de vida al paciente.

Tras finalizar la evaluación neuropsicológica, nos volvíamos a reunir con el familiar y/o cuidador para resolver, en caso de que las hubiera, las posibles dudas surgidas durante el cumplimiento de los cuestionarios, con el fin de contrastar que habían contestado de manera adecuada. Una vez concluida dicha sesión (o sesiones), y previamente a la despedida y agradecimiento a los participantes, se les comentó que podían conocer 
los resultados del estudio tras la corrección de las pruebas y análisis pertinentes.

\section{CÁLCULO DE PUNTUACIONES TRANSFORMADAS}

Tras la administración de las pruebas neuropsicológicas descritas anteriormente, las puntuaciones directas fueron transformadas en puntuaciones $\mathrm{T}$ un doble objetivo, por una parte tener una medida del grado de rendimiento en las diferentes pruebas y por tanto del deterioro en los casos que lo presentaran y por otra poder calcular las puntuaciones totales de los dominios cognitivos. De esta manera, tipificar las puntuaciones obtenidas en una prueba equivaldría a establecer las normas con las que comparar nuestros resultados, puesto que se extraen siempre del promedio de actuación de un grupo de referencia (grupo normativo) al que debe pertenecer el participante. Los métodos más utilizados para describir la posición de un sujeto respecto al grupo son las puntuaciones típicas ( $\mathrm{Z} \circ \mathrm{T}$ ) y los percentiles (más fáciles de calcular pero pueden suponer más errores ya que no son tan exactos).

En el presente estudio se han utilizado los datos de tipificación de cada prueba para establecer el grado de afectación de cada sujeto. Tras determinar con qué grupo de referencia se tenían que comparar las puntuaciones directas en cada una de las pruebas neuropsicológicas, se calculó la puntuación transformada permitiéndonos valorar el rendimiento que tuvo un sujeto en un prueba determinada (i.e., cómo de "bien" o "mal" lo hizo en relación a su grupo de referencia). Esta transformación nos permitió realizar una comparación entre-sujetos y 
valorar el rendimiento de un mismo participante en diferentes pruebas (i.e., tener una comparación intra-sujeto).

En esta investigación se han utilizado Puntuaciones Típicas (PT) sobre una escala con media 50 y desviación típica 10 . El cálculo de las puntuaciones $\mathrm{T}$ necesitó calcular previamente la puntuación $\mathrm{z}$, que se realizó restándole a la puntuación directa obtenida (PD) por el sujeto la puntuación media $(X)$ obtenida por el grupo de referencia, y dividiendo el resultado por la desviación típica del mismo grupo (DT), datos que aparecen en el manual de aplicación y corrección de cada una de las pruebas.

$$
z=\frac{P D-X}{S D}
$$

Al ser la media de la puntuación $z=0$ y la desviación típica $=1$, cualquier puntuación z negativa indicaría que la PD está por debajo de la media, y positiva por encima de la misma. Por su parte, las puntuaciones $\mathrm{T}$ (Media $=50$ y DT $=10$ ) se obtuvieron a partir de la puntuación $z$, multiplicando ésta por la DT (10) y sumándole la Media (50), según la siguiente fórmula:

$$
P T=10 z+50
$$

De esta manera, una PT = 50 indicaría un valor igual a la media, una $\mathrm{PT}=40$ una desviación típica por debajo de la media, una PT = 60 una desviación típica por encima de la media, y así sucesivamente. En la Tabla 5.2. se resume la correspondencia de las puntuaciones estandarizadas $Z$, $\mathrm{T}$ y percentil con la interpretación cualitativa. En consecuencia, en el presente estudio, cuanto mayor era el valor de la PT, mejor era el rendimiento en la prueba y, por tanto, menor era el grado de afectación el dominio evaluado. Esto no era así en el caso de las pruebas cuya puntuación directa indica el "tiempo empleado", donde valores más altos 
indicaron un rendimiento peor, como ocurre en las pruebas Color trailsparte I y Color trails-parte II (a mayor tiempo invertido, peor resultado).

Tabla 5.2. Correspondencia de las puntuaciones estandarizadas

\begin{tabular}{|c|c|c|c|c|}
\hline CENTIL & PUNT. T & PUNT. Z & $\begin{array}{l}\text { PUNT. } \\
\text { ESCALAR }\end{array}$ & $\begin{array}{c}\text { Interpretación } \\
\text { cualitativa }\end{array}$ \\
\hline$>99$ & $>77$ & $>2,7$ & $>18$ & \multirow{42}{*}{ Sin alteración } \\
\hline$>99$ & 77 & 2,7 & 18 & \\
\hline$>99$ & 76 & 2,6 & & \\
\hline 99 & 75 & 2,5 & & \\
\hline 99 & 75 & 2,5 & & \\
\hline 99 & 74 & 2,4 & & \\
\hline 99 & 73 & 2,3 & 17 & \\
\hline 99 & 73 & 2,3 & 17 & \\
\hline 99 & 72 & 2,2 & & \\
\hline 98 & 71 & 2,1 & & \\
\hline 98 & 71 & 2,1 & & \\
\hline 98 & 70 & 2 & 16 & \\
\hline 97 & 69 & 1,9 & & \\
\hline 97 & 69 & 1,9 & & \\
\hline 96 & 68 & 1,8 & & \\
\hline 96 & 67 & 1,7 & 15 & \\
\hline 95 & 67 & 1,7 & 15 & \\
\hline 95 & 66 & 1,6 & & \\
\hline 94 & 65 & 1,5 & & \\
\hline 93 & 65 & 1,5 & & \\
\hline 92 & 64 & 1,4 & & \\
\hline 91 & 63 & 1,3 & 14 & \\
\hline 90 & 63 & 1,3 & 14 & \\
\hline 88 & 62 & 1,2 & & \\
\hline 87 & 61 & 1,1 & & \\
\hline 86 & 61 & 1,1 & & \\
\hline 84 & 60 & 1 & 13 & \\
\hline 82 & 59 & 0,9 & & \\
\hline 81 & 59 & 0,9 & & \\
\hline 79 & 58 & 0,8 & & \\
\hline 77 & 57 & 0,7 & 12 & \\
\hline 75 & 57 & 0,7 & 12 & \\
\hline 73 & 56 & 0,6 & & \\
\hline 70 & 55 & 0,5 & & \\
\hline 68 & 55 & 0,5 & & \\
\hline 66 & 54 & 0,4 & & \\
\hline 63 & 53 & 0,3 & 11 & \\
\hline 61 & 53 & 0,3 & 11 & \\
\hline 58 & 52 & 0,2 & & \\
\hline 55 & 51 & 0,1 & & \\
\hline 53 & 51 & 0,1 & & \\
\hline 50 & 50 & 0 & 10 & \\
\hline
\end{tabular}


Tabla 5.2. (Continuación) Correspondencia de las puntuaciones estandarizadas

\begin{tabular}{|c|c|c|c|c|}
\hline CENTIL & PUNT. T & PUNT. Z & $\begin{array}{c}\text { PUNT. } \\
\text { ESCALAR }\end{array}$ & $\begin{array}{l}\text { Interpretación } \\
\text { cualitativa }\end{array}$ \\
\hline 47 & 49 & $-0,1$ & & \multirow{6}{*}{ Sin alteración } \\
\hline 45 & 49 & $-0,1$ & & \\
\hline 42 & 48 & $-0,2$ & & \\
\hline 39 & 47 & $-0,3$ & 9 & \\
\hline 37 & 47 & $-0,3$ & 9 & \\
\hline 34 & 46 & $-0,4$ & & \\
\hline 32 & 45 & $-0,5$ & & \multirow{9}{*}{ Alteración leve } \\
\hline 30 & 45 & $-0,5$ & & \\
\hline 27 & 44 & $-0,6$ & & \\
\hline 25 & 43 & $-0,7$ & 8 & \\
\hline 23 & 43 & $-0,7$ & 8 & \\
\hline 21 & 42 & $-0,8$ & & \\
\hline 19 & 41 & $-0,9$ & & \\
\hline 18 & 41 & $-0,9$ & & \\
\hline 16 & 40 & -1 & 7 & \\
\hline 14 & 39 & $-1,1$ & & \multirow{14}{*}{ Alteración moderada } \\
\hline 13 & 39 & $-1,1$ & & \\
\hline 12 & 38 & $-1,2$ & & \\
\hline 10 & 37 & $-1,3$ & 6 & \\
\hline 9 & 37 & $-1,3$ & 6 & \\
\hline 8 & 36 & $-1,4$ & & \\
\hline 7 & 35 & $-1,5$ & & \\
\hline 6 & 35 & $-1,5$ & & \\
\hline 5 & 34 & $-1,6$ & & \\
\hline 5 & 33 & $-1,7$ & 5 & \\
\hline 4 & 33 & $-1,7$ & 5 & \\
\hline 4 & 32 & $-1,8$ & & \\
\hline 3 & 31 & $-1,9$ & & \\
\hline 3 & 31 & $-1,9$ & & \\
\hline 2 & 30 & -2 & 4 & \multirow{12}{*}{ Alteración severa } \\
\hline 2 & 29 & $-2,1$ & & \\
\hline 2 & 29 & $-2,1$ & & \\
\hline 1 & 28 & $-2,2$ & & \\
\hline 1 & 27 & $-2,3$ & 3 & \\
\hline 1 & 27 & $-2,3$ & 3 & \\
\hline 1 & 26 & $-2,4$ & & \\
\hline 1 & 25 & $-2,5$ & & \\
\hline 1 & 25 & $-2,5$ & & \\
\hline$<1$ & 24 & $-2,6$ & & \\
\hline$<1$ & 23 & $-2,7$ & 2 & \\
\hline$<1$ & $<23$ & $<-2,7$ & $<2$ & \\
\hline
\end{tabular}

Una vez se obtuvieron las puntuaciones transformadas para cada una de las pruebas de evaluación se calcularon los diferentes dominios cognitivos realizando una media aritmética de las puntuaciones $T$ de cada 
una de las diferentes pruebas neuropsicológicas incluidas en el dominio cognitivo (Tabla 5.3.)

Tabla 5.3. Pruebas neuropsicológicas según el dominio evaluado.

\begin{tabular}{|c|c|}
\hline Función evaluada & Prueba neuropsicológica \\
\hline $\begin{array}{l}\text { Atención y procesamiento de la } \\
\text { información }\end{array}$ & $\begin{array}{l}\text { Dígitos, orden directo (WAIS) } \\
\text { Localización espacial, orden directo (WMS) } \\
\text { Test de cancelación de campanas } \\
\text { Test de trazados de colores, parte I } \\
\text { Continuous Performance Test-II (tiempo reacción) }\end{array}$ \\
\hline Aprendizaje y memoria & Test Auditivo Verbal España Complutense \\
\hline Memoria de trabajo & $\begin{array}{l}\text { Dígitos, orden inverso (WAIS) } \\
\text { Localización espacial, orden inverso (WMS) } \\
\text { Test de trazados de colores, parte II }\end{array}$ \\
\hline Funcionamiento ejecutivo & $\begin{array}{l}\text { Test de clasificación de cartas de Wisconsin } \\
\text { Test de Asociación controlada de palabras } \\
\text { Matrices (WAIS) } \\
\text { Test de Brixton } \\
\text { Test de búsqueda de la llave (BADS) } \\
\text { Continuous Performance Test-II (comisiones) }\end{array}$ \\
\hline
\end{tabular}

\section{ANÁLISIS ESTADÍSTICOS}

En primer lugar, se llevó a cabo un análisis descriptivo para las variables sociodemográficas, clínicas y de estudio. Las variables cuantitativas continuas que se estudiaron fueron la edad, los años de escolarización, la reserva cognitiva, la conciencia de déficit, el nivel de actividad, las diferentes pruebas neuropsicológicas, los dominios cognitivos, la alteración conductual, los cuestionarios de participación y el cuestionario de calidad de vida, para las que se calculó la media, desviación típica, rango de puntuaciones y valores mínimos y máximos para los cuestionarios. Las variables cualitativas que se analizaron a través de valores de frecuencias y porcentajes fueron datos sociodemográficos 
(género, nivel educativo, estado civil, ocupación previa, situación laboral y convivencia), variables clínicas de la lesión (diagnóstico principal, etiología del ACV, tipo de ACV, causa del TCE, tipo de TCE, tipo de trastorno motor), así como el grado de alteración en el rendimiento en los diferentes dominios cognitivos.

Antes de abordar los análisis estadísticos, se valoró si las variables cuantitativas continuas seguían o no una distribución normal, para determinar si se empleaban o no pruebas paramétricas. Para ello, se llevó a cabo la prueba de Kolmogorov-Smirnov para una muestra. Los resultados de la misma apuntan a que la mayoría de variables seguían una distribución normal, excepto las variables "Barthel al alta" $(p=0,000)$ y "Reserva Cognitiva" ( $p=0,024)$.

Con el objeto de determinar si el funcionamiento cognitivo de la muestra difería significativamente del de la población general, se llevaron a cabo análisis de diferencia de medias de las puntuaciones globales de cada dominio cognitivo con el valor preestablecido de 50 mediante una tstudent para una muestra. La elección del valor 50 se debe a que por definición, se trata del valor medio de las puntuaciones $T$ de la población general. Para determinar si la etiología de la lesión introducía diferencias en la calidad de vida resultante, se llevó a cabo una diferencia de media de las diferentes puntuaciones de la escala de calidad de vida entre los sujetos que habían sufrido un TCE versus AVC mediante una t-student para muestras independientes.

Para determinar las asociaciones entre las diferentes variables de estudio, se ha calculado el coeficiente de correlación de Pearson, excepto cuando alguna de las variables introducidas no seguía una distribución normal, en cuyo caso se calculó la rho de Spearman. Para los análisis predictivos, se llevaron a cabo una serie de análisis de regresión lineal por pasos sucesivos, introduciendo como variable dependiente el resultado 
de la escala de Calidad de Vida (Total y Subescalas) y como variables independientes o factores (predictores) las variables cognitivas, de conducta e independencia funcional-participación que habían mostrado correlaciones significativas con el resultado de la escala de Calidad de Vida.

El análisis estadístico de los datos obtenidos en el presente estudio se llevó a cabo con el paquete IBM SPSS Statistics versión 20. 



\section{Resultados}

Predictores de Calidad de Vida en pacientes con Daño Cerebral Adquirido: Déficit,

Actividad y Participación

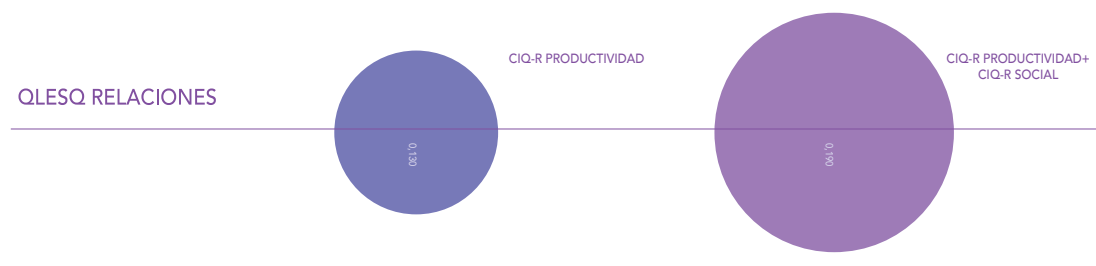

CIQ-R PRODUCTIVIDAD+

CIQ-R SOCIAL+
CHART COGNITIVO

DEX TOTAL 



\section{DATOS SOCIODEMOGRÁFICOS}

Los datos sociodemográficos de la muestra total se resumen en la Tabla 6.1. Los participantes en el presente estudio eran en su mayoría varones (73\%); el rango de edad de la muestra total es entre 18 y 74 años, obteniendo una media de edad de 50,25 años (DT 12,59) mientras que la media de años de escolarización es de 10,56 (DT 3,53) distribuidos de la siguiente manera: $1,1 \%$ era analfabeto, un $2,2 \%$ no tenía estudios reglados pero podía leer y escribir, el $46,1 \%$ había completado estudios primarios, el $33,7 \%$ tenía estudios medios (bachiller, FP) y el $16,9 \%$ disponía de estudios universitarios. En cuanto al estado civil, el 62,2\% estaban casados, el 10,1\% divorciados/separados, el $18 \%$ eran solteros, el $4,5 \%$ viudos y el $4,5 \%$ tenían pareja. Respecto a la ocupación y situación laboral encontramos que antes de la lesión, el 38,6\% de los pacientes eran empleados sin cualificar, el $27,3 \%$ empleados cualificados, el $11,4 \%$ no presentaban actividad remunerada, el $10,2 \%$ eran profesionales o directivos, otro $10,2 \%$ autónomos o trabajadores en empresa familiar y por último un $2,3 \%$ de la muestra eran empresarios con empleados a su cargo. Respecto a la situación laboral tras el daño, en el momento de la valoración neuropsicológica concluido el proceso de neuro-rehabilitación, casi la mitad de la muestra $(40,9 \%)$ recibían una pensión por invalidez, el $20,5 \%$ se encontraban en incapacidad temporal, el $18,2 \%$ estaban jubilados, el $10,1 \%$ se encontraban laboralmente activos, el $4,5 \%$ se encargaban de las tareas del hogar, el 3,4\% eran estudiantes y el $2,2 \%$ se encontraban en paro ( $1,1 \%$ paro con subsidio y otro $1,1 \%$ paro $\sin$ subsidio). Referente a la convivencia de los pacientes, más de la mitad de la muestra vivían en pareja, entre ellos, el 29,2\% únicamente con el cónyuge y el $34,8 \%$ con el cónyuge e hijos, el $12,4 \%$ vivían con los padres, el $9 \%$ soleo, el $4,5 \%$ con los hijos, el $2,2 \%$ con hermanos, el $1,1 \%$ en 
institución, el 1,1\% vivía en institución y el 6,7\% presentaba otro tipo de convivencia como por ejemplo cuidadores.

\section{Tabla 6.1. Datos sociodemográficos}

\begin{tabular}{|c|c|c|c|c|}
\hline & Frecuencia & Media & DT & Rango \\
\hline \multicolumn{5}{|l|}{ Género } \\
\hline Varones & $73 \%$ & & & \\
\hline Mujeres & $27 \%$ & & & \\
\hline Edad & & 50,25 & 12,59 & $18-74$ \\
\hline Años de escolaridad & & 10,56 & 3,53 & $0-17$ \\
\hline \multicolumn{5}{|l|}{ Nivel educativo } \\
\hline Analfabeto & $1,1 \%$ & & & \\
\hline Lee y escribe & $2,2 \%$ & & & \\
\hline Primarios & $46,1 \%$ & & & \\
\hline Bachiller/FP & $33,7 \%$ & & & \\
\hline Universitarios & $16,9 \%$ & & & \\
\hline \multicolumn{5}{|l|}{ Estado civil } \\
\hline Casado & $62,2 \%$ & & & \\
\hline Divorciado/separado & $10,1 \%$ & & & \\
\hline Soltero & $18 \%$ & & & \\
\hline Viudo & $4,5 \%$ & & & \\
\hline Unión & $4,5 \%$ & & & \\
\hline \multicolumn{5}{|l|}{ Ocupación previa } \\
\hline Sin actividad remunerada & $11,4 \%$ & & & \\
\hline Empleado sin cualificar & $38,6 \%$ & & & \\
\hline Empleado cualificado & $27,3 \%$ & & & \\
\hline Profesional/directivo & $10,2 \%$ & & & \\
\hline Autónomo/empresa familiar & $10,2 \%$ & & & \\
\hline Empresario con empleados & $2,3 \%$ & & & \\
\hline \multicolumn{5}{|l|}{ Situación laboral } \\
\hline Pensión de invalidez & $40,9 \%$ & & & \\
\hline Paro sin subsidio & $1,1 \%$ & & & \\
\hline Paro con subsidio & $1,1 \%$ & & & \\
\hline Pensión de jubilación & $18,2 \%$ & & & \\
\hline Ama de casa & $4,5 \%$ & & & \\
\hline Estudiantes & $3,4 \%$ & & & \\
\hline Incapacidad temporal & $20,5 \%$ & & & \\
\hline En activo & $10,1 \%$ & & & \\
\hline \multicolumn{5}{|l|}{ Convivencia } \\
\hline Pareja & $29,2 \%$ & & & \\
\hline Pareja e hijos & $34,8 \%$ & & & \\
\hline Solo & $9,0 \%$ & & & \\
\hline Padres & $12,4 \%$ & & & \\
\hline Hijos & $4,5 \%$ & & & \\
\hline Hermanos & $2,2 \%$ & & & \\
\hline Institución & $1,1 \%$ & & & \\
\hline Otros & $6,7 \%$ & & & \\
\hline
\end{tabular}




\section{VARIABLES CLÍNICAS DE LA LESIÓN:}

Los datos médicos correspondientes a la lesión de los participantes en el estudio han sido proporcionados por el facultativo especialista correspondiente (un neurólogo o un médico rehabilitador, dependiendo del caso), de manera consensuada y protocolizada al formar parte del equipo investigador. La información principal que nos facilitaban correspondía al diagnóstico principal, etiología y tipo de daño, causa del daño así como el posible trastorno motor que en ese momento presentaban. Analizando estos datos, se obtiene una muestra total de 89 sujetos con daño cerebral adquirido, la mayoría de ellos con diagnóstico principal de AVC $(70,8 \%)$ siguiendo con una frecuencia menor el diagnóstico de TCE $(24,7 \%)$, y con menor frecuencia aún los de anoxia $(1,1 \%)$, infección cerebral $(1,1)$ y tumor $(2,2 \%)$. Del total de ACVs, más de la mitad $(62,3 \%)$ son isquémicos, el resto hemorrágicos $(37,7 \%)$; de este total se puede obsrvar los diferentes tipos y frecuencias en la Tabla 6.2., así como el resto de información recogida en estos párrafos referente a la variables clínicas de la lesión.

Un porcentaje mínimo $(3,4 \%)$ son indeterminados según el diagnóstico clínico del facultativo. Las causas de los TCEs del estudio han sido los accidentes de tráfico $(85,7 \%)$ y los accidentes laborales $(14,3 \%)$, dando lugar a lesiones difusas en la mitad de la muestra (50\%), multifocales $(37,5 \%)$ y focales con evacuación posterior $(12,5 \%)$ en el resto.

Los trastornos motores derivados de las diferentes lesiones que han sufrido los participantes han sido principalmente hemiparesias (34\%) y hemiplejias (34\%) aunque, en menor grado, también se han presentado paraparesias (2\%) y tetraparesias (2\%). El $28 \%$ de la muestra total no sufre ningún trastorno motor en el momento del estudio. 
Tabla 6.2. Datos clínicos de la lesión

\begin{tabular}{|c|c|}
\hline & Frecuencia \\
\hline \multicolumn{2}{|l|}{ Diagnóstico principal } \\
\hline Accidente vascular cerebral & $70,8 \%$ \\
\hline Traumatismo craneoencefálico & $24,7 \%$ \\
\hline Anoxia & $1,1 \%$ \\
\hline Infección cerebral & $1,1 \%$ \\
\hline Tumor & $2,2 \%$ \\
\hline \multicolumn{2}{|l|}{ Etiología ACV } \\
\hline Isquémico & $62,3 \%$ \\
\hline Hemorrágico & $37,7 \%$ \\
\hline \multicolumn{2}{|l|}{ Tipo ACV } \\
\hline Embólico & $13,7 \%$ \\
\hline Malformación artereovenosa & $5,9 \%$ \\
\hline Trombótico & $21,6 \%$ \\
\hline Hemorrágico & $31,4 \%$ \\
\hline Lacunar & $5,9 \%$ \\
\hline $\begin{array}{l}\text { Insquemico con transformación } \\
\text { hemorrágica }\end{array}$ & $17,6 \%$ \\
\hline Indeterminado & $3,9 \%$ \\
\hline \multicolumn{2}{|l|}{ Causa TCE } \\
\hline Accidente laboral & $14,3 \%$ \\
\hline Accidente de tráfico & $85,7 \%$ \\
\hline \multicolumn{2}{|l|}{ Tipo TCE } \\
\hline Difuso & $50,0 \%$ \\
\hline Multifocal & $37,5 \%$ \\
\hline Focal/evacuado & $12,5 \%$ \\
\hline \multicolumn{2}{|l|}{ Trastorno motor } \\
\hline No presenta & $28,0 \%$ \\
\hline Hemiparesia & $34,0 \%$ \\
\hline Paraparesia & $2,0 \%$ \\
\hline Hemiplejia & $34,0 \%$ \\
\hline Tetraparesia & $2,0 \%$ \\
\hline
\end{tabular}

\section{VARIABLES COGNITIVAS}

Los análisis de las variables cognitivas se realizaron a partir de las puntuaciones T (media 50, DT 10) para poder comparar a la muestra 
evitando el efecto de la edad y nivel educativo en el rendimiento de las pruebas.

Tras el análisis de diferencia de medias realizado, todos los dominios cognitivos evaluados tienen valores significativamente inferior a la población general, por lo que en nuestra muestra las funciones de atención, aprendizaje y memoria, memoria de trabajo y funciones ejecutivas se encuentran alteradas.

Tal y como se observa en la Tabla 6.3., la atención global es la función que menor media presenta $(37,97 \pm 10,78)$, seguido de la memoria de trabajo $(39,57 \pm 13,55)$, el aprendizaje y memoria $(41,64, \pm 12,92)$ y las funciones ejecutivas $(41,97 \pm 7,30)$. El $28,1 \%$ de la muestra presenta una PT mayor o igual a 46 en atención global, un 40,5\% en aprendizaje y memoria, un $39,3 \%$ en memoria de trabajo y un $32,6 \%$ en funciones ejecutivas.

Tabla 6.3. Frecuencias del grado de alteración y medias de dominios cognitivos globales.

\begin{tabular}{|c|c|c|c|c|}
\hline & Frecuencia & Media & DT & Rango \\
\hline Atención & & 37,97 & 10,78 & $10-56$ \\
\hline $\mathrm{PT} \leq 29$ & $21,3 \%$ & & & \\
\hline PT 39-30 & $28,1 \%$ & & & \\
\hline PT 45-40 & $22,5 \%$ & & & \\
\hline $\mathrm{PT} \geq 46$ & $28,1 \%$ & & & \\
\hline Aprendizaje y memoria & & 41,64 & 12,92 & $10-70$ \\
\hline $\mathrm{PT} \leq 29$ & $17,9 \%$ & & & \\
\hline PT $39-30$ & $21,4 \%$ & & & \\
\hline PT $45-40$ & $20,2 \%$ & & & \\
\hline $\mathrm{PT} \geq 46$ & $40,5 \%$ & & & \\
\hline Memoria de trabajo & & 39,57 & 13,55 & $10-69$ \\
\hline $\mathrm{PT} \leq 29$ & $28,1 \%$ & & & \\
\hline PT 39-30 & $14,6 \%$ & & & \\
\hline PT $45-40$ & $18,0 \%$ & & & \\
\hline $\mathrm{PT} \geq 46$ & $39,3 \%$ & & & \\
\hline Funciones ejecutivas & & 41,97 & 7,30 & $28-60$ \\
\hline $\mathrm{PT} \leq 29$ & $3,4 \%$ & & & \\
\hline PT 39-30 & $38,2 \%$ & & & \\
\hline PT $45-40$ & $25,8 \%$ & & & \\
\hline $\mathrm{PT} \geq 46$ & $32,6 \%$ & & & \\
\hline
\end{tabular}




\section{Atención}

PT $\leq 29$
PT $39-30$
PT $45-40$
PT $\geq 46$

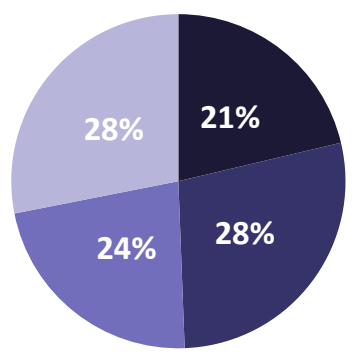

Ilustración 6.1. Porcentaje de afectación en Atención

\section{Memoria de Trabajo}

- $\quad \mathrm{PT} \leq 29$

— PT $39-30$

- РT $45-40$

PT $\geq 46$

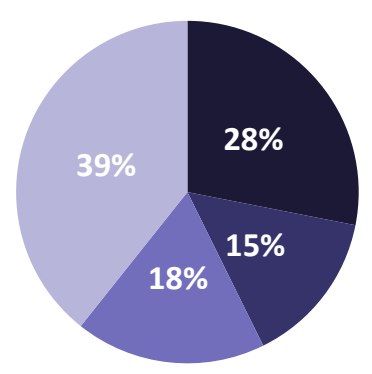

Ilustración 6.3. Porcentaje de afectación en Memoria de Trabajo

\section{Aprendizaje y Memoria}

- $\quad \mathrm{PT} \leq 29$

- PT 39-30

- PT $45-40$

- $\quad \mathrm{PT} \geq \mathbf{4 6}$

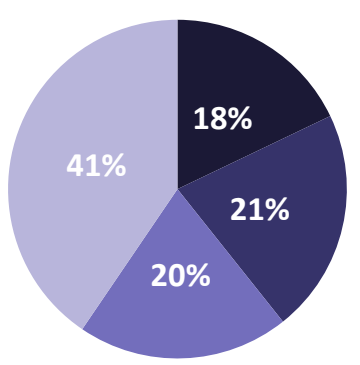

Ilustración 6.2. Porcentaje de afectación en Aprendizaje y Memoria

\section{Funciones Ejecutivas}
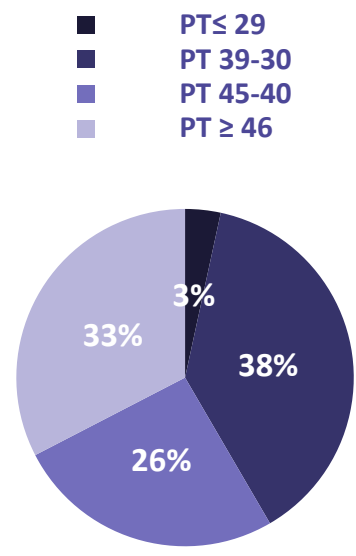

Ilustración 6.4. Porcentaje de afectación en Funciones Ejecutivas 
El análisis de cada una de las pruebas que evalúan los distintos dominios cognitivos se recoge en la Tabla 6.4. Tal y como se observa, de las pruebas que evalúan la capacidad atencional, aquella en la que peor rendimiento se ha obtenido ha sido en el Test de trazos de colores-parte I- $(33,09 \pm 17,33)$, seguido del CPT-II (medida de tiempo de reacción), dígitos directos-serie máxima-, test de cancelación de campanas y localización espacial-directos- $(41,81 \pm 16,25 ; 46,00 \pm 10,08 ; 46,27 \pm 13,01$; $48,08 \pm 12,22$, respectivamente). Entre las variables utilizadas para valorar la capacidad de aprendizaje y memoria, el recuerdo con claves a corto plazo es en el que mejor rendimiento se ha obtenido aun siendo el valor de la PT menor de $50(45,32 \pm 13,90)$; una media de 43,56 (DT: 13,18$)$ se ha obtenido en el total de aprendizaje, de 43,19 (DT: 14,20) en el recuerdo libre a corto plazo, de 42,00 (DT: 14,68) en el recuerdo libre a largo plazo, de 42,76 (DT: 16,69 ) en el recuerdo con claves a largo plazo y de 42,73 (DT: 16,24) en la discriminación. En las pruebas dígitos inversos-serie máxima y localización espacial-orden inverso, utilizadas para valorar la memoria de trabajo se ha obtenido una puntuación $\mathrm{T}$ media de $49,35 \pm 10,92$ y de $49,18 \pm 10,43$, respectivamente, mientras que en el Test de trazos de colores-parte II, destinado para la valoración del mismo dominio cognitivo la media obtenida ha sido de $32,08 \pm 17,87$, lo que indica un rendimiento considerablemente bajo. De las pruebas utilizadas para valorar las funciones ejecutivas, la puntuación T media más baja se ha obtenido en las fluencias tanto por consigna fonética como semántica $(39,00 \pm 11,17$ y $39,55 \pm 10,52$, respectivamente), seguido por los errores perseverativos del WCST $(43,10 \pm 13,33)$, el test de Brixton $(45,24 \pm 14,93)$, las matrices del WAIS $(48,50 \pm 10,90)$ y las comisiones del CPT-II $(57,29 \pm 39,96)$, sin embardo en esta prueba la puntuación se ha de interpretar de manera inversa, dado que a mayor número de comisiones y mayor Puntuación T, peor es el rendimiento. 
El hecho que las medias de Puntuaciones $T$ obtenidas en las pruebas correspondientes a las escalas Whechsler (dígitos, localización espacial y matrices) representen un rendimiento normal puede ser debido a que estas baterías de pruebas tienen baremos poco exigentes para la población adulta-mayor. No obstante, la Tabla 6.5 muestra de manera detallada el porcentaje de pacientes que presentan una determinada Puntuación T (clasificada por rangos: alteración severa, moderada, leve y no alteración) para cada una de las pruebas cognitivas.

Tabla 6.4. Medias de las Puntuaciones Típicas de las pruebas cognitivas

\begin{tabular}{|l|l|c|c|c|}
\hline & & Media & DT & Rango \\
\hline & Dígitos directos-serie máxima & 46,00 & 10,08 & $19-66$ \\
\hline \multirow{4}{*}{ Atención } & Localización espacial-directo & 48,08 & 12,23 & $20-67$ \\
& Test de cancelación de campanas & 46,27 & 13,00 & $12-83$ \\
& Test de trazo de colores-parte I & 33,09 & 17,33 & $10-64$ \\
& Tiempo de reacción (CPT-II) & 41,82 & 16,25 & $10-77$ \\
\hline \multirow{3}{*}{ Aprendizaje y } & Total de aprendizaje 5 ensayos & 43,56 & 13,18 & $10-70$ \\
\hline Memoria & Recuerdo libre a corto plazo & 43,19 & 14,20 & $10-63$ \\
& Recuerdo con claves a corto plazo & 45,32 & 13,90 & $10-62$ \\
& Recuerdo libre a largo plazo & 42,00 & 14,68 & $10-70$ \\
& Recuerdo con claves a largo plazo & 42,76 & 16,69 & $10-62$ \\
\hline \multirow{3}{*}{ Memoria } & Discriminación & 42,73 & 16,24 & $10-61$ \\
\hline de trabajo & Dígitos inversos serie-máxima & 49,35 & 10,92 & $31-81$ \\
\hline & Localización espacial-inverso & 49,18 & 10,43 & $30-67$ \\
& Test de trazo de colores-parte II & 32,08 & 17,89 & $10-60$ \\
\hline \multirow{2}{*}{ Funciones } & Errores perseverativos (WCST) & 43,10 & 13,33 & $10-80$ \\
\hline Ejecutivas & Fluencia consigna fonética & 39,00 & 11,17 & $10-73$ \\
& Fluencia consigna semántica & 39,55 & 10,52 & $10-69$ \\
& Matrices & 48,50 & 10,90 & $27-76$ \\
& Errores Brixton & 45,24 & 14,93 & $10-73$ \\
& Búsqueda llave(puntuación directa) & 9,89 & 4,11 & $2-17$ \\
& Comisiones (CPT-II) & 57,29 & 39,96 & $35-344$ \\
\hline
\end{tabular}


Tabla 6.5. Porcentaje de pacientes por rango de Puntuaciones T en cada prueba cognitiva.

\begin{tabular}{|c|c|c|c|c|c|}
\hline \multirow{6}{*}{ Atención } & & $\begin{array}{l}\text { P.T. } \\
\leq 29\end{array}$ & $\begin{array}{c}\text { P.T. } \\
\text { 39-30 }\end{array}$ & $\begin{array}{c}\text { P.T. } \\
45-40\end{array}$ & $\begin{array}{l}\text { P.T. } \\
\geq 46\end{array}$ \\
\hline & Dígitos directos-serie máxima & $4,8 \%$ & $21,7 \%$ & $24,1 \%$ & $49,4 \%$ \\
\hline & Localización espacial-directo & $4,1 \%$ & $20,4 \%$ & $18,4 \%$ & $57,1 \%$ \\
\hline & Test de cancelación de campanas & $8,2 \%$ & $12,2 \%$ & $34,7 \%$ & $44,9 \%$ \\
\hline & Test de trazo de colores-parte I & $38,2 \%$ & $16,9 \%$ & $16,8 \%$ & $28,1 \%$ \\
\hline & Tiempo de reacción (CPT-II) & $1,8 \%$ & $8,7 \%$ & $12,3 \%$ & $77,2 \%$ \\
\hline \multirow{6}{*}{$\begin{array}{l}\text { Aprendizaje y } \\
\text { Memoria }\end{array}$} & Total de aprendizaje 5 ensayos & $11,4 \%$ & $21,5 \%$ & $20 \%$ & $47,1 \%$ \\
\hline & Recuerdo libre a & $19,4 \%$ & $12,9 \%$ & $16,1 \%$ & $51,6 \%$ \\
\hline & Recuerdo con claves & $17,2 \%$ & $17,3 \%$ & $6,9 \%$ & $58,6 \%$ \\
\hline & Recuerdo libre a largo plazo & $17,1 \%$ & $12,9 \%$ & $24,3 \%$ & $45,7 \%$ \\
\hline & Recuerdo con claves a largo plazo & $26,7 \%$ & $16,6 \%$ & $0 \%$ & $56,7 \%$ \\
\hline & Discriminación & $20 \%$ & $6,7 \%$ & $20 \%$ & $53,3 \%$ \\
\hline \multirow{3}{*}{$\begin{array}{l}\text { Memoria } \\
\text { de trabajo }\end{array}$} & Dígitos inversos serie-máxima & $0 \%$ & $18,1 \%$ & $21,7 \%$ & $60,2 \%$ \\
\hline & Localización espacial-inverso & $0 \%$ & $16,3 \%$ & $24,5 \%$ & $59,2 \%$ \\
\hline & Test de trazo de colores-parte II & $40,9 \%$ & $17,1 \%$ & $7,9 \%$ & $34,1 \%$ \\
\hline \multirow{6}{*}{$\begin{array}{l}\text { Funciones } \\
\text { Ejecutivas }\end{array}$} & Errores perseverativos (WCS & $13,3 \%$ & $24 \%$ & $21,7 \%$ & $41 \%$ \\
\hline & Fluencia consigna fonética & $17,9 \%$ & $30,9 \%$ & $25 \%$ & $26,2 \%$ \\
\hline & Fluencia consigna semántica & $12,9 \%$ & $36,5 \%$ & $21,2 \%$ & $29,4 \%$ \\
\hline & Matrices & $1,2 \%$ & $18,8 \%$ & $22,4 \%$ & $57,6 \%$ \\
\hline & Errores Brixton & $16,7 \%$ & $8,9 \%$ & $19,3 \%$ & $55,1 \%$ \\
\hline & Comisiones (CPT-II) & $7 \%$ & $14,1 \%$ & $21 \%$ & $57,9 \%$ \\
\hline
\end{tabular}

\section{VARIABLES CONDUCTUALES}

Las alteraciones de conducta valoradas con el Cuestionario Disejecutivo -DEX- por parte del familiar se muestran en la Tabla 6.6., donde se representa para cada ítem del cuestionario la media obtenida, la desviación típica y el rango de puntuaciones obtenidas por la muestra. En la Tabla 6.7. aparece el porcentaje de pacientes que presentan en un grado u otro (nunca, en ocasiones, alguna veces, a menudo y muy a menudo) la dificultad que describe cada ítem. Atendiendo a esta frecuencia de aparición de alteraciones conductuales, de manera muy 
frecuente, un $22,5 \%$ de la muestra pierde la paciencia a la mínima y un $14,6 \%$ muestran despreocupación por las reglas sociales, ignorando o no importándoles cómo se sienten los demás en relación a su comportamiento. Esto último aumenta a un $20,2 \%$ de la muestra que lo presenta a menudo, al igual que distractibilidad $(19,1 \%)$, euforia $(19,1 \%)$ e impulsividad (19,1\%). Menos frecuente son los problemas de razonamiento abstracto, la falta de perspicacia y conciencia social y la perseveración, no obstante la presentan algunas veces el $32,6 \%$, el $31,5 \%$ y el $30,3 \%$ de la muestra, respectivamente. Las alteraciones menos frecuentes son las dificultades en la secuenciación temporal, la desinhibición verbal y la falta de habilidad para inhibir respuestas que la presentan ocasionalmente el $32,6 \%$ de la muestra, el $30,3 \%$ y el $28,1 \%$, respectivamente. Por último, no es habitual encontrar confabulación, inquietud y respuesta afectiva superficial ya que los familiares consideran que el $73 \%$, el $51,7 \%$ y el $47,2 \%$ respectivamente nunca lo presentan.

Tabla 6.6. Resultados del Cuestionario Disejecutivo -DEX-

\begin{tabular}{|l|c|c|c|}
\hline & Media & DT & Rango \\
\hline PUNTUACIÓN TOTAL & 27,67 & 16,26 & $0-72$ \\
\hline ITEM 1: Razonamiento abstracto & 1,08 & 1,02 & $0-3$ \\
\hline ITEM 2: Impulsividad & 1,63 & 1,24 & $0-4$ \\
\hline ITEM 3: Confabulación & 0,44 & 0,84 & $0-4$ \\
ITEM 4: Planificación & 1,71 & 1,32 & $0-4$ \\
\hline ITEM 5: Euforia & 1,66 & 1,23 & $0-4$ \\
ITEM 6: Desorientación & 1,11 & 1,07 & $0-4$ \\
ITEM 7: Perspicacia y conciencia social & 1,56 & 1,36 & $0-4$ \\
ITEM 8: Apatía y falta de iniciativa & 1,71 & 1,34 & $0-4$ \\
ITEM 9: Desinhibición verbal & 1,06 & 1,18 & $0-4$ \\
ITEM 10: Inconsistencia en el tiempo & 1,31 & 1,23 & $0-4$ \\
ITEM 11: Manifestación de emociones & 1,12 & 1,26 & $0-4$ \\
ITEM 12: Impaciencia & 1,98 & 1,42 & $0-4$ \\
ITEM 13: Indiferencia & 1,37 & 1,29 & $0-4$ \\
ITEM 14: Perseveración & 1,52 & 1,24 & $0-4$ \\
ITEM 15: Inquietud & 0,83 & 1,09 & $0-4$ \\
ITEM 16: Desinhibición acción & 1,25 & 1,31 & $0-4$ \\
\hline
\end{tabular}


Tabla 6.6. (Continuación) Resultados del Cuestionario Disejecutivo -DEX-

\begin{tabular}{|l|c|c|c|} 
& Media & DT & Rango \\
\hline ITEM 17: Inconsistencia pensamiento-acción & 1,19 & 1,15 & $0-4$ \\
\hline ITEM 18: Distractibilidad & 1,75 & 1,29 & $0-4$ \\
\hline ITEM 19: Dificultad toma decisiones & 1,61 & 1,34 & $0-4$ \\
\hline ITEM 20: Despreocupación reglas sociales & 1,76 & 1,43 & $0-4$ \\
\hline
\end{tabular}

Tabla 6.7. Frecuencia de respuestas para cada ítem del Cuestionario Disejecutivo -DEX-

\begin{tabular}{|c|c|c|c|c|c|}
\hline & NUNCA & $\begin{array}{c}\text { EN } \\
\text { OCASIONES }\end{array}$ & $\begin{array}{l}\text { ALGUNAS } \\
\text { VECES }\end{array}$ & $\begin{array}{c}\text { A } \\
\text { MENUDO }\end{array}$ & $\begin{array}{l}\text { MUY A } \\
\text { MENUDO }\end{array}$ \\
\hline $\begin{array}{l}\text { ITEM 1: Razonamiento } \\
\text { abstracto }\end{array}$ & $40,4 \%$ & $19,1 \%$ & $32,6 \%$ & $7,9 \%$ & $7,9 \%$ \\
\hline ITEM 2: Impulsividad & $24,7 \%$ & $20,2 \%$ & $29,2 \%$ & $19,1 \%$ & $19,1 \%$ \\
\hline ITEM 3: Confabulación & $73,0 \%$ & $14,6 \%$ & $9,0 \%$ & $2,2 \%$ & $2,2 \%$ \\
\hline ITEM 4: Planificación & $23,6 \%$ & $22,5 \%$ & $24,7 \%$ & $18,0 \%$ & $18,0 \%$ \\
\hline ITEM 5: Euforia & $21,3 \%$ & $25,8 \%$ & $25,8 \%$ & $19,1 \%$ & $19,1 \%$ \\
\hline $\begin{array}{l}\text { ITEM 6: Secuenciación } \\
\text { temporal }\end{array}$ & $34,8 \%$ & $32,6 \%$ & $22,5 \%$ & $6,7 \%$ & $6,7 \%$ \\
\hline $\begin{array}{l}\text { ITEM 7: Perspicacia y } \\
\text { conciencia social }\end{array}$ & $32,6 \%$ & $13,5 \%$ & $31,5 \%$ & $10,1 \%$ & $10,1 \%$ \\
\hline $\begin{array}{l}\text { ITEM 8: Apatía y falta de } \\
\text { iniciativa }\end{array}$ & $23,6 \%$ & $23,6 \%$ & $24,7 \%$ & $14,6 \%$ & $14,6 \%$ \\
\hline $\begin{array}{l}\text { ITEM 9: Desinhibición } \\
\text { verbal }\end{array}$ & $41,6 \%$ & $30,3 \%$ & $14,6 \%$ & $7,9 \%$ & $7,9 \%$ \\
\hline $\begin{array}{l}\text { ITEM 10: Inconsistencia } \\
\text { en el tiempo }\end{array}$ & $33,7 \%$ & $25,8 \%$ & $21,3 \%$ & $13,5 \%$ & $13,5 \%$ \\
\hline $\begin{array}{l}\text { ITEM 11: Manifestación } \\
\text { de emociones }\end{array}$ & $47,2 \%$ & $15,7 \%$ & $18,0 \%$ & $15,7 \%$ & $15,7 \%$ \\
\hline ITEM 12: Impaciencia & $18,0 \%$ & $24,7 \%$ & $21,3 \%$ & $13,5 \%$ & $13,5 \%$ \\
\hline ITEM 13: Indiferencia & $34,8 \%$ & $21,3 \%$ & $23,6 \%$ & $12,4 \%$ & $12,4 \%$ \\
\hline ITEM 14: Perseveración & $27,0 \%$ & $22,5 \%$ & $30,3 \%$ & $12,4 \%$ & $12,4 \%$ \\
\hline ITEM 15: Inquietud & $51,7 \%$ & $27,0 \%$ & $11,2 \%$ & $6,7 \%$ & $6,7 \%$ \\
\hline $\begin{array}{l}\text { ITEM 16: Desinhibición } \\
\text { acción }\end{array}$ & $38,2 \%$ & $28,1 \%$ & $12,4 \%$ & $13,5 \%$ & $13,5 \%$ \\
\hline $\begin{array}{l}\text { ITEM 17: Inconsistencia } \\
\text { pensamiento-acción }\end{array}$ & $38,2 \%$ & $27,0 \%$ & $14,6 \%$ & $18,0 \%$ & $18,0 \%$ \\
\hline ITEM 18: Distractibilidad & $20,2 \%$ & $25,8 \%$ & $23,6 \%$ & $19,1 \%$ & $19,1 \%$ \\
\hline $\begin{array}{l}\text { ITEM 19: Dificultad toma } \\
\text { decisiones }\end{array}$ & $28,1 \%$ & $21,3 \%$ & $23,6 \%$ & $15,7 \%$ & $15,7 \%$ \\
\hline $\begin{array}{l}\text { ITEM 20: Despreocupación } \\
\text { reglas sociales }\end{array}$ & $28,1 \%$ & $16,9 \%$ & $20,2 \%$ & $20,2 \%$ & $20,2 \%$ \\
\hline
\end{tabular}




\section{ACTIVIDAD E INDEPENDENCIA FUNCIONAL- PARTICIPACIÓN}

Tal y como se ha explicado en el Capítulo 5 de Metodología, se ha empeleado el Índice de Barthel como medida de Actividad y diferentes escalas de Independencia Funcional para valorar el grado de Participación de la muestra. La Tabla 6.8 indica los resultados obtenidos en la escala Barthel en la que se observa una media total de 85,94 (DT 20,03). Concretamente, la mayoría de los pacientes $(57,6 \%$ de la muestra) son independientes para el desempeño de las actividades básicas de la vida diaria, con un Índice de Barthel de 100, el 18,8\% presenta una dependencia moderada, el $13 \%$ severa, el $7,1 \%$ presentan esasa dependencia y el 3,5\% dependencia total.

Tabla 6.8. Resultados medida de actividad. Índice de Barthel.

\begin{tabular}{|l|c|c|c|c|c|c|}
\hline & Frecuencia & Media & DT & Mínimo & Máximo & Rango \\
\hline INDICE DE BARTHEL & & & & & & \\
Total & & 85,94 & 20,03 & 0 & 100 & 10,100 \\
\hline Dependencia Total & $3,5 \%$ & & & & & \\
Dependencia Severa & $13 \%$ & & & & & \\
Dependencia Moderada & $18,8 \%$ & & & & & \\
Escasa Dependencia & $7,1 \%$ & & & & & \\
Independencia & $57,66 \%$ & & & & & \\
\hline
\end{tabular}

La Tabla 6.9. indica la media obtenida y la DT en cada escala de Participación, tanto en la puntuación total como en cada una de sus subescalas. También se representa el rango de puntuaciones que ha obtenido la muestra y el valor mínimo y máximo que se puede obtener en la prueba, así como la media de cada subescala transformada, considerando una máxima puntuación posible de 100. 
De las tres escalas de Participación, y teneindo en cuenta que la puntuación de la escala FAST se interpreta a la inversa (mayor puntuación peor grado de participación)observamos puntuaciones más bajas en las subescalas de Funcionamiento Laboral $(59,13)$, Ocupación $(42,72)$ y Productividad $(17,40)$ de las escalas FAST, CHART Y CIQ-R, respectivamente, mientras que las puntuaciones más altas en las tres escalas se presentan en las subescalas relacionadas con la esfera social (Relaciones Interpersonales del FAST: 42,11; Integración social del CHART: 87,15 y Social del CIQ-R: 70,40).

Tabla 6.9. Resultados medidas de Independencia Funcional-Participación

\begin{tabular}{|c|c|c|c|c|c|c|}
\hline & Media & DT & Mínimo & Máximo & Rango & $\begin{array}{c}\text { Media } \\
\text { transformada }\end{array}$ \\
\hline \multicolumn{7}{|l|}{ FAST } \\
\hline Total & 34,76 & 15,90 & 0 & 72 & $0-68$ & 48,28 \\
\hline Autonomía & 5,33 & 3,941 & 0 & 12 & $0-12$ & 44,42 \\
\hline $\begin{array}{l}\text { Funcionamiento } \\
\text { laboral }\end{array}$ & 8,87 & 6,249 & 0 & 15 & $0-15$ & 59,13 \\
\hline $\begin{array}{l}\text { Funcionamiento } \\
\text { Cognitivo }\end{array}$ & 7,51 & 4,014 & 0 & 15 & $0-15$ & 50,07 \\
\hline Finanzas & 2,60 & 2,184 & 0 & 6 & $0-6$ & 43,33 \\
\hline $\begin{array}{l}\text { Relaciones } \\
\text { interpersonales }\end{array}$ & 7,58 & 4,989 & 0 & 18 & $0-18$ & 42,11 \\
\hline Ocio & 2,64 & 1,913 & 0 & 6 & $0-6$ & 44,00 \\
\hline \multicolumn{7}{|l|}{ CHART } \\
\hline Total & 345,96 & 96,98 & 0 & 500 & $104-500$ & 69,19 \\
\hline $\begin{array}{l}\text { Independencia } \\
\text { física }\end{array}$ & 68,61 & 42,024 & 0 & 100 & $0-100$ & 68,61 \\
\hline $\begin{array}{l}\text { Independencia } \\
\text { cognitiva }\end{array}$ & 62,78 & 24,767 & 0 & 100 & $12-100$ & 62,78 \\
\hline Movilidad & 84,69 & 19,059 & 0 & 100 & $10-100$ & 84,69 \\
\hline Ocupación & 42,72 & 32,551 & 0 & 100 & $0-100$ & 42,72 \\
\hline Integración social & 87,15 & 19,152 & 0 & 100 & $10-100$ & 87,15 \\
\hline \multicolumn{7}{|l|}{ CIQ-R } \\
\hline Total & 11,18 & 4,80 & 0 & 25 & $1-22$ & 44,72 \\
\hline Hogar & 3,24 & 2,79 & 0 & 10 & $0-10$ & 32,40 \\
\hline Social & 7,04 & 2,44 & 0 & 10 & $1-10$ & 70,40 \\
\hline Productividad & 0,87 & 1,44 & 0 & 5 & $0-5$ & 17,40 \\
\hline
\end{tabular}




\section{VARIABLES DE CALIDAD DE VIDA}

Según indica la Tabla 6.10. la satisfacción, valorada a través del cuestionario Q-LES-Q, que presenta la muestra de la presente investigación respecto a la calidad de vida total es de 69,65\%, concretamente en aquello relacionado con el estado de salud física la satisfacción es de un $65,11 \%$, respecto al estado de ánimo de un $71,73 \%$, $72,22 \%$ con la realización de las actividades de la casa, $72,37 \%$ con el desempeño de las actividades de ocio y tiempo libre, un $76,24 \%$ de satisfacción respecto a las relaciones sociales y un $64,17 \%$ en cuanto a las actividades generales.

Tabla 6.10. Resultados medida de Calidad de Vida.

\begin{tabular}{|c|c|c|c|c|c|c|}
\hline & Media & DT & Mínimo & Máximo & Rango & $\begin{array}{c}\text { Media } \\
\text { transformada }\end{array}$ \\
\hline $\begin{array}{l}\text { Q-LES-Q } \\
\quad \text { Total }\end{array}$ & 243,78 & 43,28 & 70 & 335 & $137-350$ & 69,55 \\
$\quad$ Salud & 42,32 & 10,624 & 13 & 65 & $12-64$ & 65,11 \\
$\quad$ Ánimo & 50,21 & 10,607 & 14 & 70 & $23-68$ & 71,73 \\
Casa & 36,11 & 8,156 & 10 & 50 & $18-50$ & 72,22 \\
\hline $\begin{array}{l}\text { Ocio } \\
\text { Relaciones }\end{array}$ & 21,71 & 5,493 & 6 & 30 & $6-30$ & 72,37 \\
$\begin{array}{l}\text { Actividades } \\
\text { generales }\end{array}$ & 41,93 & 8,509 & 11 & 55 & $19-55$ & 76,24 \\
\hline
\end{tabular}

Las Tablas 6.11-6.16 muestran la frecuencia en porcentaje de la respuesta que han dado los pacientes a cada ítem del QLESQ. Del ítem 27 al 41 y del 51 al correspondientes a la dimensión "Trabajo" y "Actividades de curso/clase" no se han analizado dado la escasa prevalencia de pacientes que se encontraban laboralmente activos o participando en algún curso en el momento de la evaluación. En cuanto a la dimensión Salud Física, que se muestra en la Tabla 6.11., el ítem que más pacientes, un $35,8 \%$ del total de la muestra, consideran satisfacer siempre con es el 
sentir que ha dormido lo suficiente, mientras el que con más frecuencia nunca o casi nunca experimentan es de no padecer problemas visuales (ítem 13) así como la sensación de estar lleno de energía y vitalidad (ítem 12), con una frecuencia de un $32,1 \%$ y un $22,2 \%$ de la muestra total, respectivamente. Respecto al Estado de ánimo, representado en la Tabla 6.12., el ítem que con más frecuencia considera la muestra (un 51,9\% del total) satisfacer siempre es el 20 , relacionado con la capacidad para comunicarse con otras personas, mientras que los ítems 18 y 25 , que preguntan sobre la frecuencia en que se sintieron independientes y capaces de desplazarse son los que nunca satisfacen un $14,8 \%$ de la muestra en ambos casos. Tal y como se observa en la Tabla 6.13., en el dominio Actividades de la Casa, los aspectos con los que que el 57,5\% y el $50 \%$ de la muestra respectivamente satisfizo siempre fueron el manejo de pago de facturas y operaciones bancarias (ítem 42) y el modo de preparar la comida (ítem 44), sin embargo aquello que más población $(19,5 \%)$ nunca hizo fue encargarse de arreglos o mantenimiento $d$ la casa (ítem 50). Referente al domino Actividades de Ocio (Tabla 6.14.), el 30,8\% de la muestra disfrutó siempre de las actividades del tiempo libre (ítem 62) y un $33,3 \%$ lo hizo a menudo. En cuanto a las Relaciones Sociales, representadas en la Tabla 6.15., un 70,4\% siempre se llevó bien con otras personas (ítem 74), mientras que el $11,3 \%$ de la muestra nunca se mostró paciente cuando otras personas le irritaron con sus acciones o palabras (ítem 71). Finalmente, respecto al domino de Actividades Generales (Tabla 6.16.), respondiendo al nivel global de satisfacción durante la semana pasada, el $30,9 \%$ y el $27,2 \%$ consideró tener un nivel de satisfacción muy bueno en lo referente a las relaciones familiares (ítem 83) y en la capacidad de desplazarse sin sentir mareos, inestabilidad o caídas (ítem 89), respectivamente. Sin embargo, el ítem que con más prevalencia (un $21,2 \%$ de la muestra) presentaba un nivel de satisfacción muy malo fue el que tenía que ver con la satisfacción en el trabajo (ítem 
80) y un nivel de satisfacción malo el relacionado con el deseo, interés o rendimiento sexual (ítem 86 ).

Tabla 6.11. Descripción del grado de satisfacción de los ítems del QLEQ relacionados con el Estado de Salud Física.

\begin{tabular}{|c|c|c|c|c|c|c|c|c|}
\hline & \multicolumn{5}{|c|}{ Frecuencias } & \multicolumn{3}{|c|}{ Descriptivos } \\
\hline & Nunca & $\begin{array}{c}\text { Casi } \\
\text { Nunca }\end{array}$ & $\begin{array}{c}\text { A } \\
\text { Veces }\end{array}$ & $\begin{array}{c}\text { A } \\
\text { Menudo }\end{array}$ & Siempre & Media & DT & Rango \\
\hline Ítem1 & $17,3 \%$ & $6,2 \%$ & $29,6 \%$ & $16,0 \%$ & $30,9 \%$ & 3,37 & 1,43 & $1-5$ \\
\hline Ítem2 & $8,6 \%$ & $14,8 \%$ & $21,0 \%$ & $29,6 \%$ & $25,9 \%$ & 3,49 & 1,27 & $1-5$ \\
\hline Ítem3 & $9,9 \%$ & $12,3 \%$ & $35,8 \%$ & $22,2 \%$ & $19,8 \%$ & 3,30 & 1,21 & $1-5$ \\
\hline Ítem4 & $16,0 \%$ & $13,6 \%$ & $24,7 \%$ & $24,7 \%$ & $21,0 \%$ & 3,21 & 1,36 & $1-5$ \\
\hline Ítem5 & $19,8 \%$ & $13,6 \%$ & $27,2 \%$ & $18,5 \%$ & $21,0 \%$ & 3,07 & 1,40 & $1-5$ \\
\hline Ítem6 & $24,7 \%$ & $12,3 \%$ & $27,2 \%$ & $17,3 \%$ & $18,5 \%$ & 2,93 & 1,43 & $1-5$ \\
\hline Ítem7 & $4,9 \%$ & $8,6 \%$ & $24,7 \%$ & $25,9 \%$ & $35,8 \%$ & 3,79 & 1,17 & $1-5$ \\
\hline Ítem8 & $11,1 \%$ & $12,3 \%$ & $25,9 \%$ & $29,6 \%$ & $21,0 \%$ & 3,37 & 1,26 & $1-5$ \\
\hline Ítem9 & $11,1 \%$ & $17,3 \%$ & $37,0 \%$ & $14,8 \%$ & $19,8 \%$ & 3,15 & 1,25 & $1-5$ \\
\hline Ítem10 & $8,6 \%$ & $8,6 \%$ & $35,8 \%$ & $23,5 \%$ & $23,5 \%$ & 3,44 & 1,19 & $1-5$ \\
\hline Ítem11 & $16,0 \%$ & $6,2 \%$ & $30,9 \%$ & $25,9 \%$ & $21,0 \%$ & 3,30 & 1,32 & $1-5$ \\
\hline Ítem12 & $22,2 \%$ & $12,3 \%$ & $25,9 \%$ & $25,9 \%$ & $13,6 \%$ & 2,96 & 1,35 & $1-5$ \\
\hline Ítem13 & $32,1 \%$ & $12,3 \%$ & $13,6 \%$ & $13,6 \%$ & $28,4 \%$ & 2,94 & 1,65 & $1-5$ \\
\hline
\end{tabular}

Tabla 6.12. Descripción del grado de satisfacción de los ítems del QLEQ relacionados con el Estado de ánimo

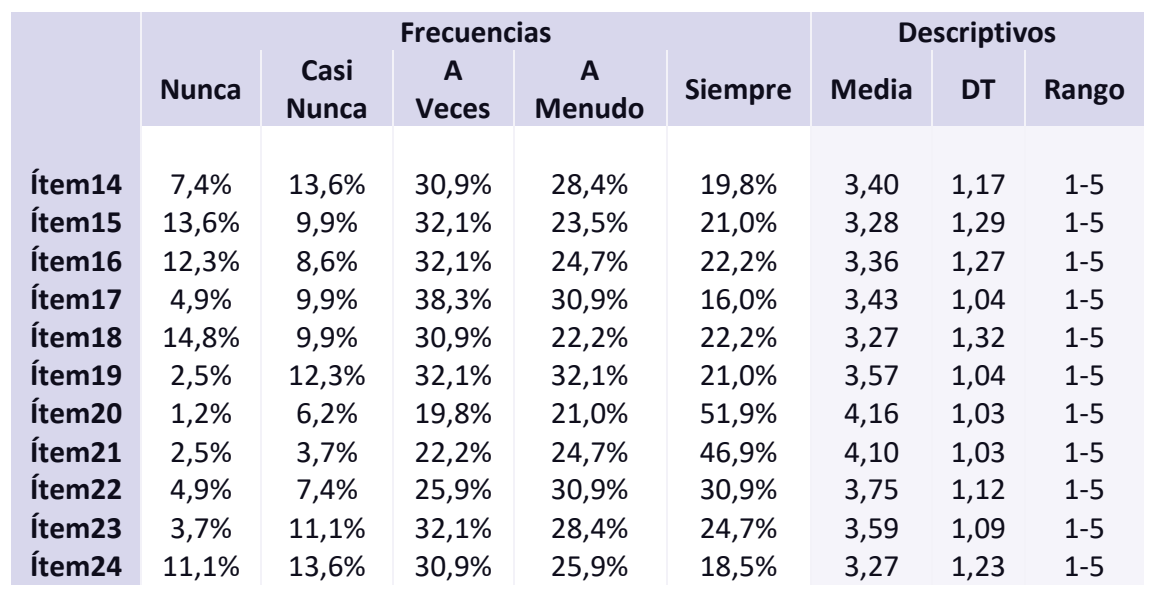


Tabla 6.12. (Continuación) Descripción del grado de satisfacción de los ítems del QLEQ relacionados con el Estado de ánimo

\begin{tabular}{|l|c|c|c|c|c|c|c|c|} 
& \multicolumn{4}{|c}{ Frecuencias } & \multicolumn{3}{c|}{ Descriptivos } \\
& Nunca & Casi & A & A & Siempre & Media & DT & Rango \\
Ítem25 & $14,8 \%$ & $14,8 \%$ & $16 \%$ & $18,5 \%$ & $35,8 \%$ & 3,46 & 1,47 & $1-5$ \\
Ítem26 & $9,9 \%$ & $6,2 \%$ & $23,5 \%$ & $22,2 \%$ & $38,3 \%$ & 3,73 & 1,30 & $1-5$ \\
Ítem27 & $7,4 \%$ & $8,6 \%$ & $22,2 \%$ & $16,0 \%$ & $45,7 \%$ & 3,84 & 1,30 & $1-5$ \\
\hline
\end{tabular}

Tabla 6.13. Descripción del grado de satisfacción de los ítems del QLEQ relacionados con las Actividades de la Casa

\begin{tabular}{|c|c|c|c|c|c|c|c|c|}
\hline \multirow[b]{3}{*}{ Ítem41 } & \multicolumn{6}{|c|}{ Frecuencias } & \multicolumn{2}{|c|}{ Descriptivos } \\
\hline & Nunca & $\begin{array}{l}\text { Casi } \\
\text { Nunca }\end{array}$ & $\begin{array}{c}\text { A } \\
\text { Veces }\end{array}$ & $\begin{array}{c}\text { A } \\
\text { Menudo }\end{array}$ & Siempre & Media & DT & Rango \\
\hline & $4,7 \%$ & $7,0 \%$ & $25,6 \%$ & $34,9 \%$ & $27,9 \%$ & 3,74 & 1,09 & $1-5$ \\
\hline Ítem42 & $10,0 \%$ & $7,5 \%$ & $10,0 \%$ & $15,0 \%$ & $57,5 \%$ & 4,03 & 1,39 & $1-5$ \\
\hline Ítem43 & $2,3 \%$ & $2,3 \%$ & $20,9 \%$ & $30,2 \%$ & $44,2 \%$ & 4,12 & 0,98 & $1-5$ \\
\hline Ítem44 & $7,5 \%$ & $5,0 \%$ & $17,5 \%$ & $20,0 \%$ & $50,0 \%$ & 4,00 & 1,26 & $1-5$ \\
\hline Ítem45 & $10,5 \%$ & $5,3 \%$ & $15,8 \%$ & $26,3 \%$ & $42,1 \%$ & 3,84 & 1,32 & $1-5$ \\
\hline Ítem46 & $4,8 \%$ & $2,4 \%$ & $26,2 \%$ & $33,3 \%$ & $33,3 \%$ & 3,88 & 1,06 & $1-5$ \\
\hline Ítem47 & $7,0 \%$ & $2,3 \%$ & $20,9 \%$ & $23,3 \%$ & $46,5 \%$ & 4,00 & 1,19 & $1-5$ \\
\hline Ítem48 & $9,8 \%$ & $9,8 \%$ & $24,4 \%$ & $19,5 \%$ & $36,6 \%$ & 3,63 & 1,34 & $1-5$ \\
\hline Ítem49 & $7,0 \%$ & $7,0 \%$ & $23,3 \%$ & $25,6 \%$ & $37,2 \%$ & 3,79 & 1,23 & $1-5$ \\
\hline Ítem50 & $19,5 \%$ & $12,2 \%$ & $14,6 \%$ & $14,6 \%$ & $39,0 \%$ & 3,41 & 1,58 & $1-5$ \\
\hline
\end{tabular}

Tabla 6.14. Descripción del grado de satisfacción de los ítems del QLEQ relacionados con las Actividades de Ocio y Tiempo Libre

\begin{tabular}{|l|l|l|c|c|c|c|c|c|}
\hline & \multicolumn{9}{c}{ Frecuencias } & \multicolumn{3}{c|}{ Descriptivos } \\
& Nunca & Casi & $\begin{array}{c}\text { A } \\
\text { Nunca }\end{array}$ & $\begin{array}{c}\text { Veces } \\
\text { Menudo }\end{array}$ & Siempre & Media & DT & Rango \\
Ítem61 & $3,8 \%$ & $9,0 \%$ & $33,3 \%$ & $30,8 \%$ & $23,1 \%$ & 3,60 & 1,06 & $1-5$ \\
Ítem62 & $5,1 \%$ & $3,8 \%$ & $26,9 \%$ & $33,3 \%$ & $30,8 \%$ & 3,81 & 1,08 & $1-5$ \\
Ítem63 & $14,3 \%$ & $13,0 \%$ & $33,8 \%$ & $19,5 \%$ & $19,5 \%$ & 3,17 & 1,30 & $1-5$ \\
Ítem64 & $3,8 \%$ & $10,3 \%$ & $23,1 \%$ & $34,6 \%$ & $28,2 \%$ & 3,73 & 1,10 & $1-5$ \\
Ítem65 & $9,3 \%$ & $6,7 \%$ & $25,3 \%$ & $30,7 \%$ & $28,0 \%$ & 3,61 & 1,23 & $1-5$ \\
Ítem66 & $3,8 \%$ & $11,5 \%$ & $20,5 \%$ & $30,8 \%$ & $33,3 \%$ & 3,78 & 1,15 & $1-5$
\end{tabular}


Tabla 6.15. Descripción del grado de satisfacción de los ítems del QLEQ relacionados con las Relaciones sociales

\begin{tabular}{|c|c|c|c|c|c|c|c|c|}
\hline \multirow[b]{3}{*}{ Ítem67 } & \multicolumn{5}{|c|}{ Frecuencias } & \multicolumn{3}{|c|}{ Descriptivos } \\
\hline & Nunca & $\begin{array}{l}\text { Casi } \\
\text { Nunca }\end{array}$ & $\begin{array}{c}\text { A } \\
\text { Veces }\end{array}$ & $\begin{array}{c}\text { A } \\
\text { Menudo }\end{array}$ & Siempre & Media & DT & Rango \\
\hline & $4,9 \%$ & $6,2 \%$ & $14,8 \%$ & $29,6 \%$ & $44,4 \%$ & 4,02 & 1,14 & $1-5$ \\
\hline Ítem68 & $3,8 \%$ & $5,0 \%$ & $26,3 \%$ & $22,5 \%$ & $42,5 \%$ & 3,95 & 1,11 & $1-5$ \\
\hline Ítem69 & $12,3 \%$ & $12,3 \%$ & $29,6 \%$ & $29,6 \%$ & $16,0 \%$ & 3,25 & 1,23 & $1-5$ \\
\hline Ítem70 & $11,1 \%$ & $6,2 \%$ & $25,9 \%$ & $25,9 \%$ & $30,9 \%$ & 3,59 & 1,30 & $1-5$ \\
\hline Ítem71 & $11,3 \%$ & $11,3 \%$ & $38,8 \%$ & $28,8 \%$ & $10,0 \%$ & 3,15 & 1,11 & $1-5$ \\
\hline Ítem72 & $6,2 \%$ & $8,6 \%$ & $27,2 \%$ & $27,2 \%$ & $30,9 \%$ & 3,68 & 1,18 & $1-5$ \\
\hline Ítem73 & $6,2 \%$ & $1,2 \%$ & $13,6 \%$ & $24,7 \%$ & $54,3 \%$ & 4,20 & 1,12 & $1-5$ \\
\hline Ítem74 & $0 \%$ & $0 \%$ & $9,9 \%$ & $19,8 \%$ & $70,4 \%$ & 4,60 & 0,66 & $3-5$ \\
\hline Ítem75 & $3,7 \%$ & $3,7 \%$ & $22,2 \%$ & $22,2 \%$ & $48,1 \%$ & 4,07 & 1,09 & $1-5$ \\
\hline Ítem76 & $8,9 \%$ & $12,7 \%$ & $21,5 \%$ & $34,3 \%$ & $22,8 \%$ & 3,49 & 1,23 & $1-5$ \\
\hline Ítem77 & $4,9 \%$ & $8,6 \%$ & $18,5 \%$ & $22,2 \%$ & $45,7 \%$ & 3,95 & 1,20 & $1-5$ \\
\hline
\end{tabular}

Tabla 6.16. Descripción del grado de satisfacción de los ítems del QLEQ relacionados con las Actividades Generales

\begin{tabular}{|c|c|c|c|c|c|c|c|c|}
\hline \multirow[b]{3}{*}{ Ítem78 } & \multicolumn{5}{|c|}{ Frecuencias } & \multicolumn{3}{|c|}{ Descriptivos } \\
\hline & $\begin{array}{l}\text { Muy } \\
\text { malo }\end{array}$ & Malo & Regular & Bueno & $\begin{array}{c}\text { Muy } \\
\text { Bueno }\end{array}$ & Media & DT & Rango \\
\hline & $7,4 \%$ & $9,9 \%$ & $30,9 \%$ & $45,7 \%$ & $6,2 \%$ & 3,33 & 1,00 & $1-5$ \\
\hline Ítem79 & $3,7 \%$ & $13,6 \%$ & $30,9 \%$ & $40,7 \%$ & $11,1 \%$ & 3,42 & 0,98 & $1-5$ \\
\hline Ítem80 & $21,2 \%$ & $15,4 \%$ & $17,3 \%$ & $32,7 \%$ & $13,5 \%$ & 3,02 & 1,38 & $1-5$ \\
\hline Ítem81 & $10,1 \%$ & $10,1 \%$ & $23,2 \%$ & $47,8 \%$ & $8,7 \%$ & 3,35 & 1,10 & $1-5$ \\
\hline Ítem82 & $1,2 \%$ & $7,4 \%$ & $17,3 \%$ & $50,6 \%$ & $23,5 \%$ & 3,88 & 0,90 & $1-5$ \\
\hline Ítem83 & $1,2 \%$ & $2,5 \%$ & $12,3 \%$ & $53,1 \%$ & $30,9 \%$ & 4,10 & 0,80 & $1-5$ \\
\hline Ítem84 & $6,2 \%$ & $6,2 \%$ & $17,3 \%$ & $51,9 \%$ & $18,5 \%$ & 3,70 & 1,04 & $1-5$ \\
\hline Ítem85 & $2,5 \%$ & $4,9 \%$ & $28,4 \%$ & $51,9 \%$ & $12,3 \%$ & 3,67 & 0,85 & $1-5$ \\
\hline Ítem86 & $12,8 \%$ & $17,9 \%$ & $28,2 \%$ & $29,5 \%$ & $11,5 \%$ & 3,09 & 1,20 & $1-5$ \\
\hline Ítem87 & $8,6 \%$ & $7,4 \%$ & $28,4 \%$ & $48,1 \%$ & $7,4 \%$ & 3,38 & 1,03 & $1-5$ \\
\hline Ítem 88 & $2,5 \%$ & $1,2 \%$ & $4,9 \%$ & $58,0 \%$ & $33,3 \%$ & 4,19 & 0,80 & $1-5$ \\
\hline Ítem89 & $7,4 \%$ & $6,2 \%$ & $27,2 \%$ & $32,1 \%$ & $27,2 \%$ & 3,65 & 1,16 & $1-5$ \\
\hline Ítem90 & $7,4 \%$ & $12,3 \%$ & $27,2 \%$ & $37,0 \%$ & $16,0 \%$ & 3,42 & 1,12 & $1-5$ \\
\hline Ítem91 & $2,5 \%$ & $9,9 \%$ & $28,4 \%$ & $49,4 \%$ & $9,9 \%$ & 3,54 & 0,90 & $1-5$ \\
\hline Ítem92 & $4,1 \%$ & $1,4 \%$ & $13,5 \%$ & $55,4 \%$ & $25,7 \%$ & 3,97 & 0,90 & $1-5$ \\
\hline Ítem93 & $1,2 \%$ & $6,2 \%$ & $24,7 \%$ & $54,3 \%$ & $13,6 \%$ & 3,73 & 0,82 & $1-5$ \\
\hline
\end{tabular}




\section{OTRAS VARIABLES NEUROPSICOLÓGICAS: CONCIENCIA DE DÉFICIT Y RESERVA COGNITIVA}

En la Tabla 6.17. se presentan las otras variables neuropsicológicas que se han valorado como la reserva cognitiva, que obtiene un valor medio de 11,96 (DT: 5,84 ) lo que indica un nivel medioalto. Concretamente un $23 \%$ de la muestra se encuentra en el nivel superior, el $40,5 \%$ en el rango medio-alto, un $24,3 \%$ presentan un nivel medio-bajo, un y un $12,2 \%$ nivel inferior.

La conciencia de déficit valorada a través del cuestionario de Flemming considera tres aspectos importantes, la conciencia de los déficits actuales, las implicaciones de los déficits y las consecuencias de las implicaciones futuras. El $31,5 \%$ de la muestra presenta buen conocimiento de sus problemas cognitivos y conductuales, el 39,7\% tiene conocimiento de alguno de sus problemas pero otros los desconoce, niega o minimiza, el $27,4 \%$ desconoce los problemas cognitivos/conductuales pero puede reconocer algún déficit aislado y el $1,4 \%$ no reconoce ninguno. En cuanto a la conciencia de las implicaciones de los déficits, el $41,1 \%$ describe de manera adecuada su situación funcional, el $31,5 \%$ conoce algunas implicaciones pero las minimiza o nieva y el $4,1 \%$ no presenta ningún conocimiento de las consecuencias de sus limitaciones. Por último, el $49,3 \%$ tiene objetivos parcialmente realistas respecto a las implicaciones futuras, reconociendo alguna posible dificultad, el $28,8 \%$ manifiesta objetivos poco realistas, creyendo que pronto volverá a su situación premórbida y el $21,9 \%$ de la muestra no reconoce problemas futuros. 
Tabla 6.17. Otras variables neuropsicológicas: Reserva cognitiva y Conciencia de déficit

Reserva cognitiva
Inferior
Medio-bajo
Medio-alto
Superior
Conciencia déficit
Buen conocimiento
Conoce algunos
Reconoce los déficits
No reconoce
Conciencia implicaciones déficit
Descripción adecuada
Alteración funcional aislada
Minimiza o niega
No reconoce consecuencias
Conciencia implicaciones futuras
Objetivos parcialmente realistas
Objetivos poco realistas
No reconoce problemas
Conciencia Total

\begin{tabular}{|c|c|c|c|}
\hline Frecuencia & Media & DT & Rango \\
\hline $12,2 \%$ & 11,96 & 5,839 & $2-31$ \\
\hline $24,3 \%$ & & & \\
$40,5 \%$ & & & \\
$23,0 \%$ & & & \\
\hline & 0,99 & 0,808 & $0-3$ \\
\hline $31,5 \%$ & & & \\
$39,7 \%$ & & & \\
$27,4 \%$ & & & \\
\hline $1,4 \%$ & & & \\
\hline $41,1 \%$ & 0,90 & 0,900 & $0-3$ \\
\hline $31,5 \%$ & & & \\
$23,3 \%$ & & & \\
$4,1 \%$ & & & \\
\hline $49,3 \%$ & 1,73 & 0,804 & $1-3$ \\
$28,8 \%$ & & & \\
$21,9 \%$ & & & \\
& 1,20 & 0,70 & $0,33-2,67$ \\
\hline
\end{tabular}

\section{ANÁLISIS DE CORRELACIONES:}

En primer lugar, para poder verificar la primera hipótesis en la que se espera encontrar una asociación significativa entre algunas variables clínicas de la lesión y variables sociodemográficas y la calidad de vida, el análisis de correlación a través del coeficiente de correlación de Pearson muestra una correlación significativa entre los años de educación, la reserva cognitiva y algunos aspectos de la calidad de vida. Concretamente los años de educación correlacionen de manera significativa $(p<0,05)$ con el QLESQ Ánimo $(0,239)$, QLESQ Casa $(0,267)$, QLESQ Actividades Generales $(0,254)$ y QLESQ Total $(0,234)$, y la reserva cognitiva con QLESQ 
Casa $(0,272 ; p<0,05)$, QLESQ Ocio $(0,244, p<0,05)$ y QLESQ Actividades Generales $(0,239, p<0,05)$. No se observa correlación entre la edad y los diferentes aspectos de la Calidad de Vida.

En segundo lugar se obtuvieron las correlaciones entre las medidas cognitivo-conductuales y la calidad de vida para verificar la segunda hipótesis en la que se espera observar una asociación significativa entre estas variables, de manera que a mayor alteración cognitivo-conductual peor calidad de vida. El análisis de correlación a través del coeficiente de correlación de Pearson muestra, tal y como refleja la Tabla 6.12., una correlación significativa $(p<0,05)$ entre QLESQ Ánimo y el domino cognitivo de atención $(0,235)$ por una parte, y el aprendizaje y memoria $(0,258)$ por otra; así como entre estos dominios y el QLESQ Actividades Generales (atención: 0,242 y aprendizaje y memoria: 0,220). Se observa también una correlación significativa entre la memoria de trabajo y QLESQ Casa $(0,308, p<0,01)$ y entre las alteraciones conductuales propias del Síndrome Disejecutivo valoradas a través del Cuestionario Disejecutivo -DEX- y el QLESQ Total $(-0,285, p<0,05)$ así como como con los dominios Casa $(-0,234, p<0,05)$, Ocio $(-0,350, p<0,01)$, Relaciones ($0,302, p<0,01)$ y Actividades Generales $(-0,318, p<0,01)$ de la Calidad de Vida.

Hay que tener en cuenta que puntuaciones superiores en la medida de la dimensión conductual de las funciones ejecutivas, el DEX-BADS, suponen una mayor alteración conductual por lo que la correlación con los dominios de $\mathrm{CV}$ tienen signo negativo. 
Tabla 6.18. Correlaciones entre los dominios cognitivo-conductuales y la CV.

\begin{tabular}{|c|c|c|c|c|c|c|c|}
\hline & $\begin{array}{l}\text { QLESQ } \\
\text { SALUD }\end{array}$ & $\begin{array}{l}\text { QLESQ } \\
\text { ANIMO }\end{array}$ & $\begin{array}{c}\text { QLESQ } \\
\text { CASA }\end{array}$ & $\begin{array}{c}\text { QLESQ } \\
\text { OCIO }\end{array}$ & $\begin{array}{l}\text { QLESQ } \\
\text { RELAC. }\end{array}$ & $\begin{array}{c}\text { QLESQ } \\
\text { ACT.GRLES }\end{array}$ & $\begin{array}{l}\text { QLESQ } \\
\text { TOTAL }\end{array}$ \\
\hline ATENCIÓN & 0,055 & $0,235^{*}$ & 0,174 & 0,114 & 0,041 & $0,242^{*}$ & 0,168 \\
\hline $\begin{array}{l}\text { APRENDIZAJE } \\
\text { Y MEMORIA }\end{array}$ & 0,106 & $0,258^{*}$ & 0,131 & 0,053 & 0,074 & $0,220^{*}$ & 0,175 \\
\hline $\begin{array}{l}\text { MEMORIA } \\
\text { DE TRABAJO }\end{array}$ & 0,022 & 0,181 & $0,308^{* *}$ & 0,097 & 0,145 & 0,029 & 0,177 \\
\hline $\begin{array}{l}\text { FUNCIONES } \\
\text { EJECUTIVAS }\end{array}$ & $-0,027$ & 0,095 & 0,005 & 0,148 & $-0,031$ & 0,127 & 0,068 \\
\hline $\begin{array}{l}\text { SINDROME } \\
\text { DISEJECUTIVO }\end{array}$ & $-0,151$ & $-0,207$ & $-0,234^{*}$ & $-0,350 * *$ & $-0,302^{* *}$ & $-0,318^{* *}$ & $-0,285 *$ \\
\hline $\begin{array}{l}\text { CONCIENCIA } \\
\text { DE DEFICIT }\end{array}$ & 0,224 & 0,040 & $-0,013$ & 0,044 & $-0,74$ & $-0,037$ & 0,11 \\
\hline
\end{tabular}

Por último, para verificar la tercera hipótesis en la que se espera encontrar una asociación significativa entre el grado de participación y la $\mathrm{CV}$ de manera que los pacientes que presenten menor nivel de participación mostrarán también menor calidad de vida, se realizó también un análisis de correlaciones a través del coeficiente de correlación de Pearson. La calidad de vida total se correlaciona de manera significativa con las medidas totales de participación (FAST: -0,316; $p<0,01$, CHART: 0,290; $p<0,05$ y ClQ-R: 0,472; $p<0,01$ ), no obstante también se observa relación significativa entre las diferentes áreas de CV y varios dominios de participación tal y como se muestra en la Tabla 6.13. Del mismo modo que ocurre con el Cuestionario Disejecutivo, la escala FAST muestra correlaciones negativas dado que a diferencia del resto de escalas de Participación a mayor puntuación, menor grado de participación. 
Tabla 6.19. Correlaciones entre las diferentes medidas de Participación y las de Calidad de Vida.

\begin{tabular}{|c|c|c|c|c|c|c|c|}
\hline & $\begin{array}{l}\text { QLESQ } \\
\text { SALUD }\end{array}$ & $\begin{array}{c}\text { QLESQ } \\
\text { ANIMO }\end{array}$ & $\begin{array}{c}\text { QLESQ } \\
\text { CASA }\end{array}$ & $\begin{array}{c}\text { QLESQ } \\
\text { OCIO }\end{array}$ & $\begin{array}{l}\text { QLESQ } \\
\text { RELAC. }\end{array}$ & $\begin{array}{c}\text { QLESQ } \\
\text { ACT.GR }\end{array}$ & $\begin{array}{l}\text { QLESQ } \\
\text { TOTAL }\end{array}$ \\
\hline \multicolumn{8}{|l|}{ FAST } \\
\hline Total & $-0,159$ & $-0,337 * *$ & $-0,219$ & $-0,249$ & $-0,148$ & $-0,229 *$ & $-0,316^{* *}$ \\
\hline Autonomía & $-0,142$ & $-0,290 * *$ & $-0,213$ & $-0,289$ & $-0,103$ & $-0,160$ & $-0,243^{*}$ \\
\hline Laboral & $-0,166$ & $-0,203$ & $-0,084$ & $-0,057$ & $-0,043$ & $-0,035$ & $-0,152$ \\
\hline Cognición & 0,029 & $-0,118$ & $-0,086$ & $-0,048$ & $-0,029$ & $-0,006$ & $-0,093$ \\
\hline Finanzas & $-0,095$ & $-0,262^{*}$ & $-0,175$ & $-0,247^{*}$ & $-0,217$ & $-0,298 * *$ & $-0,278^{*}$ \\
\hline Relaciones & $-0,084$ & $-0,268 *$ & $-0,210$ & $-0,241^{*}$ & $-0,221^{*}$ & $-0,334^{* *}$ & $-0,294$ \\
\hline Ocio & $-0,205$ & $-0,340 * *$ & $-0,253$ & $-0,283^{*}$ & $-0,098$ & $-0,267^{*}$ & $-0,334^{* *}$ \\
\hline \multicolumn{8}{|l|}{ CHART } \\
\hline Total & 0,165 & $0,301^{* *}$ & 0,186 & $0,235^{*}$ & 0,146 & $0,289 *$ & $0,290 *$ \\
\hline Físico & 0,206 & 0,168 & 0,122 & 0,079 & $-0,009$ & 0,135 & 0,149 \\
\hline Cognitivo & 0,127 & $0,307 * *$ & 0,157 & 0,222 & $-0,012$ & $0,264^{*}$ & 0,223 \\
\hline Movilidad & 0,115 & $0,245^{*}$ & 0,157 & $0,291^{*}$ & 0,152 & $0,352 * *$ & $0,282^{*}$ \\
\hline Ocupación & 0,188 & $0,275^{*}$ & $0,275^{*}$ & $0,300 * *$ & $0,272^{*}$ & 0,179 & $0,336 * *$ \\
\hline Social & $-0,227$ & 0,011 & $-0,164$ & $-0,089$ & 0,138 & 0,148 & $-0,021$ \\
\hline \multicolumn{8}{|l|}{ CIQ-R } \\
\hline Total & 0,257 & $0,475^{* *}$ & $0,355^{* *}$ & $0,426 * *$ & $0,347 * *$ & $0,497 * *$ & $0,472 * *$ \\
\hline Hogar & 0,173 & 0,187 & 0,114 & 0,137 & $-0,057$ & 0,155 & 0,137 \\
\hline Social & 0,120 & $0,350 * *$ & $0,259 *$ & $0,334 * *$ & $0,415^{* *}$ & $0,491 * *$ & $0,379 * *$ \\
\hline Productividad & 0,254 & $0,473^{* *}$ & 0,232 & $0,390 * *$ & $0,404 * *$ & $0,362 * *$ & $0,445^{* *}$ \\
\hline
\end{tabular}

\section{ANÁLISIS DE REGRESIÓN:}

Para finalizar el capítulo de resultados se presentan en este punto los análisis de regresión lineal para analizar el valor predictivo de determinadas variables sobre la $\mathrm{CV}$, mostrándose los resultados en las Tablas 6.20.-6.24.

En primer lugar (Tabla 6.20.) estudiamos el valor predictivo de las variables neuropsicológicas sobre la CV. Las alteraciones de conducta valoradas a través del Cuestionario Disejecutivo -DEX-son las que mayor valor predictivo tienen. Predicen la puntuación Total del QLESQ (8\%) así 
como cada uno de los dominios excepto el de Salud y el de Casa: el primero no está explicado por ninguna de las variables neuropsicológicas, y el segundo está explicado por la memoria (7\%). Las puntuación total del DEX, entonces, predice el 8,4\% de la varianza del QLESQ Total, el $5 \%$ de la del QLESQ Ánimo y el $11 \%$ de la del QLESQ Actividades generales. La varianza del QLESQ Ocio se predice en un $11,9 \%$ por estas alteraciones de conducta, pero al sumarle la conciencia de déficit, llegan a predecir ambas variables el $16,7 \%$. De manera similar ocurre con el QLESQ Relaciones, el DEX total predice el $8,6 \%$ de su varianza, al sumarle las funciones ejecutivas llegan a explicar el $13 \%$ y si además se añade la memoria, las tres variables explican un total del $17,3 \%$ de la varianza del QLESQ Relaciones.

Tabla 6.20. Variables neuropsicológicas predictoras de CV mediante Análisis de Regresión Lineal.

\begin{tabular}{|c|c|c|c|c|}
\hline $\begin{array}{c}\text { VBLE. } \\
\text { DEPENDIENTE }\end{array}$ & MODELO & $\begin{array}{l}\text { VBLE. } \\
\text { PREDICTORA }\end{array}$ & $\begin{array}{c}\mathbf{R}^{2} \\
\text { CORREGIDA }\end{array}$ & $\begin{array}{l}\text { SIGNIFICACIÓN } \\
\text { (p) }\end{array}$ \\
\hline $\begin{array}{l}\text { QLESQ } \\
\text { TOTAL }\end{array}$ & 1 & DEX TOTAL & 0,084 & 0,012 \\
\hline $\begin{array}{l}\text { QLESQ } \\
\text { SALUD }\end{array}$ & - & [ninguna] & -- & n.s. \\
\hline $\begin{array}{l}\text { QLESQ } \\
\text { ANIMO }\end{array}$ & 1 & DEX TOTAL & 0,050 & 0,039 \\
\hline $\begin{array}{l}\text { QLESQ } \\
\text { CASA }\end{array}$ & 1 & MEMORIA & 0,070 & 0,020 \\
\hline \multirow{2}{*}{$\begin{array}{c}\text { QLESQ } \\
\text { OCIO }\end{array}$} & 1 & DEX TOTAL & 0,119 & 0,003 \\
\hline & 2 & $\begin{array}{c}\text { DEX TOTAL + } \\
\text { CONCIENCIA DÉFICIT }\end{array}$ & 0,167 & 0,001 \\
\hline \multirow{3}{*}{$\begin{array}{c}\text { QLESQ } \\
\text { RELACIONES }\end{array}$} & 1 & DEXTOTAL & 0,086 & 0,009 \\
\hline & 2 & $\begin{array}{c}\text { DEX TOTAL + } \\
\text { FUNCIONES EJECUTIVAS }\end{array}$ & 0,130 & 0,004 \\
\hline & 3 & $\begin{array}{c}\text { DEX TOTAL + } \\
\text { FUNCIONES EJECUTIVAS+ } \\
\text { MEMORIA }\end{array}$ & 0,173 & 0,002 \\
\hline $\begin{array}{c}\text { QLESQ } \\
\text { ACTIVIDADES } \\
\text { GENERALES }\end{array}$ & 1 & DEX TOTAL & 0,109 & 0,004 \\
\hline
\end{tabular}


En segundo lugar realizamos los análisis de regresión con las diferentes escalas de participación como variables predictoras de CV. Por lo que respecta al CHART (Tabla 6.21), es el dominio de Ocupación el que más peso tienes sobre CV, explicando el $10,1 \%$ de la varianza del QLESQ Total, el 8,3\% de la del QLESQ Casa, el 7,8\% del QLESQ Ocio, el 6,2\% del QLESQ Relaciones y el 7,9\% del QLESQ Salud al incluir en este modelo el CHART social. Por su parte, el CHART cognitivo predice el $8,3 \%$ de la varianza del QLESQ Ánimo y el CHART Movilidad el $11,2 \%$ de la del QLESQ Actividades Generales.

Tabla 6.21. CHART como predictor de CV mediante Análisis de Regresión Lineal.

\begin{tabular}{|c|c|c|c|c|}
$\begin{array}{c}\text { VBLE. } \\
\text { DEPENDIENTE } \\
\begin{array}{c}\text { QLESQ } \\
\text { TOTAL }\end{array}\end{array}$ & MODELO & $\begin{array}{c}\text { VBLE. } \\
\text { PREDICTORA }\end{array}$ & $\begin{array}{c}\mathbf{R}^{\mathbf{2}} \\
\text { CORREGIDA }\end{array}$ & $\begin{array}{c}\text { SIGNIFICACIÓN } \\
(\mathbf{p})\end{array}$ \\
\hline $\begin{array}{c}\text { QLESQ } \\
\text { SALUD }\end{array}$ & 1 & CHART OCUPACIÓN & 0,101 & 0,003 \\
\hline $\begin{array}{c}\text { QLESQ } \\
\text { ANIMO }\end{array}$ & 1 & CHART SOCIAL & 0,039 & 0,045 \\
$\begin{array}{c}\text { QLESQ } \\
\text { CASA }\end{array}$ & 1 & $\begin{array}{c}\text { CHART SOCIAL + } \\
\text { CHART OCUPACIÓN }\end{array}$ & 0,079 & 0,016 \\
$\begin{array}{c}\text { QLESQ } \\
\text { OCIO }\end{array}$ & 1 & CHART COGNITIVO & 0,083 & 0,006 \\
$\begin{array}{c}\text { QLESQ } \\
\text { RELACIONES }\end{array}$ & 1 & CHART OCUPACIÓN & 0,078 & 0,008 \\
$\begin{array}{c}\text { QLESQ } \\
\text { ACTIVIDADES } \\
\text { GENERALES }\end{array}$ & 1 & CHART OCUPACIÓN & 0,062 & 0,015 \\
\hline
\end{tabular}

En cuanto al valor predictivo del cuestionario CIQ-R (Tabla 6.22), únicamente los dominios Social y Productividad predicen la CV. EI CIQ-R Productividad predice de manera aislada la varianza del QLESQ Salud y 
QLESQ Ocio un 5,8\% y un 14,5\%, respectivamente. Si al modelo se le añade el QLEQ Social, las dos variables explican el 23,9\% de la varianza del QLESQ Total, el 25,9\% de la del QLESQ Ánimo, el 22,9\% de la del QLESQ Relaciones y el $27 \%$ de la del QLESQ Actividades Generales.

Tabla 6.22. CIQ-R como predictor de CV mediante Análisis de Regresión Lineal.

\begin{tabular}{|c|c|c|c|c|}
\hline $\begin{array}{l}\text { VBLE. } \\
\text { DEPENDIENTE }\end{array}$ & MODELO & $\begin{array}{l}\text { VBLE. } \\
\text { PREDICTORA }\end{array}$ & $\begin{array}{c}\mathbf{R}^{2} \\
\text { CORREGIDA }\end{array}$ & SIGNIFICACIÓN (p) \\
\hline \multirow{2}{*}{$\begin{array}{l}\text { QLESQ } \\
\text { TOTAL }\end{array}$} & 1 & CIQ-R PRODUCTIVIDAD & 0,186 & $<0,001$ \\
\hline & 2 & $\begin{array}{c}\text { CIQ-R PRODUCTIVIDAD + } \\
\text { CIQ-R SOCIAL }\end{array}$ & 0,239 & $<0,001$ \\
\hline $\begin{array}{l}\text { QLESQ } \\
\text { SALUD }\end{array}$ & 1 & CIQ-R PRODUCTIVIDAD & 0,058 & 0,022 \\
\hline \multirow{2}{*}{ QLESQ ANIMO } & 1 & CIQ-R PRODUCTIVIDAD & 0,213 & $<0,001$ \\
\hline & 2 & $\begin{array}{c}\text { CIQ-R PRODUCTIVIDAD + } \\
\text { CIQ-R SOCIAL }\end{array}$ & 0,259 & $<0,001$ \\
\hline $\begin{array}{l}\text { QLESQ } \\
\text { CASA }\end{array}$ & 1 & CIQ-R SOCIAL & 0,057 & 0,029 \\
\hline $\begin{array}{l}\text { QLESQ } \\
\text { OCIO }\end{array}$ & 1 & CIQ-R PRODUCTIVIDAD & 0,145 & 0,001 \\
\hline \multirow{2}{*}{$\begin{array}{c}\text { QLESQ } \\
\text { RELACIONES }\end{array}$} & 1 & CIQ-R SOCIAL & 0,149 & $<0,001$ \\
\hline & 2 & $\begin{array}{c}\text { CIQ-R SOCIAL + } \\
\text { CIQ-R PRODUCTIVIDAD }\end{array}$ & 0,229 & $<0,001$ \\
\hline \multirow{2}{*}{$\begin{array}{c}\text { QLESQ } \\
\text { ACTIVIDADES } \\
\text { GENERALES }\end{array}$} & 1 & CIQ-R SOCIAL & 0,223 & $<0,001$ \\
\hline & 2 & $\begin{array}{c}\text { CIQ-R SOCIAL + } \\
\text { CIQ-R PRODUCTIVIDAD }\end{array}$ & 0,270 & $<0,001$ \\
\hline
\end{tabular}

Respecto al cuestionario FAST, es el que menos valor predictivo tiene sobre la CV (Tabla 6.23). La subescala Ocio explica un 9,9\% de la varianza del QLESQ Total, un 10,4\% de la del QLESQ Ánimo y un 5,1\% de la del QLESQ Casa. El FAST autonomía un 7,1\% del QLEQ Ocio, y el FAST relaciones un 3,7\% y un 10\% del QLESQ Relaciones y del QLES Actividades Generales, respectivamente. 
Tabla 6.23. FAST como predictor de CV mediante Análisis de Regresión Lineal.

\begin{tabular}{|c|c|c|c|c|}
\hline $\begin{array}{c}\text { VBLE. } \\
\text { DEPENDIENTE }\end{array}$ & MODELO & $\begin{array}{c}\text { VBLE. } \\
\text { PREDICTORA }\end{array}$ & $\mathrm{R}^{2}$ CORREGIDA & SIGNIFICACIÓN (P) \\
\hline QLESQ TOTAL & 1 & FAST OCIO & 0,099 & 0,003 \\
\hline QLESQ SALUD & - & [ninguna] & -- & N.S. \\
\hline QLESQ ANIMO & 1 & FAST OCIO & 0,104 & 0,002 \\
\hline QLESQ CASA & 1 & FAST OCIO & 0,051 & 0,032 \\
\hline QLESQ OCIO & 1 & FAST AUTONOMIA & 0,071 & 0,011 \\
\hline $\begin{array}{c}\text { QLESQ } \\
\text { RELACIONES }\end{array}$ & 1 & FAST RELACIONES & 0,037 & 0,049 \\
\hline $\begin{array}{c}\text { QLESQ } \\
\text { ACTIVIDADES } \\
\text { GENERALES }\end{array}$ & 1 & FAST RELACIONES & 0,100 & 0,003 \\
\hline
\end{tabular}

Por último, se muestran los análisis predictivos incluyendo únicamente las variables que en los modelos de regresión anteriores han resultado significativas para poder así valorar si la suma de varias de ellas predicen en mayor medida la CV (Tabla 6.24). De esta manera, para cada uno de los dominios del QLESQ se observa lo siguiente:

El $28,7 \%$ de la varianza del QLESQ Total se explica por la suma del CIQ-R Productividad, CIQ-R Social y CHART Social. La suma de la Conciencia total, el FAST Ocio y el DEX Total predicen el 20\% de la varianza del QLESQ Salud. El 34,5\% de la varianza del QLEQ Ánimo se explica por la unión del CIQ-R Productividad, el CIQ-R Social y el FAST Ocio, el 17,2 \% de la del QLEQ Casa por el CHART Social y el CIQ-R Social y el $31,4 \%$ de la del QLEQ Ocio se explica por la suma del CIQ-R Productividad, el DEX Total, la Conciencia de déficit Total y el FAST Relaciones. Por su parte, la varianza del QLEQ Relaciones se predice en el 35,2\% por el CIQ-R Productividad, CIQ-R Social, CHART Cognitivo y DEX Total. Finalmente el $26,1 \%$ de la varianza del QLEQ Actividades Generales se predice por la suma del CIQR Social y el CIQ-R Productividad. 
Tabla 6.24. Análisis de regresión lineal introduciendo como predictores las variables neuropsicológicas, y las tres escalas de participación.

\begin{tabular}{|c|c|c|c|c|}
\hline $\begin{array}{c}\text { VBLE. } \\
\text { DEPENDIENTE }\end{array}$ & MODELO & $\begin{array}{c}\text { VBLE. } \\
\text { PREDICTORA }\end{array}$ & $\begin{array}{c}R^{2} \\
\text { CORREGIDA }\end{array}$ & $\begin{array}{l}\text { SIGNIFICACIÓN } \\
\text { (p) }\end{array}$ \\
\hline \multirow{3}{*}{$\begin{array}{l}\text { QLESQ } \\
\text { TOTAL }\end{array}$} & 1 & CIQ-R PRODUCTIVIDAD & 0,188 & 0,000 \\
\hline & 2 & $\begin{array}{c}\text { CIQ-R PRODUCTIVIDAD + } \\
\text { CIQ-R SOCIAL }\end{array}$ & 0,240 & 0,000 \\
\hline & 3 & $\begin{array}{c}\text { CIQ-R PRODUCTIVIDAD + } \\
\text { CIQ-R SOCIAL+ } \\
\text { CHART SOCIAL }\end{array}$ & 0,287 & 0,000 \\
\hline \multirow{3}{*}{$\begin{array}{l}\text { QLESQ } \\
\text { SALUD }\end{array}$} & 1 & CONCIENCIA TOTAL & 0,054 & 0,039 \\
\hline & 2 & $\begin{array}{l}\text { CONCIENCIA TOTAL+ } \\
\text { FAST OCIO }\end{array}$ & 0,132 & 0,006 \\
\hline & 3 & $\begin{array}{l}\text { CONCIENCIA TOTAL+ } \\
\text { FAST OCIO+ } \\
\text { DEX TOTAL }\end{array}$ & 0,200 & 0,001 \\
\hline \multirow{3}{*}{$\begin{array}{l}\text { QLESQ } \\
\text { ANIMO }\end{array}$} & 1 & CIQ-R PRODUCTIVIDAD & 0,216 & 0,000 \\
\hline & 2 & $\begin{array}{c}\text { CIQ-R PRODUCTIVIDAD+ } \\
\text { CIQ-R SOCIAL }\end{array}$ & 0,290 & 0,000 \\
\hline & 3 & $\begin{array}{c}\text { CIQ-R PRODUCTIVIDAD+ } \\
\text { CIQ-R SOCIAL+ } \\
\text { FAST OCIO }\end{array}$ & 0,345 & 0,000 \\
\hline \multirow{2}{*}{$\begin{array}{l}\text { QLESQ } \\
\text { CASA }\end{array}$} & 1 & CHART SOCIAL & 0,059 & 0,036 \\
\hline & 2 & $\begin{array}{l}\text { CHART SOCIAL+ } \\
\text { CIQ-R SOCIAL }\end{array}$ & 0,172 & 0,002 \\
\hline \multirow{4}{*}{$\begin{array}{l}\text { QLESQ } \\
\text { OCIO }\end{array}$} & 1 & CIQ-R PRODUCTIVIDAD & 0,160 & 0,001 \\
\hline & 2 & $\begin{array}{c}\text { CIQ-R PRODUCTIVIDAD+ } \\
\text { DEX TOTAL }\end{array}$ & 0,215 & 0,000 \\
\hline & 3 & $\begin{array}{l}\text { CIQ-R PRODUCTIVIDAD+ } \\
\text { DEX TOTAL+ } \\
\text { CONCIENCIA TOTAL }\end{array}$ & 0,257 & 0,000 \\
\hline & 4 & $\begin{array}{l}\text { CIQ-R PRODUCTIVIDAD+ } \\
\text { DEX TOTAL+ } \\
\text { CONCIENCIA TOTAL+ } \\
\text { FAST RELACIONES }\end{array}$ & 0,314 & 0,000 \\
\hline \multirow{4}{*}{$\begin{array}{c}\text { QLESQ } \\
\text { RELACIONES }\end{array}$} & 1 & CIQ-R PRODUCTIVIDAD & 0,130 & 0,002 \\
\hline & 2 & $\begin{array}{l}\text { CIQ-R PRODUCTIVIDAD+ } \\
\text { CIQ-R SOCIAL }\end{array}$ & 0,190 & 0,001 \\
\hline & 3 & $\begin{array}{l}\text { CIQ-R PRODUCTIVIDAD+ } \\
\text { CIQ-R SOCIAL+ } \\
\text { CHART COGNITIVO }\end{array}$ & 0,269 & 0,000 \\
\hline & 4 & $\begin{array}{c}\text { CIQ-R PRODUCTIVIDAD+ } \\
\text { CIQ-R SOCIAL+ } \\
\text { CHART COGNITIVO+ } \\
\text { DEX TOTAL }\end{array}$ & 0,352 & 0,000 \\
\hline \multirow{2}{*}{$\begin{array}{l}\text { QLESQ } \\
\text { ACTIVIDADES } \\
\text { GENERALES }\end{array}$} & 1 & CIQ-R SOCIAL & 0,197 & 0,000 \\
\hline & 2 & $\begin{array}{c}\text { CIQ-R SOCIAL+ } \\
\text { CIQ-R PRODUCTIVIDAD }\end{array}$ & 0,261 & 0,000 \\
\hline
\end{tabular}




\section{Discusión}

Predictores de Calidad de Vida en pacientes con Daño Cerebral Adquirido: Déficit, Actividad y Participación 

La presente tesis doctoral se ha centrado en el estudio de los predictores de calidad de vida en pacientes con daño cerebral, estableciendo como marco teórico la Clasificación Internacional de Funcionamiento, Discapacidad y Salud. Para ello se han analizado los dominios referentes al déficit, actividad y participación como potenciales predictores, a partir de la realización de una valoración neuropsicológica que incluía medidas cognitivas, conductuales, de actividad y de participación. Para poder comprobar las hipótesis de estudio se han realizado análisis correlacionales y predictivos conociendo, de esta manera, cuáles son las variables que más se asocian con la calidad de vida y cuáles de ellas la predicen.

En primer lugar, los resultados de nuestro trabajo han permitido confirmar la presencia de alteraciones neuropsicológicas como consecuencia del daño cerebral adquirido, observando un rendimiento cognitivo significativamente inferior al de la población general. Al mismo tiempo, en esta muestra de pacientes se observa una desregulación conductual y emocional asociadas a la disfunción ejecutiva, con manifestaciones tales como apatía, impulsividad o dificultades en la capacidad de planificación, entre otras. Por lo que respecta a la limitación funcional, se observa baja participación por parte de los pacientes en algunos ámbitos de su vida, especialmente en los referentes a la productividad-ocupación. Los resultados relacionados con la calidad de vida demuestran la presencia de un mayor grado de satisfacción en los aspectos relacionados con las relaciones sociales, y peor satisfacción en las cuestiones vinculadas con las actividades generales. Igualmente, se observó una relación significativa inversa entre calidad de vida y frecuencia de alteraciones de conducta que presenta el paciente, así como una relación positiva entre niveles de calidad de vida y grado de participación, quedando validada de esta manera la tercera hipótesis planteada sobre la existencia de una asociación entre estas dos últimas 
variables. Por último, los análisis de regresión demuestran que el dominio con mayor valor predictivo sobre la percepción de calidad de vida es la participación, comparado con el déficit y la actividad. Más concretamente, serían la participación social y participación relacionada con la productividad los dominios con mayor valor predictivo. En consecuencia, quedan confirmadas las dos últimas hipótesis de estudio que postulaban la existencia de un valor predictivo de la participación sobre la calidad de vida mayor que el que proporcionaba el déficit o la actividad, y que entre los dominios de participación, las relaciones sociales predecían mejor la calidad de vida.

A continuación se discuten los principales resultados para los análisis descriptivos, correlacionales y de regresión lineal en relación a la literatura existente en este ámbito de estudio. En primer lugar, nos centraremos en el perfil neuropsicológico y funcional, así como de calidad de vida que presentan los pacientes con DCA. A este respecto, los resultados de la presente tesis doctoral sugieren la presencia de alteraciones neuropsicológicas como consecuencia del daño cerebral adquirido, en total consonancia con diversas fuentes bibliográficas (BenYishay, 1993; Bour, Rasquin, Limburg, \& Verhey, 2011; Lezak, Howieson, \& Loring, 2004; Prigatano, 1992; van de Weg, Kuik, \& Lankhorst, 1999). A nivel cognitivo, tanto la capacidad atencional como de memoria de trabajo, de aprendizaje y memoria, y funcionamiento ejecutivo se encuentran ligera o moderadamente alteradas en casi la mitad de la muestra (entre el 39,3\% y el 49,4\% del total, dependiendo de la función), siendo la función atencional en la que encontramos un rendimiento menor. Por lo que respecta a las alteraciones de conducta, las que presentan los pacientes con más frecuencia, según refieren los familiares en el Cuestionario Disejecutivo, son impaciencia, despreocupación por las reglas sociales, distractibilidad, planificación, euforia, dificultad en la toma de decisiones, apatía y falta de iniciativa e impulsividad. Esta última 
también se evidencia en una de las pruebas que valoran las funciones cognitivas como dominio cognitivo, concretamente el índice de comisiones del test CPT-II, en que el $90 \%$ de la muestra presenta una importante alteración.

Los resultados de este trabajo también muestran la presencia de limitaciones a nivel funcional en estos pacientes con lesión cerebral, tal y como evidencian otros estudios (Novack \& Alderson, 2000; Ponsford, Draper, \& Schönberger, 2008). En las medidas de independencia funcional-participación, donde mayor grado de participación presentan los pacientes de esta muestra sería en los ámbitos sociales, mientras que es mucho menor en los ámbitos laborales y de ocupación-productividad. Estos resultados coinciden con los publicados por otros estudios anteriores (Novack \& Alderson, 2000; Ponsford et al., 2008). Igualmente, estos hallazgos van en la misma línea que los datos sociodemográficos referidos a la situación laboral, indicando que aproximadamente el $80 \%$ de los pacientes no estaban trabajando en el momento de la valoración, encontrándose con una pensión de invalidez, de jubilación o una incapacidad temporal. La baja prevalencia de actividad laboral coincide con los datos publicados por la Fundación ONCE (ONCE, 2014) en su estudio sobre el Daño Cerebral y la inserción laboral en el que confirman que el $42,86 \%$ de las personas con DCA se encuentran jubiladas o prejubiladas por incapacidad laboral. En la misma línea, Luna-Lario y colaboradores (Luna-Lario, Blanco-Beregaña, Tirapu-Ustárroz, Ojeda, \& Mata-Pator, 2013), en su estudio con 129 pacientes con DCA se le reconoció la discapacidad al $85 \%$ de los solicitantes, por factores psíquicos o físicos y al $89 \%$ por factores únicamente psíquicos, y se demostró que el déficit de memoria fue un factor decisivo para explicar las dificultades de volver al empleo. 
Para analizar el grado de participación de nuestros pacientes se revisaron las escalas existentes en la literatura relacionadas con la evaluación de este constructo, tal y como se define desde el modelo CIF, debiendo incluir por lo menos los dominios de habilidades comunicativas y/o cognitivas, capacidad para moverse por el entorno, cuidado personal, relaciones sociales y personales, actividades de la vida diaria y vida social. Para valorar el grado de independencia funcional-participación, muchos de los estudios revisados (Hall, Bushnik, Lakisic-Kazazic, Wright, \& Cantagallo, 2001; Hammond et al., 2001; Kashluba, Hanks, Casey, \& Millis, 2008) utilizan medidas acerca de la capacidad del individuo para el desempeño de una determinada acción o actividad -tales como el Índice de Barthel, el Funcional Assessment Measure, o el Disability Rating Scale, entre otras-, pero no medidas sobre si la persona efectivamente realiza o no esa acción. Es decir, emplean instrumentos de evaluación que, por la formulación de sus ítems, miden en realidad -en términos de la CIF- el grado de actividad y no el de participación. Tras la revisión de la literatura bibliográfica, se seleccionaron la Escala FAST y los Cuestionarios CIQ-R y el CHART, coincidiendo estos dos últimos con la propuesta del programa del Sistema Modelo de Daño Cerebral Traumático (The Traumatic Brain Injury Model Systems -TBIMS-) patrocinado por el Instituto Nacional de Discapacidad, Vida Independiente e Investigación en Rehabilitación de Estados Unidos (National Institute on Disability, Independent Living, and Rehabilitation Research -NIDILRR-) (Bushnik, 2003). Estos cuestionarios, aparte de ser unos instrumentos validados con correctas características psicométricas por su elevada fiabilidad y validez, y haber sido utilizados en otros estudios con pacientes con DCA (Devitt et al., 2006; Hall et al., 2001), están estructurados de manera que permiten reconocer los dominios que está evaluando. Por tanto, los cuestionarios utilizados finalmente nos permitieron valorar los nueve dominios de Actividad y Participación que incluye la CIF: Aprendizaje y aplicación de 
conocimientos, Tareas y demandas generales, Comunicación, Movilidad, Autocuidado, Vida doméstica, Interacciones y relaciones interpersonales, Áreas principales de la vida y Vida comunitaria, cívica y social.

De forma similar, en relación a las escalas para valorar el grado de Calidad de Vida subjetiva, se eligió la escala Q-LES-Q porque igualmente recogía los dominios contemplados por la CIF. A este respecto, los resultados obtenidos en la presente tesis doctoral sobre la percepción de calidad de vida sugieren que los aspectos relacionados con las actividades generales, concretamente los que tienen que ver con la satisfacción en el trabajo o en el interés y desempeño sexual, son donde globalmente el paciente percibe un menor grado de satisfacción. El segundo dominio con menor grado de satisfacción es el que se refiere al estado de salud física, específicamente en la sensación de estar lleno de energía y vitalidad, así como en la preocupación sobre el propio estado de salud. Por su parte, la muestra de pacientes de nuestro estudio percibe un mayor grado de satisfacción en lo referente a las relaciones sociales. En esta línea, diversas investigaciones que estudian la calidad de vida en esta población de pacientes, han observado un bajo nivel de satisfacción en diferentes áreas como el desempeño de roles a causa de limitación física (Jönsson, Lindgren, Hallström, Norrving, \& Lindgren, 2005), la interacción social (Kwok et al., 2006), el rendimiento sexual y actividades de tiempo libre (Koskinen, 1998), así como en el ámbito de salud y funcionamiento (Jaracz \& Kozubski, 2003). Dichos estudios relacionaron la calidad de vida con factores como la edad, el género y el estado funcional (Jönsson et al., 2005), el estado de ánimo e interacción social (Kwok et al., 2006), las alteraciones emocionales y conductuales (Koskinen, 1998) o el soporte familiar, la depresión y la dependencia física (Jaracz \& Kozubski, 2003), entre otros. 
En relación a los resultados sobre los análisis de correlación entre la calidad de vida y el resto de variables incluidas en el presente estudio, una de las principales hipótesis planteadas predecía que una mayor gravedad de las alteraciones neuropsicológicas se asociaría a peores niveles de calidad de vida. En este sentido, hemos hallado que efectivamente la gravedad de las alteraciones conductuales y emocionales se relaciona significativa y negativamente con la calidad de vida total. En cuanto al rendimiento cognitivo, nuestros resultados muestran una correlación significativa entre algunas funciones cognitivas y diferentes dominios de calidad de vida, concretamente entre la capacidad atencional y la de aprendizaje y memoria con los dominios de ánimo y de actividades generales. No obstante, no se observa ninguna asociación entre el funcionamiento cognitivo y la medida de calidad de vida total, un hallazgo consistentemente replicado en la literatura científica. De hecho, diferentes investigaciones que han explorado la relación entre diferentes variables clínicas y calidad de vida han encontrado una asociación entre la calidad de vida percibida y el rendimiento cognitivo (Adamit et al., 2015; Azouvi et al., 2016; Jönsson et al., 2005) .Sin embargo, en algunos de estos trabajos (Azouvi et al., 2016; Jönsson et al., 2005) el cálculo del rendimiento cognitivo se realizó a través de medidas de screening (Neurobehavioural Rating Scale-Revised y Mini Mental State Examination), que no ofrecen baremos en función de las características concretas de la población y presentan un efecto techo importante. Por su parte, el trabajo de Adamit et al. (2015) nos parece especialmente relevante dado que estudia los factores asociados a la calidad de vida en DCA a través de dominios cognitivos específicos y no mediante una medida general de rendimiento cognitivo. Si bien utiliza el instrumento MoCa (Montreal Cognitive Assessment) para valorar la cognición, emplea una medida concreta de funciones ejecutivas que permite evaluar cinco componentes ejecutivos: iniciación de tarea, 
organización, secuenciación, capacidad de juicio y finalización de tareas. No obstante, sus resultados son parcialmente diferentes a los de nuestro trabajo, puesto que también observan una correlación significativa entre la alteración conductual y la percepción de calidad de vida, pero no encuentran relación entre ésta y la participación.

Por el contrario, el estudio llevado a cabo por Chou (2015), en el que se incluyeron factores sociodemográficos, aspectos cognitivos y psicosociales como posibles predictores de calidad de vida, sugiere que la participación social auto-informada, la limitación de la actividad y la capacidad de comunicación (considerando tanto lenguaje como habilidades comunicativas) parecen ser fuertes determinantes de CV. En esta línea, destacamos el estudio de Visser-Meily y colaboradores en pacientes con hemorragia subaracnoidea secundario a un aneurisma, el cual pretendía valorar la relación entre calidad de vida y las características sociodemográficas y sintomatología psicológica, incluyendo la presencia de quejas cognitivas junto con estado de ánimo y fatiga (Visser-Meily, Rhebergen, Rinkel, van Zandvoort, \& Post, 2009). Sus resultados mostraron una asociación significativa entre una menor percepción de calidad de vida y el perfil psicológico (fatiga, estado de ánimo y quejas cognitivas) y los estilos de afrontamiento pasivo. Más concretamente, observaron que un menor grado de fatiga, un menor número de quejas cognitivas y un mayor estado de ánimo se relacionaban con una mayor percepción de calidad de vida total. En resumen, nuestros hallazgos respecto a la asociación entre calidad de vida y la presencia de alteraciones conductuales son coherentes con los resultados de otros trabajos (Adamit et al., 2015; Azouvi et al., 2016; Chou, 2015; Visser-Meily et al., 2009). Sin embargo, no existe esta coincidencia en cuanto a la posible relación entre cognición y calidad de vida. Las discrepancias pueden explicarse por el hecho de que en algunos casos las medidas de rendimiento cognitivo utilizadas son herramientas de cribado y en otros 
casos no se refieren a rendimiento cognitivo objetivo sino quejas subjetivas al respecto, por lo que sería coherente que correlacione con la percepción de calidad de vida por el propio carácter subjetivo de la misma.

Otra de las hipótesis planteadas en el presente trabajo esperaba encontrar una asociación entre el grado de independencia funcionalparticipación y la percepción de calidad de vida. Nuestros resultados demuestran que todas las medidas de participación correlacionan significativamente tanto con los diferentes dominios de calidad de vida como con su medida total, de manera que aquellos pacientes con mayor grado de participación presentan mayor percepción de calidad de vida.

Los estudios publicados por otros autores (Almkvist Muren, Hütler, \& Hooper, 2008; Chang et al., 2016; dos Santos Oliveira, Moreno Valdes, \& da Silva, 2011; Langhammer, Stanghelle, \& Lindmark, 2008; Scholten et al., 2015) muestran resultados similares a los nuestros, revelando una asociación significativa entre la calidad de vida y diferentes variables de actividad e independencia funcional. No obstante, las medidas de independencia funcional-participación utilizadas en estos trabajos revisados responden en realidad a conceptos muy diversos, desde independencia para el desempeño de las actividades de la vida diaria, gravedad del daño, independencia funcional, incluso percepción del propio paciente respecto a la capacidad para desempeñar determinadas actividades, con la posible interferencia que puede suponer la falta de conciencia de déficit frecuentemente asociada a pacientes con daño cerebral.

Teniendo en cuenta cada una de las subescalas de las medidas de participación que hemos utilizado, la mayoría de ellas muestran una correlación significativa con al menos dos dominios del cuestionario de calidad de vida. Cabe destacar la escasa asociación entre los aspectos 
físicos y cognitivos de los cuestionarios FAST y CHART y la calidad de vida, relacionándose únicamente con el dominio Ánimo del Cuestionario de calidad de vida. Este hallazgo puede parecer contradictorio a los señalados previamente (Almkvist Muren et al., 2008; Chang et al., 2016; dos Santos Oliveira et al., 2011; Langhammer et al., 2008; Scholten et al., 2015) donde se evidenciaba una relación entre aspectos físicos y CV. Una vez más consideramos que la fuente de discrepancia tiene que ver con el tipo de medidas utilizadas (relativas a déficit, actividad o participación) y los instrumentos empleados para ello. En nuestro estudio, de los tres que hemos utilizado, el que muestra mayor tamaño del efecto es el CIQ-R ya que su grado de correlación con la medida de calidad de vida total es mayor que el de los otros. Además todos los dominios del cuestionario de calidad de vida se asocian de manera significativa con al menos un par de subescalas del CIQ-R. Este hecho parece estar relacionado con que el CIQ$\mathrm{R}$ evalúa el grado de participación a través de preguntas relacionadas sobre si el paciente desempeña o no una determinada área de funcionamiento (por ejemplo, encargarse de las tareas de la casa, hacer la compra, aprender nueva información, hacer cálculos mentales, etc.) o con qué frecuencia la realiza, mientras que el FAST hace referencia a la actividad al preguntar acerca de la dificultad que presenta el paciente para realizarla.

El uso de estos cuestionarios multidimensionales en esta investigación nos ha permitido conocer la implicación de cada uno de los dominios de participación sobre la calidad de vida. La fuerte relación observada entre estas variables junto la escasa asociación entre la CV y las variables clínicas del déficit tanto físicas como neuropsicológicas, nos recuerdan que la percepción de calidad de vida y grado de satisfacción están mediados por multitud de variables personales e individuales, apoyando su carácter subjetivo, por definición. En este sentido, a diferencia de lo que cabría esperar en una primera aproximación, no 
resulta tan importante el déficit como el grado de participación en sí, coincidiendo con lo que proponen Kwok y colaboradores (Kwok, Pan, Lo, \& Song, 2011).

Respecto a la predicción de la calidad de vida, una de las hipótesis principales del presente estudio era que las medidas de participación serían mejores predictores de la CV resultante en pacientes con DCA que las medidas de déficit y actividad. En efecto, hemos hallado que las variables clínicas del déficit y de la actividad como son el diagnóstico principal, la etiología del daño, el trastorno motor y el Índice de Barthel al alta, no contribuían a predecir la CV. Entre las variables neuropsicológicas, aunque la función mnésica, las alteraciones de conducta y la conciencia de déficit explicaban algunos de los dominios del cuestionario de calidad de vida, muestran un bajo valor predictivo (8,4\% del QLESQ Total, 5\% del dominio Ánimo, 7\% del de Casa, 16,7\% del de Ocio, 17,3\% de Relaciones y $10,9 \%$ del QLESQ Actividades Generales. El dominio de Salud no se explica por ninguna variable). En cambio, todas las medidas de participación predecían a través de alguno de sus dominios la calidad de vida total, explicando hasta el $29 \%$ de la varianza de la misma.

En este sentido, el estudio realizado por Corrigan, Bogner, Mysiw, Clinchot y Fugate (2001) mostró que tener un empleo remunerado en el momento del seguimiento estaba asociado con mayor satisfacción en la vida, tanto 1 como 2 años después de la lesión. La integración social y la ausencia de estado de ánimo depresivo predecían a los 2 años de seguimiento un $8, \%$ y un $16,5 \%$ de la varianza de la satisfacción vital, respectivamente. En el trabajo de Azouvi y colaboradores (2016), aunque no incluyeron medidas de participación, encontraron que el estado de ánimo y la alteración cognitiva, entre otras variables como los datos sociodemográficos, la gravedad del daño y las alteraciones físicas, tenían un mayor valor predictivo, aunque no especificaron cuánto explicaba 
cada factor dada la fuerte correlación entre ambos, si bien el que más se asociaba con la calidad de vida era el estado de ánimo. Por su parte, en el estudio llevado a cabo por Visser-Meyer y colaboradores (2009) se encontró una asociación significativa entre el estado de ánimo, la fatiga, la presencia de quejas cognitivas y los estilos de afrontamiento pasivo con una menor percepción de calidad de vida, sin considerar ninguna variable relacionada con el grado de participación.

Otra de las hipótesis de este trabajo planteaba que entre todos los dominios de participación, la participación social sería la que en mayor medida predeciría la calidad de vida. En este sentido, tanto los dominios referentes a las relaciones sociales como los que tienen que ver con la productividad-ocupación predicen la calidad de vida, de hecho el valor predictivo que tienen las dos variables por separado es mayor al juntar ambas. Estos resultados van en la línea de los publicados por Erikson y colaboradores (Eriksson, Kottorp, Borg, \& Tham, 2009; Eriksson, Tham, \& Borg, 2006) que, aunque no realizan análisis predictivos, demuestran una correlación significativa entre la participación en ocupaciones diarias y la satisfacción vital entre uno y cuatro años después de la lesión cerebral, así como confirman que tener un empleo o recuperar las actividades de ocio previas influyen en la CV.

Dentro de este contexto cabe destacar que los resultados hallados tienen que ver también con la manera en que se realiza la recogida de información, en este caso, referente a la participación. De las tres escalas utilizadas, en el FAST -de acuerdo al juicio del clínico o del familiar tras una entrevista estructurada- se valora la capacidad del paciente en función del grado de dificultad que puede presentar para la realización de una determinada actividad, por lo que el constructo que valorara estaría más cerca al de actividad que no al de participación. El CIQ-R tiene que ver con el ejercicio de roles, es decir con el concepto de participación, y el 
CHART, que también mide el mismo constructo, lo hace a partir de indagar sobre la frecuencia con la que el sujeto hace actividades productivas (independencia física, cognitiva, integración social, ocupación...) y el grado de dificultad o de ayuda-supervisión que le supone el desempeño. Estas particularidades pueden estar apoyando los resultados de los análisis de regresión en el sentido que, son estas dos últimas escalas, el CHART y el $\mathrm{CIQ}-\mathrm{R}$ las que más valor predictivo tienen sobre la medida de calidad de vida total así como la de sus subdominios, quedando el FAST en un segundo lugar. Especificando aún más, dado el poder predictivo de las dos primeras, sabemos que el ejercicio de roles predice mejor la CV que el tiempo invertido en la realización de las tareas, esto es, en términos generales el individuo percibe mayor calidad de vida por el hecho de que puede desempeñar una tarea y no tanto por el tiempo que ha dedicado a la realización de la misma.

Los resultados presentados subrayan la importancia del grado de participación del paciente sobre la percepción que tiene de su calidad de vida, enfatizando la utilidad de considerar el modelo CIF como marco teórico de atención al paciente con daño cerebral adquirido. En este sentido, la Clasificación Internacional de Funcionamiento, Discapacidad y Salud que pertenece al conjunto de clasificaciones internacionales que propone la Organización Mundial de la Salud (OMS) aborda el funcionamiento desde una perspectiva global, la "persona como un todo" y es una taxonomía en la cual la persona puede ser descrita en términos de sistema corporal, actividad funcional y participación y factores contextuales. Tal y como describe este sistema, la afectación estructural, bioquímica y funcional del cerebro (patología) interacciona con los déficits cognitivos, físicos, alteraciones conductuales y emocionales y otras manifestaciones psicopatológicas (déficits generados por la patología) y con variables físicas y personales (factores ambientales). Es esta interacción la que condiciona las repercusiones funcionales 
(actividad) y el grado de participación del paciente en relación a su entorno. De esta manera, la concepción actual de salud, no sólo hace referencia a la presencia o ausencia de una patología, sino a las consecuencias de la misma sobre el nivel de funcionamiento del paciente, en relación a sí mismo, su entorno y su posición en la sociedad. Así, el impacto del DCA debe ser analizado de acuerdo a cuatro niveles: patología, déficit, actividad (antes denominado discapacidad) y participación (previamente referido como minusvalía) (Halligan, PW; Wade, 2005). Nuestros hallazgos unidos a la propuesta de la OMS nos proporciona un marco de intervención orientado no sólo a la rehabilitación de los déficits sino a conseguir una mayor autonomía y aumentar el grado de independencia funcional y de participación, restituyendo, minimizando y/o compensando en la medida de lo posible los déficits funcionales resultantes de la lesión cerebral. Tal y como sugieren nuestros resultados, así como los de otros estudios (Jönsson et al., 2005; Kwok et al., 2011), mejorando el grado de participación aumentará la percepción de calidad de vida por parte del paciente.

En este contexto, según lo que proponen Verdugo y colaboradores (Verdugo, Schalock, Keith, \& Stancliffe, 2005), el obtener un medida de CV se debe a tres motivos principalmente. El primer motivo es que se ha producido un cambio de creencia en relación con los factores que mejorarían la CV de los pacientes. Ya no se considerarían únicamente los avances médicos, científicos y tecnológicos, considerándose primordial interacción entre el bienestar personal, familiar, social y comunitario, los valores, percepciones y condiciones ambientales del individuo. El segundo motivo refleja el hecho de que el concepto de CV representa avanzar en el proceso de normalización, considerando como medida de resultado de la integración comunitaria los servicios basados en la comunidad que realiza el individuo, que va en la línea de los resultados obtenidos en este estudio. El tercero y último se refiere a la cada vez más presente 
planificación centrada en la persona, rendimiento personal y autodeterminación. En este sentido, los resultados de esta investigación nos permiten elaborar programas de intervención centrados en la persona, teniendo en cuenta sus deseos e intereses para mejorar su percepción de calidad de vida y no dirigidos únicamente a mejorar la patología y el déficit, sino a aumentar el grado de participación en los ámbitos que el paciente considera importante satisfacer.

Los análisis de regresión que se han realizado incluyendo aquellas variables con mayor valor predictivo en los análisis previos indican que llega a predecir el $29 \%$ de la varianza de la puntuación total del cuestionario de calidad de vida. Esto confirma que la calidad de vida es una valoración subjetiva y personal que realiza el sujeto sin que haya unas variables que puedan explicarla objetivamente en su totalidad. De esta manera habrá que analizar de manera individual, para cada uno de nuestros pacientes, aquellos factores que la persona considera importantes y determinantes de su nivel de satisfacción y percepción de calidad de vida. Además, puede que un mismo paciente considere necesario tener unas necesidades satisfechas y no otras según el ámbito al que nos estemos refiriendo; por ejemplo, si preguntamos por la esfera de las relaciones sociales, puede que la persona dé más importancia a la capacidad de comunicación y no tanto las funciones de memoria o movilidad; o si se le pregunta por el nivel de satisfacción en el desarrollo de tareas del hogar, un individuo puede priorizar sus capacidades de movilidad o dominios cognitivos y no tanto la capacidad de comunicación. Con esto, los determinantes de calidad de vida, aparte de ser individuales y personales, por el propio carácter subjetivo del concepto de CV, también dependerán del aspecto concreto de calidad de vida al que se le está haciendo referencia al paciente para valorar su nivel de satisfacción. En síntesis, resulta relevante considerar los aspectos que se han ido describiendo en el campo que nos ocupa de la neuro-rehabilitación de 
pacientes con daño cerebral adquirido. Este proceso debe ir enfocado a mejorar la calidad de vida tal y como propone la OMS y, es interesante saber a raíz de los resultado de esta investigación, cómo variables antes consideradas determinantes de CV pasa a un segundo plano ejerciendo ahora un papel importante el grado de participación.

En cuanto a las implicaciones clínicas de esta tesis doctoral, es importante tener en cuenta la experiencia subjetiva de los pacientes con daño cerebral adquirido y las percepciones y cogniciones relacionadas con su recuperación. Coincidiendo con la propuesta que realizan Teoh y colaboradores en su estudio (Teoh, Sims, \& Milgrom, 2009), los programas de rehabilitación deberían incorporar sesiones de apoyo y discusión relacionado con la percepción de control, manejo del estrés, encontrar significados a las preguntas o cuestiones que inquietan, búsqueda de nuevos propósitos relacionados con la satisfacción y disfrute de la vida, entre otros. Es decir, considerar la rehabilitación como un proceso mutidimensional con el objetivo de promover la adopción de mejores estrategias de adaptación y de afrontamiento por parte del individuo de tal manera que alcance la CV más alta posible, haciendo hincapié no sólo a lo que el propio paciente valora como factores importantes para ese nivel de calidad de vida, sino dada la evidencia, a promover una mayor autonomía, recuperación de roles y una buena participación a nivel social y de productividad, no limitándonos exclusivamente a la rehabilitación del déficit o la patología.

Para finalizar, cabe mencionar algunas aportaciones de la presente tesis doctoral. Por una parte, el carácter multicéntrico del estudio, que ha permitido obtener una muestra experimental muy amplia. Por otra parte, nos parece adecuado metodológicamente el hecho de que la valoración del estado cognitivo de los pacientes a partir de dominios cognitivos específicos se haga mediante diferentes pruebas y no a través de medidas 
de screening cognitivo, aumentando la validez de constructo de este trabajo. Este hecho confiere además la ventaja de haber incluido medidas independientes de déficit, a parte de las de actividad y de participación. El uso de dominios cognitivos, así como de medidas de participación y calidad de vida con subescalas o ámbitos de actuación, permite explorar qué función cognitiva o qué aspecto concreto de participación tiene mayor valor predictivo sobre la calidad de vida, imposible de conseguir a partir de una única medida de rendimiento cognitivo o de participación global. Es importante resaltar que la metodología empleada en la presente tesis midiendo conjuntamente los dominios de déficit, la actividad y participación con diferentes escalas y de acuerdo al modelo CIF dota de un carácter práctico los hallazgos obtenidos, relacionado principalmente con la valoración de estos pacientes y el diseño de los planes de tratamiento. Este método de evaluación utilizado da una visión integradora de la calidad de vida, en comparación con otros estudios similares que no tienen en cuenta tantas variables. De hecho, no parecen haber trabajos previos que hayan realizado una valoración tan exhaustiva como el protocolo de evaluación que se describe en nuestra investigación, sobre todo en lo referente a la valoración del déficit (neuropsicológico) y la participación.

Finalmente, cabe destacar que este estudio no está exento de limitaciones. La más representativa tiene que ver con el hecho de no haber incluido la valoración objetiva del estado de ánimo en el protocolo de nuestro estudio, teniendo en cuenta que la literatura existente apunta a la implicación de las variables emocionales en la calidad de vida (Jaracz \& Kozubski, 2003; Kauhanen et al., 2000; King, 1996; Kwok et al., 2006; Teoh et al., 2009; Von Steinbuchel et al., 2010). También consideramos que hubiera sido adecuado hacer una evaluación más detallada del déficit físico y motor, dado que las limitaciones en este ámbito pueden comprometer la participación del individuo y, por tanto, su calidad de 
vida. Por otra parte, nuestro estudio no ha tenido en cuenta el tiempo transcurrido desde el alta del proceso neuro-rehabilitador hasta la valoración en ningún paciente, de modo que la percepción de calidad de vida podría variar desde el momento del alta médica y unos meses después por haberse adaptado a la nueva vida.

En relación al futuro de esta línea de investigación, parece necesario incluir otras variables como potenciales predictores de la CV en pacientes con DCA. Tal y como señalábamos anteriormente, alguna de ellas sería el tiempo de evolución, así como considerar una medida de estado de ánimo por la implicación que supone en la explicación de la calidad de vida. No obstante, aunque en esta investigación no se ha tenido en cuenta ninguna medida objetiva de estado de ánimo para poder incluirla en los análisis correlacionales y predictivos, considerando este hecho como una limitación del estudio, podemos estimar los resultados obtenidos en la subescala de calidad de vida como un indicador de satisfacción de los diferentes aspectos relacionados con el estado anímico de los sujetos de estudio. Concretamente, los ítems de esta escala que preguntan sobre la frecuencia con la que se siente alegre o animado, contento o a gusto con su vida pueden ser los que podrían dar más información sobre el estado de ánimo del paciente. Por último, consideramos importante el desarrollo de escalas específicas que permitan abordar la complejidad de de esta población de pacientes. 



\section{CONCLUSIONES}

Predictores de Calidad de Vida en pacientes con Daño Cerebral Adquirido:

Déficit, Actividad y Participación 

Las personas con daño cerebral adquirido presentan como consecuencia del mismo alteraciones neuropsicológicas, que afectan al menos a los siguientes dominios: atención, capacidad de aprendizaje y memoria, memoria de trabajo y funciones ejecutivas, tanto en su dimensión cognitiva como conductual. También presentan, en el ámbito funcional, limitaciones en el grado de participación sobre todo a nivel de productividad.

Existe una relación significativa entre estas alteraciones neuropsicológicas y las limitaciones en la actividad y participación y algunos dominios de la calidad de vida, y la calidad de vida total.

Entre las alteraciones neuropsicológicas presentes en los pacientes con daño cerebral adquirido, la disfunción ejecutiva en su dimensión emocional/conductual es la que mayor valor predictivo tiene sobre la percepción de calidad de vida.

En pacientes con DCA, el grado de participación es la variable que más varianza explica de la variable de calidad de vida. De esta manera, entre los diferentes dominios de la CIF la participación es la que mayor valor predictivo tiene sobre la percepción de calidad de vida, especialmente aquellos dominios relacionados con la participación en los ámbitos de las relaciones sociales y de productividad. 



\section{BIBLIOGRAFÍA}

Predictores de Calidad de Vida en pacientes con Daño Cerebral Adquirido:

Déficit, Actividad y Participación 

Aaronson, N. K. (1988). Quality of life: what is it? How should it be measured? Oncology (Williston Park, N.Y.), 2(5), 69-76, 64.

Aaronson, N. K. (1989). Quality of life assessment in clinical trials: Methodologic issues. Controlled Clinical Trials, 10(4), 195-208.

Adamit, T., Maeir, A., Ben Assayag, E., Bornstein, N. M., Korczyn, A. D., \& Katz, N. (2015). Impact of first-ever mild stroke on participation at 3 and 6 month post-event: The TABASCO study. Disability and Rehabilitation, 37(8), 667-673.

Adekoya, N., Thurman, D. J., White, D. D., \& Webb, K. W. (2002). Surveillance for Traumatic Brain Injury Deaths United States, 1989-1998. MMWR CDC Surveillance Summaries, 51(SS10), 1-16.

Adell-Serrano, B., Perrot-González, J. C., Escribano Stable, D. A., Castañeda-Galeano, V. E., Usabiaga Bernal, T., \& Aguilar Naranjo, J. J. (2013). Relación entre reserva cognitiva y déficit cognitivo en el ictus. Rehabilitación, 47(1), 27-34.

Ahlsiö, B., Britton, M., Murray, V., \& Theorell, T. (1984). Disablement and quality of life after stroke. Stroke; a Journal of Cerebral Circulation, 15(5), 886-890.

Aiachini, B., Pisoni, C., Cieza, A., Cazzulani, B., Giustini, A., \& Pistarini, C. (2010). Developing ICF core set for subjects with traumatic brain injury: an Italian clinical perspective. European Journal of Physical and Rehabilitation Medicine, 46(1), 27-36.

Albrecht, G. L., \& Devlieger, P. J. (1999). The disability paradox: high quality of life against all odds. Social Science \& Medicine, 48(8), 977-988.

Alguren, B., Fridlund, B., Cieza, A., Sunnerhagen, K. S., Christensson, L., Algurén, B., Christensson, L. (2012). Factors Associated With HealthRelated Quality of Life After Stroke: A 1-Year Prospective Cohort Study. Neurorehabilitation and Neural Repair, 26(3), 266-274.

Almkvist Muren, M., Hütler, M., \& Hooper, J. (2008). Functional Capacity and Health-Related Quality of Life in Individuals Post Stroke. Topics in Stroke Rehabilitation, 15(1), 51-58. 
Anderson, C., Laubscher, S., \& Burns, R. (1996). Validation of the Short Form 36 (SF-36) Health Survey Questionnaire Among Stroke Patients. Stroke, 27(10).

Anderson, K. L., \& Burckhardt, C. S. (1999). Conceptualization and measurement of quality of life as an outcome variable for health care intervention and research. Journal of Advanced Nursing, 29(2), 298-306.

Ayuso-Mateos, J. L., Nieto-Moreno, M., Sánchez-Moreno, J., \& Vazquez-Barquero, J. L. (2006). Clasificación Internacional del Funcionamiento, la Discapacidad y la Salud (CIF): aplicabilidad y utilidad en la práctica clínica. Med Clin (Barc), 126(12), 461-6.

Azouvi, P., Ghout, I., Bayen, E., Darnoux, E., Azerad, S., Ruet, A., Jourdan, C. (2016). Disability and health-related quality-of-life 4 years after a severe traumatic brain injury: A structural equation modelling analysis. Brain Injury, 30(13-14), [Epub ahead of print].

Baddeley, A., \& Hitch, G. (1974). Working memory. In G. A. Bower ed (Ed.), The psychology of learning and cognition (pp. 47-89). New York: Academic Press.

Baddeley, A., \& Wilson, B. (1988). Frontal amnesia and the dysexecutive syndrome. Brain and Cognition, 7(2), 212-230.

Ben-Yishay, D. L. (1993). Cognitive remediation in traumatic brain injury: update and issues. Arch Phys Med Rehab, 74, 204-213.

Benedet, M. J., \& Alexandre, M. A. (1998). Test de Aprendizaje Verbal España-Complutense (TAVEC). (TEA, Ed.). Madrid.

Berg, J., Tagliaferri, F., \& Servadei, F. (2005). Cost of trauma in Europe. European Journal of Neurology, 12(s1), 85-90.

Bergner, M., Bobitt, R. A., Carter, W. B., \& Gilson, B. S. (1981). The Sickness Impact Profile: Development and Final Revision of a Health Status Measure. Medical Care, 19(8), 787-805.

Bilbao, A., Jiménez, M. D., \& Palomar, M. V. (2014). Guía de familias. Daño cerebral adquirido. (FEDACE). Madrid. 
Borthwick-Duffy, S. A. (1992). Quality of Life and Quality of Care in Mental Retardation. Mental Retardation in the Year 2000, 52-66.

Bour, A., Rasquin, S., Limburg, M., \& Verhey, F. (2011). Depressive symptoms and executive functioning in stroke patients: a follow-up study. International Journal of Geriatric Psychiatry, 26(7), 679-86.

Breed, S. T., Flanagan, S. R., \& Watson, K. R. (2004). The relationship between age and the self-report of health symptoms in persons with traumatic brain injury. Archives of Physical Medicine and Rehabilitation, $85,61-67$.

Brooks, N., McKinlay, W., Symington, C., Beattie, A., \& Campsie, L. (1987). Return to work within the first seven years of severe head injury. Brain Injury, 1(1), 5-19.

Brott, T., \& Bogousslavsky, J. (2000). Treatment of Acute Ischemic Stroke. New England Journal of Medicine, 343(10), 710-722.

Brown, I., Keith, K., \& Schalock, R. (2004). Quality of life conceptualisation, measurement, and application. Journal of Intellectual Disability Research, 48(4), 451.

Burgess, P. \& Shallice, T. (1997). The Hayling and Brixton Tests. Test manual. (T. V. T. Company., Ed.). Bury St Edmunds, UK.

Burgess, P. W. (1997). Theory and methodology in executive function research. In P. Rabbitt (Ed.), Methodology of frontal and executive function. (p. 81-111.). Hove, UK: Psychology Press.

Burgess, P. W., Alderman, N., Evans, J., Emslie, H., \& Wilson, B. A. (1998). The ecological validity of tests of executive function. Journal of the International Neuropsychological Society, 4(6), 547-558.

Bushnik, T. (2003). Introduction: The Traumatic Brain Injury Model Systems of Care. Archives of Physical Medicine and Rehabilitation, 84(2), 151-152.

Carlsson, G., Möller, A., \& Blomstrand, C. (2004). A qualitative study of the consequences of "hidden dysfunctions" one year after a mild stroke in persons $<75$ years. Disability and Rehabilitation, 26(23), 1373-1380. 
Carod-Artal, F. J., \& Egido, J. A. (2009). Quality of life after stroke: The importance of a good recovery. Cerebrovascular Diseases, 27(SUPPL. 1), 204-214.

Castellví, M., Carneado, J., Claramonte, B., Chamorro, R., Diaz, I., Fernandez, S., Villanueva, V. (2007). Guía de información al paciente con Ictus (Generalita).

Chang, W. H., Sohn, M. K., Lee, J., Kim, D. Y., Lee, S. G., Shin, Y. II, Kim, Y. H. (2016). Predictors of functional level and quality of life at 6 months after a first-ever stroke: the KOSCO study. Journal of Neurology, 263(6), 1166-1177.

Chaytor, N., \& Schmitter-Edgecombe, M. (2007). Fractionation of the dysexecutive syndrome in a heterogeneous neurological sample: Comparing the Dysexecutive Questionnaire and the Brock Adaptive Functioning Questionnaire. Brain Injury, 21(6), 615-621.

Chou, C. (2015). Determinants of the Health-related Quality of Life for Stroke Survivors. Journal of Stroke and Cerebrovascular Diseases, 24(3), 655-662.

Cieza, A., Geyh, S., Chatterji, S., Kostanjsek, N., Stü N, B., \& Stucki, G. (2005). ICF linking rules: an update based on lessons learned. J Rehabil Med, 37, 212-218.

Conners, C. K., \& Staff, M. H. S. (2000). Conners' Continuous Performance Test II (CPT II). (M.-H. S. Inc., Ed.). North TOnawanda, NY.

Coons, S. J., Rao, S., Keininger, D. L., \& Hays, R. D. (2000). A comparative review of generic Quality-of-Life instruments. PharmacoEconomics, 17(1), 13-35.

Corrigan, J. D., Bogner, J. A., Mysiw, W. J., Clinchot, D., \& Fugate, L. (2001). Life Satisfaction After Traumatic Brain Injury. The Journal of Head Trauma Rehabilitation, 16(6), 543-555.

D’Elia, L. F., Satz, P., Uchiyama, C. L., \& White, T. (1996). Color Trails Test. Odessa, FL: PAR.

Daneski, K., Coshall, C., Tilling, K., \& Wolfe, C. D. A. (2003). Reliability and validity of a postal version of the Reintegration to Normal 
Living Index, modified for use with stroke patients. Clinical Rehabilitation, 17(8), 835-839.

de Haan, R., Aaronson, N., Limburg, M., Hewer, R. L., \& van Crevel, H. (1993). Measuring quality of life in stroke. Stroke, 24(2).

Delis, D. C., Kramer, J. H., Kaplan, E., \& Thomkins, B. A. O. (1987). CVLT, California Verbal Learning Test: Adult Version: Manual. (Psychological Corporation, Ed.).

Devitt, R., Colantonino, A., Dawson, D., Teare, G., Ratcliff, G., \& Chase, S. (2006). Prediction of long-term occupational performance outcomes for adults after moderate to severe traumatic brain injury. Disability and Rehabilitation, 28(9), 547-559.

Díez-Tejedor, E., Fuentes, B., Gil Nuñez, A. C., Gil Perlta, A., \& Matías Guiu, J. (2006). Guía para el tratamiento preventivo de la isquemia cerebral. In Guías para el diagnóstico y tratamiento del ictus. Guías oficiales de la Sociedad Española de Neurologia. (Prous Scie). Barcelona.

Domínguez-Morales, M. R., Balmaseda Serrano, R., León Carrión, J., \& García Bernal, M. I. (2000). Recuperación funcional de pacientes cerebrocasculares después de tratamiento intensivo: datos preliminares. Revista Española de Neuropsicología, 2(3), 44-61.

Dorman, P. J., Waddell, F., Slattery, J., Dennis, M., \& Sandercock, P. (1997). Is the EuroQol a Valid Measure of Health-Related Quality of Life After Stroke? Stroke, 28(10).

dos Santos Oliveira, K., Moreno Valdes, M. T., D., D. P. L., \& da Silva, C. E. (2011). Factors associated with health-related quality of life for adults with stroke sequelae. Arquivos De Neuro-Psiquiatria, 69(2B), 371376.

Doyle, P. J. (2002). Measuring health outcomes in stroke survivors. Archives of Physical Medicine and Rehabilitation, 83, S39-S43.

Doyle, P. J., McNeil, M., Hula, W., \& Mikolic, J. (2003). The Burden of Stroke Scale (BOSS): Validating patient-reported communication difficulty and associated psychological distress in stroke survivors. Aphasiology, 17(3), 291-304. 
Dubos, R. (1976). The State of Health and the Quality of Life. The Western Journal of Medicine, 125(1), 8-9.

Duncan, P. W., Jorgensen, H. S., \& Wade, D. T. (2000). Outcome Measures in Acute Stroke Trials A Systematic Review and Some Recommendations to Improve Practice. Stroke, 31(6).

Duncan, P. W., Reker, D. M., Horner, R. D., Samsa, G. P., Hoenig, H., LaClair, B. J., \& Dudley, T. K. (2002). Performance of a mail-administered version of a stroke-specific outcome measure, the Stroke Impact Scale. Clinical Rehabilitation, 16(5), 493-505.

Duncan, P. W., Wallace, D., Lai, S. M., Johnson, D., Embretson, S., \& Laster, L. J. (1999). The Stroke Impact Scale Version 2.0. Stroke, 30(10).

Ebrahim, S., Barer, D., \& Nouri, F. (1986). Use of the Nottingham Health Profile with patients after a stroke. Journal of Epidemiology and Community Health, 40(2), 166-9.

Edwards, D. F., Hahn, M., Baum, C., \& Dromerick, A. W. (2006). The Impact of Mild Stroke on Meaningful Activity and Life Satisfaction. Journal of Stroke and Cerebrovascular Diseases, 15(4), 151-157.

Elber Tafur C, J. (2012). Tratado de Neuropsicologia Clinica Del Adulto. (F. Román, M. P. Sánchez, \& M. J. Rabadán, Eds.). Lima, Perú: Neurohealth.

Endicott, J., Krithika, R., Margaret, M., \& Wayne, M. (2007). A randomized, double-blind, placebo-controlled study of quetiapine in the treatment of bipolar I and II depression: improvements in quality of life. International Clinical Psychopharmacology, 22(1), 29-37.

Endicott, J., Nee, J., Harrison, W., \& Blumenthal, R. (1993). Quality of life enjoyment and satisfaction questionnaire: $A$ new measure. Psychopharmacology Bulletin, 29(2), 321-326.

Eriksson, G., Kottorp, A., Borg, J., \& Tham, K. (2009). Relationship between occupational gaps in everyday life, depressive mood and life satisfaction after acquired brain injury. Journal of Rehabilitation Medicine, 41(3), 187-194. 
Eriksson, G., Tham, K., \& Borg, J. (2006). Occupational gaps in every day life 1-4 years after acquired brain injury. Journal of Rehabilitation Medicine, 38(3), 159-165.

Fayers, P., \& Machin, D. (2007). Quality of Life: The Assessment, Analysis and Interpretation of Patient-Reported Outcomes (2nd ed.). Chichester, UK: John Wiley \& Sons.

FEDACE. (2006). Neuropsicología y daño cerebral. (Federación Española de Daño Cerebral Adquirido, Ed.). Madrid: Cuadernos FEDACE sobre DCA.

FEDACE. (2009). Rehabilitación de las alteraciones conductuales derivadas del daño cerebral adquirido. (Federación Española de Daño Cerebral Adquirido, Ed.). Madrid: Cuadernos FEDACE sobre DCA.

FEDACE. (2015). Encuentro DCA: Aproximación demográfica y necesidades de las personas con DCA y sus familias.

Felce, D., \& Perry, J. (1995). Quality of life: Its definition and measurement. Research in Developmental Disabilities, 16(1), 51-74.

Ferran, C., \& Powes, M. (1985). Quality of life index: development and psychometric properties. Advances in Nursing Science, 8, 15-24.

FEVADACE. (2004). http://fevadace.org/el-dano-cerebral-adquirido/.

Gauthier, L., Dehaut, F., \& Joanette, Y. (1989). The bells test: A quantitative and qualitative test for visual neglect. International Journal of Clinical Neuropsychology, 11, 49-53.

Gerstorf, D., Siedlecki, K. L., Tucker-Drob, E. M., \& Salthouse, T. A. (2008). Executive Dysfunctions Across Adulthood: Measurement Properties and Correlates of the DEX Self-Report Questionnaire. Aging, Neuropsychology, and Cognition, 15(4), 424-445.

Geyh, S., Cieza, A., Kollerits, B., Grimby, G., \& Stucki, G. (2007). Content comparison of health-related quality of life measures used in stroke based on the international classification of functioning, disability and health (ICF ): a systematic review. Qual Life Res, 16, 833-851. 
Golomb, B. A., Vickrey, B. G., \& Hays, R. D. (2001). A Review of Health-Related Quality-of-Life Measures in Stroke. PharmacoEconomics, 19(2), 155-185.

Gomez, M., \& Sabeh, E. N. (2001). Calidad de vida. evolución del concepto y su influencia en la investigación y la práctica. Gac Sanit, (15 (supl 4), 24-43.

Gompertz, P., Pound, P., \& Ebrahim, S. (1993). The reliability of stroke outcome measures. Clinical Rehabilitation, 7(4), 290-296.

Gough, I. R., Furnival, C. M., Schilder, L., \& Grove, W. (1983). Assessment of the quality of life of patients with advanced cancer. European Journal of Cancer and Clinical Oncology.

Guyatt, G. H., Jaeschke, R., Feeny, D. H., \& Patrick, D. L. (1996). Measurements in clinical trials: choosing the right approach. In B. Spilker (Ed.), Quality of life and pharmacoeconomics in clinical trials (pp. 41-8). New York: Raven Press.

Haacke, C., Althaus, A., Spottke, A., Siebert, U., Back, T., \& Dodel, R. (2005). Long-Term Outcome After Stroke. Stroke, 37(1).

Hagen, S., Bugge, C., \& Alexander, H. (2003). Psychometric properties of the SF-36 in the early post-stroke phase. Journal of Advanced Nursing, 44(5), 461-468.

Hall, K. M., Bushnik, T., Lakisic-Kazazic, B., Wright, J., \& Cantagallo, A. (2001). Assessing traumatic brain injury outcome measures for longterm follow-up of community-based individuals. Archives of Physical Medicine and Rehabilitation, 82(3), 367-374.

Halligan, PW; Wade, D. (2005). Effectiveness of rehabilitation for cognitive deficits. (Oxford). Oxford University Press.

Hamedani, A. G., Wells, C. K., Brass, L. M., Kernan, W. N., Viscoli, C. M., Maraire, J. N., Horwitz, R. I. (2001). A Quality-of-Life Instrument for Young Hemorrhagic Stroke Patients. Stroke, 32(3).

Hammond, F. M., Grattan, K. D., Sasser, H., Corrigan, J. D., Bushnik, T., \& Zafonte, R. D. (2001). Long-term recovery course after traumatic brain injury: A comparison of the Functional Independence Measure and 
disability rating scale. Journal of Head Trauma Rehabilitation, 16(4), 318329.

Harwood, R. H., Rogers, A., Dickinson, E., \& Ebrahim, S. (1994). Measuring handicap: the London Handicap Scale, a new outcome measure for chronic disease. Quality and Safety in Health Care, 3(1), 1116.

Hatano, S. (1976). Experience from a multicentre stroke register: a preliminary report. Bulletin of the World Health Organization, 54(5), 541553.

Heaton, R. K., Chelune, G. J., Talley, J. L., Hay, G. G., \& Curtiss, G. (2001). Test de Clasificación de Tarjetas de Wisconsin. T. Ediciones, Ed. (Segunda). Madrid.

Hilari, K., \& Byng, S. (2001). Measuring Quality of Life in People with Aphasia: The Stroke Specific Quality of Life Scale. International Journal of Language \& Communication Disorders, 36(s1), 86-91.

Hilari, K., Byng, S., Lamping, D. L., \& Smith, S. C. (2003). Stroke and Aphasia Quality of Life Scale-39 (SAQOL-39). Stroke, 34(8).

Hope, M. L., Page, A. C., \& Hooke, G. R. (2009). The value of adding the Quality of Life Enjoyment and Satisfaction Questionnaire to outcome assessments of psychiatric inpatients with mood and affective disorders. Quality of Life Research, 18(5), 647-655.

Hörnquist, J. O. (1982). The concept of quality of life. Scand J Soc Med, 10, 57-61.

Huertas Hoyas, E., Pedrero Perez, E. J., Águila Maturana, A. M., García López-Alberca, S., \& González Alted, C. (2015). Predictores de funcionalidad en el dano cerebral adquirido. Neurología, 60(6), 339-346.

Jaillard, A., Grand, S., Le Bas, J. F., \& Hommel, M. (2010). Predicting cognitive dysfunctioning in nondemented patients early after stroke. Cerebrovascular Diseases , 29(5), 415-23.

Jaracz, K., \& Kozubski, W. (2003). Quality of life in stroke patients. Acta Neurologica Scandinavica, 107(5), 324-9. 
Jenkinson, C., Mant, J., Carter, J., Wade, D., \& Winner, S. (2000). The London handicap scale: a re-evaluation of its validity using standard scoring and simple summation. Journal of Neurology, Neurosurgery, and Psychiatry, 68(3), 365-7.

Jones, C. (1979). Glasgow Coma Scale. AJN The American Journal of Nursing, 79(9), 1551-1557.

Jönsson, A. C., Lindgren, I., Hallström, B., Norrving, B., \& Lindgren, A. (2005). Determinants of Quality of Life in Stroke Survivors and Their Informal Caregivers. Stroke, 36(4).

Kaplan, C. P. (2001). The community integration questionnaire with new scoring guidelines: concurrent validity and need for appropriate norms. Brain Injury, 15(8), 725-731.

Kashluba, S., Hanks, R. A., Casey, J. E., \& Millis, S. R. (2008). Neuropsychologic and Functional Outcome After Complicated Mild Traumatic Brain Injury. Archives of Physical Medicine and Rehabilitation, 89(5), 904-911.

Kauhanen, M. L., Korpelainen, J. T., Hiltunen, P., Nieminen, P., Sotaniemi, K. A., \& Myllylä, V. V. (2000). Domains and determinants of quality of life after stroke caused by brain infarction. Archives of Physical Medicine and Rehabilitation, 81(12), 1541-1546.

King, R. B. (1996). Quality of Life After Stroke. Stroke, 27(9).

Koskinen, S. (1998). Quality of life 10 years after a very severe traumatic brain injury (TBI): the perspective of the injured and the closest relative. Brain Injury, 12(8), 631-648.

Koskinen, S., Hokkinen, E. M., Sarajuuri, J., \& Alaranta, H. (2007). Applicability of the ICF checklist to traumatically brain-injured patients in post-acute rehabilitation settings. Journal of Rehabilitation Medicine, 39(6), 467-472.

Kotila, M., Numminen, H., Waltimo, O., \& Kaste, M. (1999). Poststroke depression and functional recovery in a population-based stroke register. The Finnstroke study. European Journal of Neurology. 
Kreutzer, J. S., Marwitz, J. H., Walker, W., Sander, A., Sherer, M., Bogner, J., Bushnik, T. (2003). Moderating Factors in Return to Work and Job Stability After Traumatic Brain Injury. Journal of Head Trauma Rehabilitation, 18(2), 128-138.

Kwakkel, G., \& Kollen, B. J. (2013). Predicting Activities after Stroke: What is Clinically Relevant? International Journal of Stroke, 8(1), 25-32.

Kwok, T., Lo, R. S., Wong, E., Wai-Kwong, T., Mok, V., \& Kai-Sing, W. (2006). Quality of Life of Stroke Survivors: A 1-Year Follow-Up Study. Archives of Physical Medicine and Rehabilitation, 87(9), 1177-1182.

Kwok, T., Pan, J., Lo, R., \& Song, X. (2011). The influence of participation on health-related quality of life in stroke patients patients. Disability and Rehabilitation, 33(21-22), 1990-1996.

Labi, M. L., Phillips, T. F., \& Greshman, G. E. (1980). Psychosocial disability in physically restored long-term stroke survivors. Archives of Physical Medicine and Rehabilitation, 61(12), 561-5.

Langhammer, B., Stanghelle, J. K., \& Lindmark, B. (2008). Exercise and health-related quality of life during the first year following acute stroke. A randomized controlled trial. Brain Injury, 22(2), 135-145.

León Valenzuela, A. (2011). Valoracion de la independencia funcional y grado de discapacidad en lesionados medulares tras el tratamiento rehabilitador. Portalesmedicos.Com, 16.

Lezak, M. D. (1988). Brain damage is a family affair. Journal of Clinical and Experimental Neuropsychology, 10(1), 111-123.

Lezak, M., Howieson, D., \& Loring, D. (2004). Neuropsychological Assessment (4th ed.). Oxford: Oxford University Press.

Luna-Lario, P., Blanco-Beregaña, M., Tirapu-Ustárroz, J., Ojeda, N., \& Mata-Pator, I. (2013). Trayectoria laboral, discapacidad y dependencia tras el daño cerebral adquirido: estudio prospectivo en los dos años siguientes a la lesión cerebral. Revista de Neurología, 57(6), 241-250.

Luna-Lario, P., Seijas-Gómez, R., Tirapu-Ustárroz, J., Hernáez-Goñi, P., \& Mata-Pastor, I. (2012). Estructura factorial del cuestionario disejecutivo en una muestra de población Española con daño cerebral 
adquirido y quejas de déficit de memoria. Revista de Neurologia, 55(11), 641-650.

Machuca, F., León-Carrión, J., \& Barroso, J. (2006). Eficacia de la rehabilitación neuropsicológica de inicio tardío en la recuperación funcional de pacientes con daño cerebral. Revista Española de Neuropsicología, 8(3-4), 81-103.

Mahoney, F. I., \& Barthel, D. (1965). Functional evaluation: The Barthel Index. Maryland State Medical Journal, 14, 56-61.

Mansueti, L., De Frias, C. M., Bub, D., \& Dixon, R. A. (2008). Exploring Cognitive Effects of Self Reported Mild Stroke in Older Adults: Selective but Robust Effects on Story Memory. Aging, Neuropsychology, and Cognition, 15(5), 545-573.

Mateer, C. (2003). Introducción a la rehabilitación cognitiva. Avances En Psicología Clínica Latinoamericana, 21, 11-20.

Mcdougall, J., Wright, V., \& Rosenbaum, P. (2010). The ICF model of functioning and disability: Incorporating quality of life and human development. Developmental Neurorehabilitation, 13(3), 204-211.

McGuire, B. E., Morrison, T. G., Barker, L. A., Morton, N., McBrinn, J., Caldwell, S., ... Walsh, J. (2014). Impaired self-awareness after traumatic brain injury: inter-rater reliability and factor structure of the Dysexecutive Questionnaire (DEX) in patients, significant others and clinicians. Frontiers in Behavioral Neuroscience, 8, 352.

McHorney, C. A. (1999). Helath Status Assessment Methods for Adults: Past Accomplishments and Future Challenges. Annual Review of Public Health, 20(1), 309-335.

Mick, E., Biederman, J., Spencer, T., Faraone, S. V., \& Zhang, H. (2006). The validity of the quality of life enjoyment and satisfaction questionnaire in adults with ADHD. European Neuropsychopharmacology, 16(Supplement 4), S533-S533.

Mooney, B., Walmsley, C., \& McFarland, K. (2006). Factor Analysis of the Self-Report Dysexecutive (DEX-S) Questionnaire. Applied Neuropsychology, 13(1), 12-18. 
Moons, P., Budts, W., \& De Geest, S. (2006). Critique on the conceptualisation of quality of life: A review and evaluation of different conceptual approaches. International Journal of Nursing Studies, 43(7), 891-901.

National Institutes of Health (NIH). (1998). Rehabilitation of persons with traumatic brain injury. Paper presented at the $\mathrm{NIH}$,Washington, D.C. In National Institutes of Health consensus statement.

Nichols-Larsen, D. S., Clark, P. C., Zeringue, A., Greenspan, A., \& Blanton, S. (2005). Factors influencing stroke survivors' quality of life during subacute recovery. Stroke, 36(7), 1480-1484.

Nilsen, D. M., Gillen, G., DiRusso, T., \& Gordon, A. M. (2012). Effect of Imagery Perspective on Occupational Performance After Stroke: A Randomized Controlled Trial. American Journal of Occupational Therapy, 66(3), 320-329.

Novack, T. A., \& Alderson, A. L. (2000). Cognitive and functional recovery at 6 and 12 months post-TBI. Brain Injury, 14(11), 987-996.

Obembe, A. O., \& Eng, J. J. (2016). Rehabilitation Interventions for Improving Social Participation After Stroke: A Systematic Review and Meta-analysis.

Oleson, M. (1990). Subjectively Perceived Quality of Life. Image: The Journal of Nursing Scholarship, 22(3), 187-190.

OMS. Organización Mundial de la Salud. (2001). Clasificación Internacional del Funcionamiento, de la Discapacidad y de la Salud (Ministerio). Madrid: Organización Mundial de la Salud.

ONCE, F. Estudio sobre daño cerebral e inserción laboral. (Porgrama Operativo del FSE de Inclusión Social y Economía Social, Ed.) (2014). Fundación ONCE.

Orgogozo, J. M. (1994). The Concepts of Impairment, Disability and Handicap. Cerebrovascular Diseases, 4(2), 2-6. 
Owolabi, M. O. (2010). Which is more valid for stroke patients: generic or stroke-specific quality of life measures? Neuroepidemiology, $34(1), 8-12$.

Pan, J. H., Song, X. Y., Lee, S. Y., \& Kwok, T. (2008). Longitudinal Analysis of Quality of Life for Stroke Survivors Using Latent Curve Models. Stroke, 39(10).

Partington, J. E., \& Leiter, R. G. (1949). Partington's Pathway Test. The Psychological Service Center Bulletin, 1, 9-20.

Patrick, D. L., \& Erickson, P. (1993). Assessing health-related quality of life for clinical decision-making. In Quality of Life Assessment: Key Issues in the 1990s (pp. 11-63). Dordrecht: Springer Netherlands.

Pedrero-Pérez, E. J., Ruiz-Sánchez de León, J. M., Lozoya-Delgado, P., Llanero-Luque, M., Rojo-Mota, G., \& Puerta-García, C. (2011). Evaluación de los síntomas prefrontales: Propiedades psicométricas y datos normativos del cuestionario disejecutivo (DEX) en una muestra de población Española. Revista de Neurologia, 52(7), 394-404.

Peña-Casanova, J. (2007). Neurología de la conducta y neuropsicología. Madrid: Editorial Médica Panamericana.

Ponsford, J., Draper, K., \& Schönberger, M. (2008). Functional outcome 10 years after traumatic brain injury: its relationship with demographic, injury severity, and cognitive and emotional status. Journal of the International Neuropsychological Society : JINS, 14(2), 233-42.

Post, M. W., de Witte, L. P., \& Schrijvers, A. J. (1999). Quality of life and the ICIDH: towards an integrated conceptual model for rehabilitation outcomes research. Clinical Rehabilitation, 13, 5-15.

Prieto, R., Gutiérrez-González, R., Pascual, J. M., Roda, J. M., Cerdán, S., Matias-Guiu, J., \& Barcia, J. A. (2009). Neurocirugía. Neurocirugía (Vol. 20). Elsevier B.V.

Prigatano, G. P. (1992). Personality disturbances associated with traumatic brain injury. Journal of Consulting and Clinical Psychology, 60(3), 360-368. 
Rami, L., Valls-Pedret, C., Bartres-Faz, D., Caprile, C., Sole-Padulles, C., Castellvi, M., Molinuevo, J. L. (2011). Cuestionario de reserva cognitiva. Valores obtenidos en población anciana sana y con enfermedad de Alzheimer. Revista de Neurología, 52, 195-201.

Reitan, R. M. (1958). Validity of the trail making test as an indicator of organic brain damage. Perceptual and Motor Skills, 8(3), 271-276.

Ribero Rosa, A., Sánchez-Moreno, J., Martínez-Aran, A., Godelieve van Riel, W., Del Mar Bonnín, C., Ayuso-Mateos, J. L., Vieta, E. (2008). Prueba breve de evaluación del funcionamiento (FAST). Cibersam, Ed.

Ríos-Lago, M., Benito-León, J., Paul, N., \& Tirapu-Ustárroz, J. (2008). Neuropsicología del daño cerebral adquirido. En TirapuUstárroz, J., RíosLago, M \& Maestú, F (Eds.), Manual de neuropsicología. Barcelona: Viguera.

Ritchie, L., Wright-St Clair, V. A., Keogh, J., \& Gray, M. (2014). Community Integration After Traumatic Brain Injury: A Systematic Review of the Clinical Implications of Measurement and Service Provision for Older Adults. Archives of Physical Medicine and Rehabilitation, 95(1), 163-174.

Ritsner, M., Kurs, R., Kostizky, H., Ponizovsky, A., \& Modai, I. (2002). Subjective quality of life in severely mentally ill patients: a comparison of two instruments. Quality of Life Research : An International Journal of Quality of Life Aspects of Treatment, Care and Rehabilitation, 11(6), 553561.

Roberts, L., \& Counsell, C. (1998). Assessment of Clinical Outcomes in Acute Stroke Trials. Stroke, 29(5).

Salter, K., Jutai, J. W., \& Bayley, M. (2005). Issues for selection of outcome measures in stroke rehabilitation: ICF activity. Disability and Rehabilitation, 27(6), 315-340.

Salter, K., Jutai, J. W., Teasell, R., Foley, N., Bitensky, J., \& Bayley, M. (2005a). Issues for selection of outcome measures in stroke rehabilitation : ICF Participation. Disability and Rehabilitation, 27(9), 507528. 
Salter, K., Jutai, J. W., Teasell, R., Foley, N. C., \& Bitensky, J. (2005b). Issues for selection of outcome measures in stroke rehabilitation: ICF Body Functions. Disability and Rehabilitation, 27(4), 191-207.

Sánchez-Cubillo, I., Lertxundi, N., Quemada, J. I., \& Ruiz-Ruiz, R. (2007). Trastornos del comportamiento en daño cerebral adquirido. Acción Psicológica, 4(3), 101-113.

Sander, A. M., Fuchs, K. L., High, W. M., Hall, K. M., Kreutzer, J. S., \& Rosenthal, M. (1999). The community integration questionnaire revisited: An assessment of factor structure and validity. Archives of Physical Medicine and Rehabilitation, 80(10), 1303-1308.

Schalock, R. L., Brown, I., Brown, R., Cummins, R. A., Felce, D., Matikka, L., ... Parmenter, T. (2002). Conceptualization, Measurement, and Application of Quality of Life for Persons With Intellectual Disabilities: Report of an International Panel of Experts. Mental Retardation, 4O(6), 457-470.

Schmidt, W. P., Roesler, A., Kretzschmar, K., Ladwig, K. H., Junker, R., \& Berger, K. (2004). Functional and Cognitive Consequences of Silent Stroke Discovered Using Brain Magnetic Resonance Imaging in an Elderly Population. Journal of the American Geriatrics Society, 52(7), 1045-1050.

Scholten, A. C., Haagsma, J. A., Andriessen, T. M. J. C., Vos, P. E., Steyerberg, E. W., Van Beeck, E. F., \& Polinder, S. (2015). Health-related quality of life after mild, moderate and severe traumatic brain injury: Patterns and predictors of suboptimal functioning during the first year after injury. Injury, 46(4), 616-624.

Schönberger, M., Ponsford, J., Olver, J., Ponsford, M., \& Wirtz, M. (2011). Prediction of functional and employment outcome 1 year after traumatic brain injury: A structural equation modelling approach. Journal of Neurology, Neurosurgery and Psychiatry, 82(8), 936-941.

Schubert, D. S. P., Taylor, C., Lee, S., Mentari, A., \& Tamaklo, W. (1992). Physical consequences of depression in the stroke patient. General Hospital Psychiatry, 14(1), 69-76. 
Servicio de Neurorrehabilitación. Hospitales Nisa. (2015). Traumatismo creneoencefálico. https://www.neurorhb.com/traumatismocraneoencefalico/.

Servicio Neurorehabilitación. Hospitales Nisa. (2016). Epidemiología del Daño Cerebral Adquirido en España. Retrieved from https://www.neurorhb.com/blog-dano-cerebral/epidemiologia-deldano-cerebral-adquirido-espana/

Shames, J., Treger, I., Ring, H., \& Giaquinto, S. (2007). Return to work following traumatic brain injury: Trends and challenges. Disability and Rehabilitation, 29(17), 1387-1395.

Sholberg, M. M., \& Mateer, C. A. (1989). Remediation of executive functions impairments. In M. M. Sholberg \& C. A. Mateer (Eds.), Introduction to cognitive rehabilitation. New York: Guilford Press.

Silver, J., MaCallister, T., \& Yudofsky, S. (2004). Textbook of traumatic brain injury. Washington: Amer Psychiatric Pub Inc.

Spreen, O., \& Strauss, E. (1998). A compendium of neuropsychological tests (2nd ed.). New York: Oxford University Press.

Srikanth, V. K., Thrift, A. G., Saling, M. M., Anderson, J. F. I., Dewey, H. M., Richard A.L., Geoffrey A.D. (2003). Increased Risk of Cognitive Impairment 3 Months After Mild to Moderate First-Ever Stroke. A Community-Based Prospective Study of Nonaphasic English-Speaking Survivors. Stroke, 34, 1136-1143.

Stern, Y. (2002). What is cognitive reserve? Theory and research application of the reserve concept. Journal of the International Neuropsychological Society : JINS, 8(3), 448-60.

Stucki, G., Ewert, T., \& Cieza, A. (2002). Disability and Rehabilitation Value and application of the ICF in rehabilitation medicine Principles of rehabilitation. Disability and Rehabilitation, 24(17), 932-938.

Sturm, J. W., Donnan, G. A., Dewey, H. M., Macdonell, R. A. L., Gilligan, A. K., Srikanth, V., \& Thrift, A. G. (2004). Quality of life after stroke: The North East Melbourne Stroke Incidence Study (NEMESIS). Stroke, 35(10), 2340-2345. 
Tagliaferri, F., Compagnone, C., Korsic, M., Servadei, F., \& Kraus, J. (2006). A systematic review of brain injury epidemiology in Europe. Acta Neurochirurgica, 148(3), 255-268.

Taricco, M., \& Liberati, A. (2006). Rehabilitation of traumatic brain injury. Current guidelines and beyond. Europa Medicophysica, 42(1), 6971.

Teoh, V., Sims, J., \& Milgrom, J. (2009). Psychosocial predictors of quality of life in a sample of community-dwelling stroke survivors: A longitudinal study. Topics in Stroke Rehabilitation, 16(2), 157-166.

The Stroke Unit Trialist's Collaboration. (2002). Organised inpatient (stroke unit) care for stroke. Cochralen Database of Systematic Reviews, 1(CD000197).

The WHOQOL Group. (1998). The Workd Health Organization Quality of Life Assessment (WHO-QOL): Developlment and general psychometric qualities. Social Science and Medicine, 46(12), 1569-1585.

Thornhill, S., Teasdale, G. M., Murray, G. D., McEwen, J., Roy, C. W., \& Penny, K. I. (2000). Disability in young people and adults one year after head injury: prospective cohort study. BMJ, 320(7250).

TraumaticBrainInjury.com. (2001). Definitions related to TBI. http://www.traumaticbraininjury.com/understanding-tbi/definitionsrelated-to-tbi/

Turner-Stokes, L., Nair, A., Sedki, I., Disler, P. B., \& Wade, D. T. (2005). Multi-disciplinary rehabilitation for acquired brain injury in adults of working age. In L. Turner-Stokes (Ed.), Cochrane Database of Systematic Reviews. Chichester, UK: John Wiley \& Sons, Ltd.

Ueda, S., \& Okawa, Y. (2003). The subjective dimension of functioning and disability: what is it and what is it for? Disability and Rehabilitation, 25(11-12), 596-601.

Van de Port, I. G. ., Ketelaar, M., Schepers, V. P. M., Van den Bos, G. A. M., \& Lindeman, E. (2004). Monitoring the functional health status of stroke patients: the value of the Stroke-Adapted Sickness Impact Profile30. Disability and Rehabilitation, 26(11), 635-640. 
van de Weg, F. B., Kuik, D. J., \& Lankhorst, G. J. (1999a). Post-stroke depression and functional outcome: a cohort study investigating the influence of depressión on functional recovery from stroke. Clinical Rehabilitation, 2155(99), 268-272.

van de Weg, F. B., Kuik, D. J., \& Lankhorst, G. J. (1999b). Post-stroke depression and functional outcome: a cohort study investigating the influence of depression on functional recovery from stroke. Clinical Rehabilitation, 13(3), 268-272.

van Straten, A., de Haan, R. J., Limburg, M., Schuling, J., Bossuyt, P. M., \& van den Bos, G. A. M. (1997). A Stroke-Adapted 30-Item Version of the Sickness Impact Profile to Assess Quality of Life (SA-SIP30). Stroke, 28(11).

Verdugo, M. A., Schalock, R. L., Keith, K. D., \& Stancliffe, R. J. (2005). Quality of life and its measurement: important principles and guidelines. Journal of Intellectual Disability Research, 49(10), 707-717.

Viitanen, M., Fugl-Meyer, K. S., Bernspång, B., \& Fugl-Meyer, A. R. (1988). Life satisfaction in long-term survivors after stroke. Scandinavian Journal of Rehabilitation Medicine, 20(1), 17-24.

Visser-Meily, J. M. A., Rhebergen, M. L., Rinkel, G. J. E., van Zandvoort, M. J., \& Post, M. W. M. (2009). Long-Term Health-Related Quality of Life After Aneurysmal Subarachnoid Hemorrhage. Stroke, 40(4).

Von Steinbuchel, N., Wilson, L., Gibbons, H., Hawthorne, G., Hofer, S., Schmidt, S., Truelle, J. L. (2010). Quality of life after brain injury (QOLIBRI): scale validity and correlates of quality of life. Journal of Neurotrauma, 27(7), 1157-1166.

Wade, D. T. (2003). Outcome Measures for Clinical Rehabilitation Trials: Impairment, Function, Quality of LIfe, or Value? Am J Phys Med Rehabil, 82(Suppl), S26-S31.

Wade, D. T., \& De Jong, B. A. (2000). Recent advances in rehabilitation. $B M J, 320,1385-1388$.

Weber, K. T., Guimarães, V. A., Pontes-Neto, O. M., Leite, J. P., Takayanagui, O. M., \& Santos-Pontelli, T. E. G. (2016). Predictors of quality 
of life after moderato to severe traumatic brain injury. Arquivos de NeuroPsiquiatria, 74(5), 409-415.

Wechsler, D. (1997). Wechsler Memory Scale-Third Edition. (T. E. The Psychological Corporation. Adaptación Española, 2004, Ed. San Antonio, TX.

Wechsler, D. (1999). WAIS-III. Escala de inteligencia de Wechsler para adultos-III. TEA, Ed. Madrid.

Weimar, C., König, I. R., Kraywinkel, K., Ziegler, A., \& Diener, H. C. (2003). Age and National Institutes of Health Stroke Scale Score Within 6 Hours After Onset Are Accurate Predictors of Outcome After Cerebral Ischemia. Stroke, 35(1).

Wenger, N. K., Mattson, M. E., Furberg, C. D., \& Elinson, J. (1984). Preface. In N. K. Wenger, M. E. Mattson, C. D. Furberg, \& J. Elinson (Eds.), Assessment of quality of life in clinical trials of cardiovascular therapies (pp. 11-15). Washington DC.: Le Hacq.

Whiteneck, G. G. (1992). Craig handicap assessment and reporting technique. A. Publishers., Ed.

Willer, B., Rosenthal, M., Kreutzer, S., Gordon, A., \& Rempel, R. (1993). Assessment of community integration following rehabilitation for traumatic brain injury. Journal of Head Trauma Rehabilitation, 8(2).

Williams, L. S., Weinberger, M., Harris, L. E., Clark, D. O., \& Biller, J. (1999). Development of a Stroke-Specific Quality of Life Scale. Stroke, 30(7).

Wilson, B. A. (1999). Case studies in neuropsychological rehabilitation. Oxford: Oxford University Press.

Wilson, B. A., Emsile, H., Evans, J. J., Alderman, N., \& Burgess, P. W. (1996). Behavioural Assessment of the Dysexecutive Syndrome (BADS).UK: Pearson, Ed.

Wood-Dauphinee, S. L., Opzoomer, M. A., Williams, J. I., Marchand, B., \& Spitzer, W. O. (1988). Assessment of global function: The Reintegration to Normal Living Index. Archives of Physical Medicine and Rehabilitation, 69(8), 583-90. 
World Health Organization. (1946). Constitution of the world health organization: chronicle of the world health organization 1. Geneva: World Health Organization, Ed.

World Health Organization. (1980). International Classification of Impairment, Disabilities and Handicaps. Geneva: World Health Organization.

World Health Organization. (2006). Neurological disorders. Public health challenges. Geneva, Switzerland: World Health Organization.

World Health Organization. (1999). ICIDH-2: International classification of functioing and disability, Beta-2 Draft, Short Version. (World Health Organization, Ed.). Geneva, Switzerland: World Health Organization.

World Health Organization. (2002). Towards a common language for functioning, disability and health: ICF. (World Heal). Geneva: World Health Organization.

Wouter, V., Steyerberg, E. W., Essink-Bot, M. L., van Beeck, E. F., Meeuwis, J. D., \& Loek, P. H. (2005). Prevalence and Determinants of Disabilities and Return to Work after Major Trauma. Journal of Trauma and Acute Care Surgery, 58(1), 126-135.

Ylvisaker, M., Turkstra, L. ., \& Coelho, C. (2005). Behavioral and Social Interventions for Individuals with Traumatic Brain Injury: A Summary of the Research with Clinical Implications. Seminars in Speech and Language., 26(4). 
